\title{
COLLECTIVE ACTION FOR SMALL-SCALE IRRIGATION FACILITIES IN NORTHWEST CHINA
}

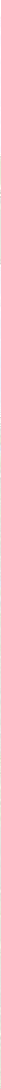

Shanshan Miao 



\section{Propositions}

1. Social capital is shaped by the people's economic situation.

(this thesis)

2. A combination of high trust and low control mechanism improves commons governance of small-scale irrigation facilities in case of small user groups. (this thesis)

3. Management practice in China is based too much on control, and too little on trust.

4. Environmental governance in China should be decentralized in order to address location specific problems.

5. Gender balance in human resource management is crucial to attract talented female scientists.

6. Solving scientific problems makes you grow personally.

Propositions belonging to the thesis, entitled:

Collective Action for Small-scale Irrigation Facilities in Northwest China

Shanshan Miao

Wageningen, 2 July, 2019 



\section{Collective Action for Small-scale Irrigation Facilities in Northwest China}

Shanshan Miao 


\section{Thesis committee}

\section{Promotors}

Prof. Dr W.J.M. Heijman

Professor of Regional Economics, Agricultural Economics and Rural Policy Group

Wageningen University \& Research

Dr X. Zhu

Associate professor, Environmental Economics and Natural Resource Group

Wageningen University \& Research

\section{Other members}

Prof. Dr J.D. van der Ploeg, Wageningen University \& Research

Prof. Dr N.B.M. Heerink, Wageningen University \& Research

Dr W.J.J. Bijman, Wageningen University \& Research

Dr Y. Jiang, IHE Delft Institute for Water Education

This research was conducted under the auspices of Wageningen School of Social Science (WASS). 


\title{
Collective Action for Small-scale Irrigation Facilities in Northwest China
}

\author{
Shanshan Miao
}

\section{Thesis}

submitted in fulfilment of the requirements for the degree of doctor at Wageningen University and Research by the authority of the Rector Magnificus,

Prof. Dr A.P.J. Mol, in the presence of the

Thesis Committee appointed by the Academic Board to be defended in public on Tuesday 2 July 2019 at 4 p.m. in the Aula. 
Shanshan Miao

Collective Action for Small-scale Irrigation Facilities in Northwest China 162 pages.

PhD thesis, Wageningen University and Research, Wageningen, The Netherlands(2019) With references, with summaries in English

ISBN: 978-94-6343-987-9

DOI: https://doi.org/10.18174/477552 


\section{Contents}

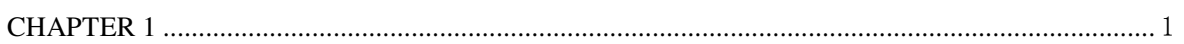

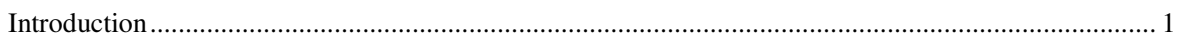

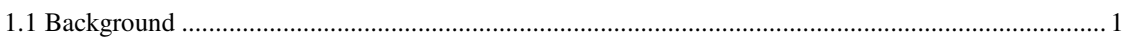

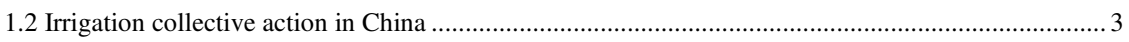

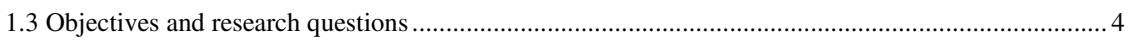

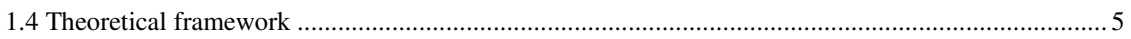

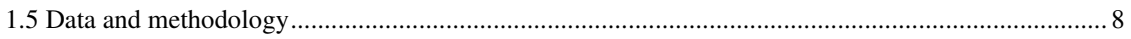

1.6 Outline

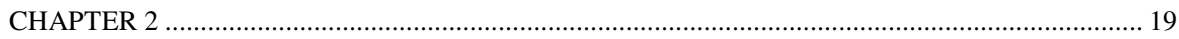

Why Farmers Don't Fit Their Deeds to Their Words? The Attitude-behaviour Paradox in Small-scale

Irrigation Facilities Collective Action ........................................................................................ 19

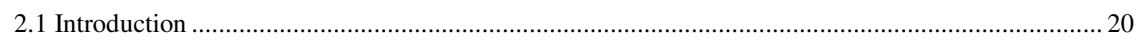

2.2 Heterogeneity and collective dilemma: A theoretical background ……......................................... 21

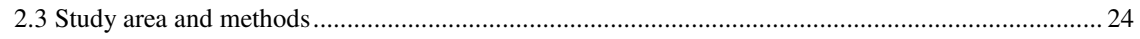

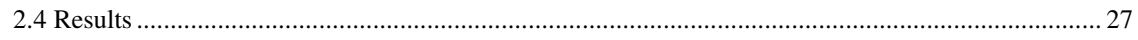

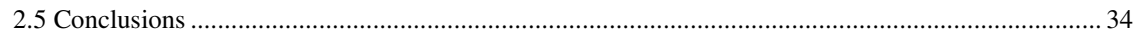

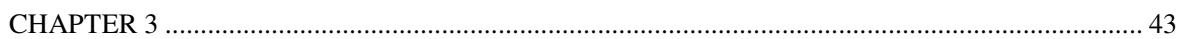

Social Capital Influences Farmer Participation in Collective Irrigation Management in Shaanxi

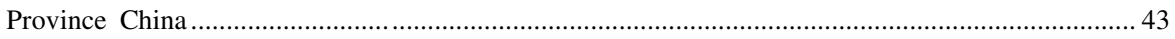

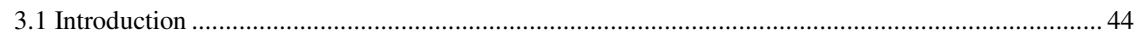

3.2 Theoretical background on the relationship between social capital and collective action ...................45

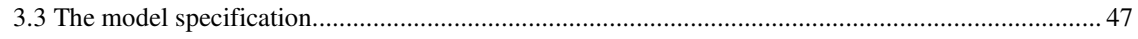

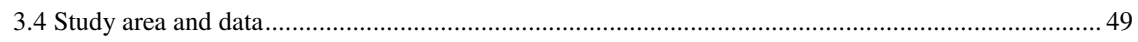

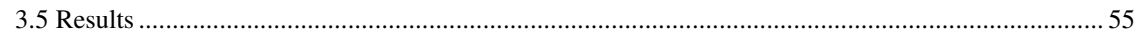

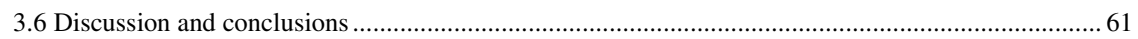


Income Groups, Social Capital and Collective Action on Small-Scale Irrigation Facilities:

A Multi-Group Analysis Based on a Structural Equation Model.

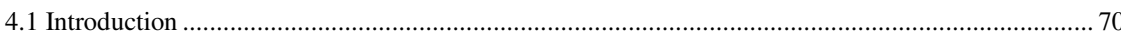

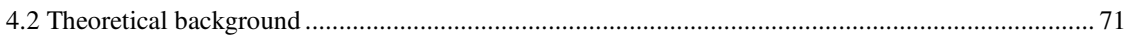

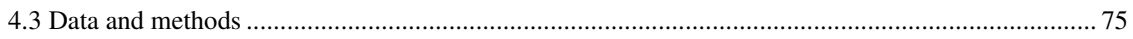

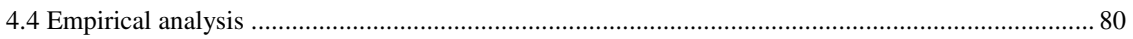

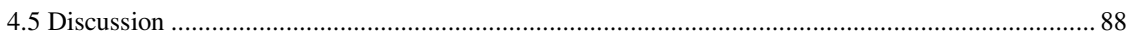

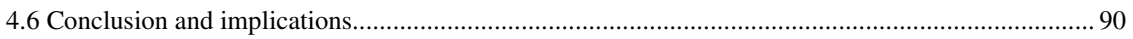

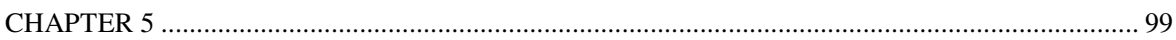

Trust or Control? The Role of Group Size in Governing Small-scale Irrigation Facilities .................. 99

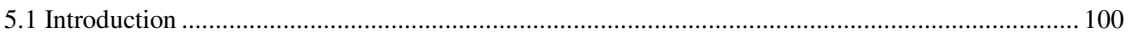

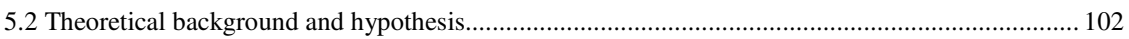

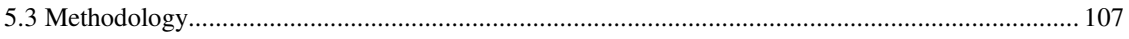

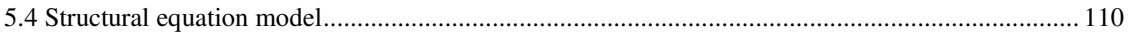

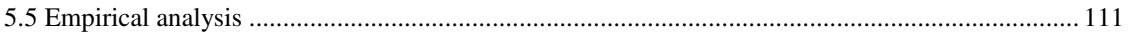

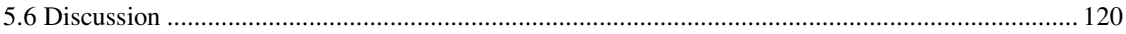

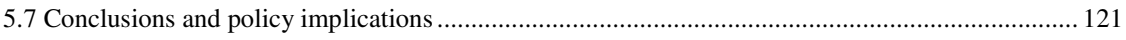

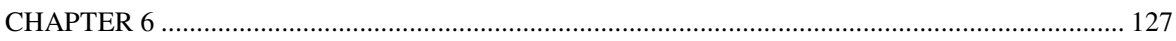

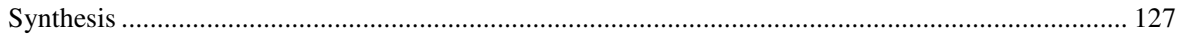

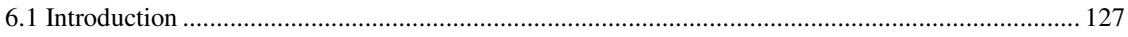

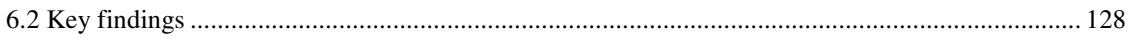

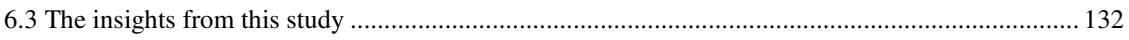

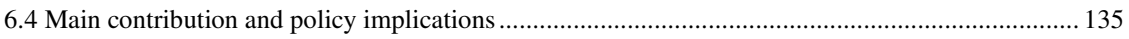

6.5 Limitations and suggestions for future research ............................................................ 137

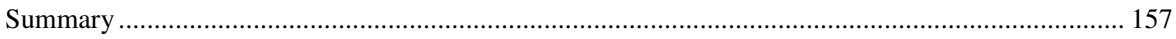




\section{CHAPTER 1}

\section{Introduction}

\subsection{Background}

China is a country with seriously uneven water distribution between the northern and the southern part. Based on the statistics from Ministry of Water Resource, agricultural sector accounts for $62.4 \%$ of the country's total water consumption ${ }^{1}$. Water availability in northern China is $25 \%$ lower than the international water scarcity threshold (which is defined as 1000 cubic metres per person, Zhang et al., 2014). More seriously, with the rapid industrialization and urbanization, competition on water consumption between agricultural and industrial use is escalating (Narain, 2018). China's agricultural production, particularly in the Northern part, is facing a serious challenge in water shortage. Therefore, developing irrigation agriculture could be the key to the improvement of rural livelihood in the Loess Plateau Area of Northwest China. Although the national government has invested a large amount of financial support on developing irrigation facilities, most of the investment is focusing on large-scale facilities (e.g., large-scale reservoir around urban cities, the Three Gorges Dam). Rural farmers in an economically underdeveloped area are trapped with this "last kilometre" problem of connecting tunnels and reservoirs with their farmlands. Many irrigation facilities in the remoted regions were even constructed in 1960th, and no new investment has been made after the adoption of the household responsibility system reform in the 1980s.

The provision of irrigation facilities often demands substantial investment. However, the farming system in the Northern China is characterized as a smallholder farming system. Without large stakeholders being involved, smallholders simply cannot afford such an expensive investment. Therefore, when there is no efficient provision from either public or private sectors, collective action for small-scale irrigation facilities has been promoted by the national governments and international organizations. The advantage of fostering collective action in providing common pool resources among smallholders can be summarized in two aspects. It can not only be a reasonable solution to public goods provision, but also can foster an inclusive community development pathway towards poverty alleviation and rural livelihoods improvement. Despite the obvious advantage of collective action in rural communities, the initiation of such action faces formidable challenges. The first challenge is

\footnotetext{
${ }^{1}$ Ministry of Water Resources of the People's Republic of China. 2017. National Statistical Bulletin of Water Resource Consumption $[\mathrm{M}]$. Beijing: China water conservancy and hydropower press.
} 
how to initiate collective action under a fast social transformation from an acquaintance society to an atomized society. Therefore, questions arise on what the driving forces are for farmers to cooperate and how consistent it is between farmers' attitudes and decisions. Another challenge lies in how Chinese smallholder farmers sustain and manage collective action under increasing economic heterogeneity and social stratification.

There is a large amount of literature arguing that social capital is of crucial importance in promoting collective action and enhancing resource sustainability (Ostrom, 2000; Basili et al., 2006; Ishihara and Pascual, 2013; Halimatussadiah et al., 2017; Takayama et al., 2018). The possibility of initiating and managing collective action by enhancing social capital can be channelled by its role in reducing transaction costs, refraining from free-riding, and increasing individual contributions through cultivating altrusim (Ostrom, 2000; Paavola and Adger, 2005). The complicated relationship between social capital and collective action rests on its multidimensionalities (Iravani, 2010). Some scholars argued for the role of trust in collective action problem (Ostrom and Ahn, 2003), and others argued for how social reciprocity affecting collective action (Lins et al, 2017). Recent institutional economics stressed the role of informal institutions in collective action (Poteete and Ostrom, 2004). All these elements can be summarized into the broad concept of social capital. However, only limited studies examined its relationship with collective action theoretically and empirically. The lack of understanding of social capital has also led to endless debate on policies concerning provision of public goods and services. Therefore, how to integrate social capital and collective action into a wellrounded framework of common pool resource management theory becomes an interesting research question, which could help China's irrigation issues.

Early theoretical and empirical studies showed a rather mixed result about the relationship between economic heterogeneity and collective action (Gehrig et al., 2019; Ervin et al., 2019; Wangel and Blomkvist, 2013). Olson (1965) found that economic heterogeneity and collective action have a positive relationship, while Ostrom (1990) later found a negative relationship. Baland and Platteau (1997) found that it is difficult to deduct a general relationship between economic heterogeneity and success in managing the commons. Some other scholars argued that the relationship between economic heterogeneity and collective action is U-shaped (Dayton-Johnson, 2000; Bardhan, 2000; Molinas, 1998). The lack of consensus is not only due to the heterogeneity in including many aspects, but also due to the ignorance of key variables (e.g., the role of institutions). Since heterogeneity is not the only condition for collective action, missing other crucial variables might lead to misleading conclusions (Varughese and Ostrom, 2001). Recently, Wang et al. (2016) studied the impact of migration on collective action, after controlled the theoretically relevant variables, such as economic heterogeneity, social capital, 
leadership, sense of community, resource dependency, and found that migration was negatively associated with collective irrigation, which is quite contradicted with the early studies on the role of social capital. Although there is a large amount of literature on the relationship between social capital and collective action (Ervin, 2019; Van Oel et al., 2019; Talo, 2018; Nitzan and Ueda, 2018), how economic heterogeneity influences the relationship between social capital and collective action is still unclear, which need further studies.

\subsection{Irrigation collective action in China}

The Chinese irrigation systems were mainly constructed during its early planned economy periods from 1950s till 1980s. Large-scale hydraulic projects were mainly financed by the central government, while most of the small-scale irrigation facilities were financed and built by local communities as a collective arrangement. Since the agrarian reforms initiated in 1978, a series of new institutions have been introduced to manage these public facilitates, such as village council management, water user organizations and contracting services (Qu et al., 2011; Wang et al., 2010). Central government's fiscal budgets are mainly allocated for construction and maintenance of major rivers, reservoirs and big dams, while local governments mainly invest in urban water conservancy projects. Small-scale irrigation facilities are left to rural communities for self-governance.

The national policy on accelerating the reform and the development of small-scale irrigation facilities was eventually promulgated in 2011 by the Central Committee of the Communist Party and the State Council ${ }^{2}$. Policies promoting the development of collective action for small-scale irrigation facilities were published in 2014 as "Guidelines for Encouraging and Supporting the Innovative Development of Farmers' Water User Organizations." Therefore, collective action for small-scale irrigation facilities, as a new way to pursue the common interests in management and sustainable exploitation of common pool resources, has attracted numerous attentions as a key solution to water shortage.

Collective action for small-scale irrigation facilities is initiated by two approaches: the top-down approach, and the bottom-up approach. The institutional arrangements for such collective action can be categorized into three forms. The first two forms are rather a reflection of the top-down approach through the establishment of water user organizations and village council management at the local community level. The bottom-up approach is mainly achieved through contracting services. Water user organization, village council or contractors are responsible for connecting to the dams or reservoirs outside the village for constructing wells

${ }^{2}$ http://www.moa.gov.cn/ztzl/yhwj/wjhg/201202/t20120215_2481550.htm 
and canals within the villages. In this sense, the repairing and maintenance of irrigation facilities, the sequences of water distribution, as well as the collection of irrigation fees are all bundled responsibilities of these institutions.

However, to initiate and sustain collective action for small-scale irrigation facilities, there are a series of questions that need to be addressed. For instance, how can we resolve social dilemmas of farmers' attitude-behaviour paradox? What is the function of social capital in promoting collective action? Whether the relationship between social capital and farmers' willingness to cooperate is different among various groups of income? How trust and control mechanism influence commons governance considering the role of group size? These issues need careful analysis, which will be addressed in detail in this thesis.

\subsection{Objectives and research questions}

The importance of collective action for small-scale irrigation facilities has been widely recognized for enhancing grain output, accelerating agricultural development as well as improving farmers' well-being (Mojo et al., 2017). A body of research examines the relationship between institutions and collective action (Nagrah et al., 2016), impact of economic and cultural heterogeneity on farmers' participation (Oliver et al., 1985; Poteeteand Ostrom, 2004) and contextual factors such as water scarcity, access to markets and size of the community (Meinzen-Dick et al., 2002). Given the urgent need for collective action for smallscale irrigation facilities in Northwest China, understanding the mechanisms of initiating and managing collective action is of vital importance.

The objective of this study is to improve our understanding of elements that influence collective action and to explore the mechanisms to initiate and manage collective action for small-scale irrigation facilities in Northwest China. Particularly, it aims to understand social dilemmas of attitude-behaviour paradox in participation in collective action due to social network heterogeneity and income differentials, which are prevailing in this area. Moreover, it constructs a framework of social capital components to examine their relationships with collective action, and examines how participants' income influences this relationship. It also illustrates how trust and control mechanisms influence the commons governance for irrigation facilities for different organizational heterogeneity.

Accordingly, in order to achieve the objective, four research questions are formulated as follows:

Q1. How do social network heterogeneity and relative income positions affect social dilemmas of farmers' attitude-behaviour paradox? 
Q2. What is the relationship between components of social capital and farmers' participative behaviour in collective action?

Q3. Whether the relationship between social capital components and farmers' willingness to cooperate is moderated by their incomes?

Q4. How does group size influence the commons governance for small-scale irrigation facilities based on the trust and control mechanisms?

These questions will be answered in the following chapters.

\subsection{Theoretical framework}

Our research mainly concentrated on how to deal with social dilemmas and collective action for small-scale irrigation facilities in Northwest China. The focus is on the initiation of collective action, and management of collective action. In order to conceptualize these issues into a theoretical framework, three strands of literature are employed on social dilemmas, social capital, heterogeneity and collective action, as well as commons governance respectively.

\subsubsection{Social dilemmas}

The key to initiating collective action is contingent upon how to overcome social dilemmas (Baldwin et al., 2018). "Tragedy of the commons" described by Hardin (1968) is taken as "problems that have no technical solution," since individual interests are incongruity with social interests. The difficulties in addressing the "social dilemma" is not merely related to contradiction between individual and collective interests, but also the lack of understanding about each participant's motivation (Rockmann and Northcraft, 2018). Recent studies demonstrate that people generally are conditional co-operators (Guido et al., 2019; Fischbacher et al., 2001), which means cooperators "would reduce their efforts if they had a capable partner who free-rode on their efforts" (Kerr, 1983). Conditional co-operators' decision and level of contribution are strongly affected by other's behaviour (Totin et al., 2014).

The coincidence of conditional co-operators and free-riders may lead to socially undesirable outcomes (de Oliveira et al., 2015; Burlando and Guala, 2005). An essential element in overcoming social dilemmas is on the so-called "social capital" (Ostrom, 2000). However, as Kelly et al. (2017) stated that "...simply relying on social capital alone is insufficient to successfully manage a common resource...", economic heterogeneity (Oliver et al., 1985; Poteeteand Ostrom, 2004) as well as contextual factors such as community characteristics are also relevant (Meinzen-Dick et al., 2002). How to address social dilemmas from social and economic perspective is a prerequisite for initiating and managing collective 
action (Bednarik et al., 2019; Panchanathan and Boyd, 2004; Berger, 2011). We will study social dilemmas of farmers' attitude-behaviour paradox from the perspective of social capital and economic heterogeneity in Chapter 2. We divide farmers' attitude-behaviour paradox into "having attitude but no behaviour" and "having behaviour but no attitude" to explore the heterogeneous effects of social network and relative income position on collective action.

\subsubsection{Social capital, heterogeneity and collective action}

Social capital is defined as "features of social organization such as networks, norms and trust that facilitate coordination and co-operation for mutual benefit" (Putnam et al., 1994). The importance of social capital in promoting collective irrigation management has been widely accepted (Ostrom, 1994; Rudd, 2000; Putnam, 2000; Takayama et al., 2018). For example, Remmington (2018) demonstrated that social capital could mitigate hydrological and climate uncertainty in water management. Kelly et al. (2017) also found that social capital and sense of ownership facilitate sustainable community participation in the irrigation water system. However, the negative effect of social capital as well as how its multi-dimensional nature linked to collective action have not attracted enough attention (Adhikari and Goldey, 2010). Thus, Chapter 3 investigates the effects of four components (e.g., social network, social trust, social reciprocity and social participation) of social capital on farmers' participative behaviour in collective action and show how positive and negative roles of social capital exerted in initiating collective action for small-scale irrigation facilities in Northwest China.

Olson (1965) argued that heterogeneous interests were conducive for public goods provision. Kollock (1998) contended that interaction between group heterogeneity and the shape of the production function for collective goods influenced social dilemma situations. Varughese and Ostrom (2001) addressed the role of institutions in mediating the effect of heterogeneity on collective action. Despite extensive studies on the relationship between social capital and collective action for the common pool resource management (Yu et al., 2016; Agrawal, 2014, Sharp et al., 2012; Lane and McDonald, 2005; López-Gunn, 2012), and on the relationship between heterogeneity (income, wealth, preference, gender or ethnicity) and collective action (Iliopoulos and Valentinov, 2017; MccarthyandKilic, 2015; Kurian and Dietz, 2013), an integrated understanding about the interaction among social capital, heterogeneity and collective action is rather limited. Few studies have examined the role of heterogeneity in moderating the relationship between social capital and collective action. In Chapter 4 , we will examine whether the relationship between social capital components and the willingness of farmers to cooperate in collective action is moderated by the farmers' incomes. 


\subsubsection{Commons governance}

Commons governance is another key to sustain collective action. To reduce the opportunity for free-riding or shirking behaviours, the collective action theory emphasizes the use of control measures such as rules and regulations, monitoring as well as sanctions to punish violators (Das \& Teng, 2001). The importance of trust was also significantly recognized by scholars (Ostrom, 1990; Edelenbos and Eshuis, 2012). Therefore, both trust and control measures are governance mechanisms which can be used to reduce uncertainties and promote sustainable governance of collective action (Pilkiene et al., 2018; Vallentin and Thygesen, 2018).

Early studies mainly focused on rewards and punishments (Oliver, 1980). Stoop et al. (2018) examined the relationship between rewards and cooperation in social dilemma games, and found that rewards were more effective for public goods, but not for common pool resources. The function of punishments on the evolution of cooperation has also been comprehensively examined (Nakamaru et al., 2018; Rand et al., 2010, Sigmund et al., 2010, Sasaki et al., 2015). The dispute was mainly concentrated on the relationship between trust and control, whether they are complementary or substitutes (Varoutsa and Scapens, 2018; Six, 2013). The enforcement of trust and control in commons governance not only influences the interaction of these two modes of management but also influenced by other contextual variables such as group size. Few studies have addressed the importance of this issue. In Chapter 5, we will examine how group size influences commons governance for small-scale irrigation facilities based on trust and control mechanisms.

In short, we organize our study into four issues related to initiation and management (sustainability) of collective action. First, socio-economic heterogeneity imposes obstacles for initiating collective action in the form of attitude-behaviour paradox. This is a social dilemma that needs to be overcome in order to make collective action successful. This issue is studied in Chapter 2. Second, social capital has been recognized as a key factor in the realisation of collective action. Social capital can be measured in different ways. How various elements of social capital contribute to the collective action that needs to be well understood. This issue is dealt with in Chapter 3. Third, economic heterogeneity particularly income levels of smallholder farmers would influence their motivation to participate in collective action and subsequently also have impacts on the sustainability of the collective action. This issue is addressed in chapter 4 . Fourth, the sustainability of collective action is closely related to the organizational forms. Therefore, organizational heterogeneity is an important issue which requires detailed research. This issue is detailed in chapter 5. Figure 1.1 illustrates the 
framework for studying collective action for small-scale irrigation facilities in Northwest China.

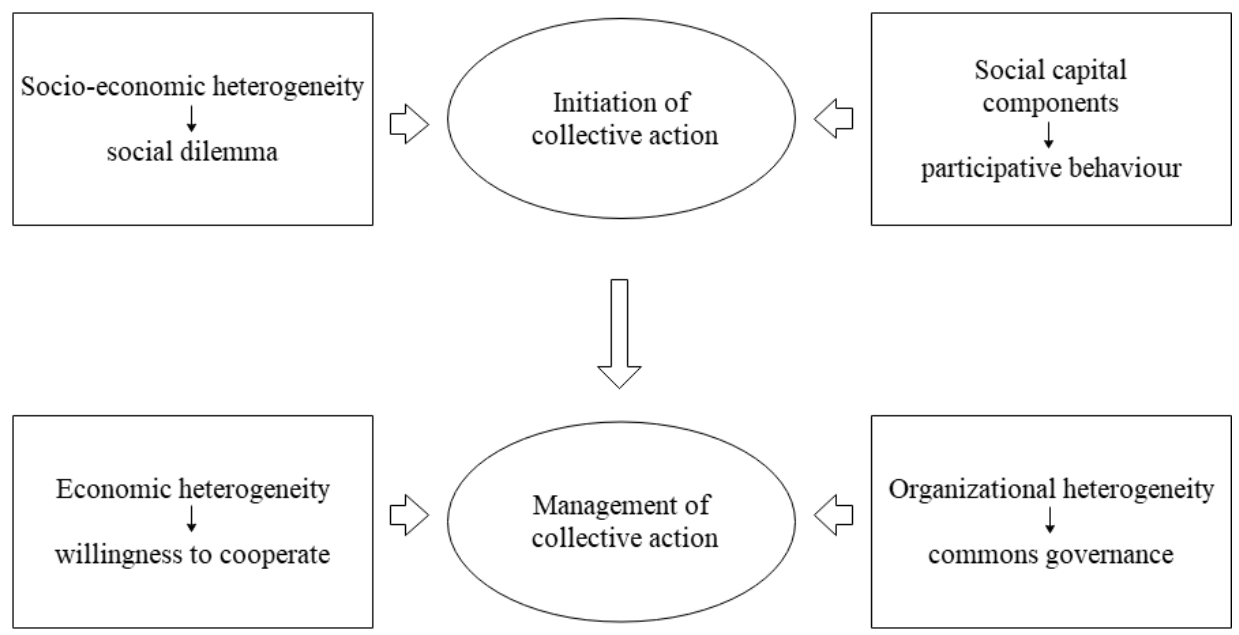

Figure 1.1 Framework of collective action for small-scale irrigation facilities

\subsection{Data and methodology}

\subsubsection{Study area and data collection}

The study area covered in this thesis is the Loess Plateau Area of Northwest China (Shaanxi Province, Gansu Province, Ningxia Province and Shanxi Province). The plateau slopes are ranging from the northwest (around 2000 meters) to the southeast (about 1250 meters). The Loess Plateau Area has been seriously eroded by flowing water for quite a long time and gradually forms a special natural landscape with fragmented terrains of gullies and ravines. The annual precipitation ranges from $313.6 \mathrm{~mm}$ to $657.4 \mathrm{~mm}$, with a declining rate of $0.79 \mathrm{~mm} / \mathrm{a}$. The rainfall displays an uneven pattern over the year, mainly concentrated in summer $(239.4 \mathrm{~mm})$ and autumn season $(108.4 \mathrm{~mm})$. These two seasons account for $79 \%$ of the annual precipitation (Xiao et al., 2017). The average daily temperature difference is 14degree centigrade. The cropping system is mainly on wheat-maize rotation (or one-harvest-ayear). Loess Plateau Area's irrigation water mainly comes from the Yellow River, and its subbranches (e.g., the Wei River, the Fen River, and the Zuli River). Another main source of irrigation is ground water, which is extracted from wells with 60-70 meters depth. The detailed study areas are demonstrated in Figure 1.2. 


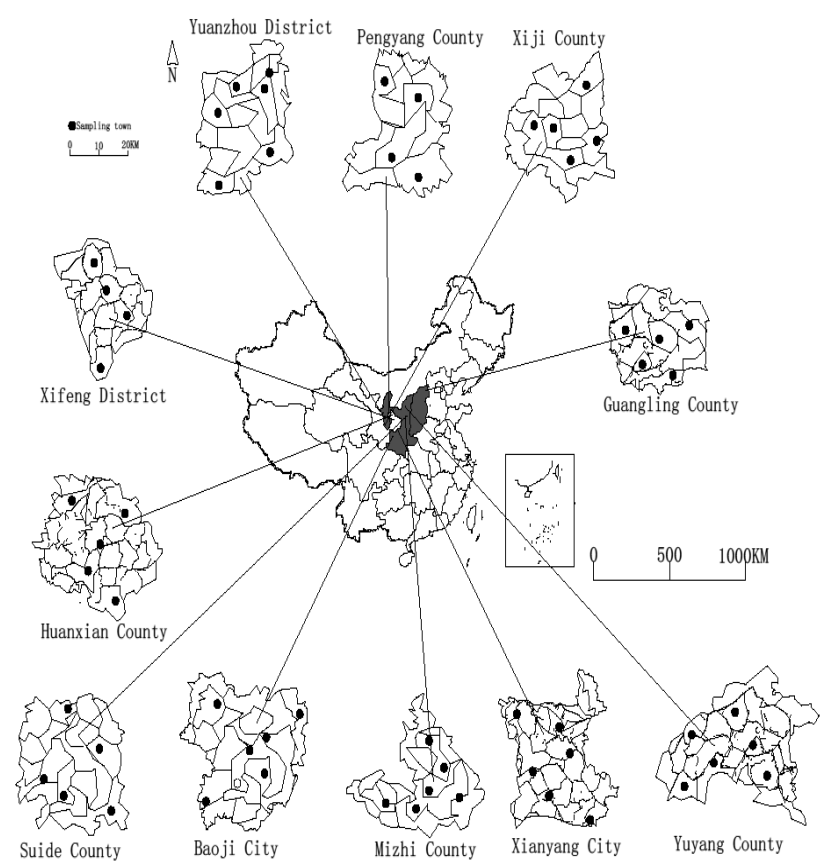

Figure 1.2 The map of the surveyed areas (source: S. Xu)

The data used for the empirical analyses were collected through two research projects. The chapter 2 to chapter 4 used the data from the National Science Foundation Project "Collective action for small-scale irrigation facilities in rural communities from the perspective of farmers' income and social capital heterogeneity"(See in Appendix Questionnaires 1). Specifically, the household survey was conducted in Shanxi and Shaanxi Province in 2011 and 2012. Household interviews were carried out in 20 villages in Shaanxi Province, and five villages in Shanxi Province. A stratified random sampling technique was employed for the villages with small-scale irrigation facilities. Information was acquired by a combination of field survey and in-depth interviews. The content of the survey includes crop production, water use, natural conditions, village characteristics, individual characteristics, social capital characteristics, supply and maintenance of irrigation facilities, irrigation management institutions, government subsidy policy, water pricing reform and farmers' payment conditions, water saving technology as well as farmers' perceptions and participative behaviour on collective actions. 
The chapter 5 used the data collected from the National Science Foundation Project “Collective action participation and farmers' water and soil conservation technology adopting behaviour" (See in Appendix Questionnaire 2 ). The household survey was conducted in Yulin districts of Shaanxi Province, Qingyang Districts of Gansu Province and Guyuan Districts of Ningxia Province in October and November 2016. A combination of multistage stratified sampling and simple random sampling methods were employed to select three counties in Shaanxi Province, two counties in Gansu Province and two counties in Ningxia Province as the investigation units, then 10-15 villages were randomly selected and 10-15 farmers were randomly selected in each village. This resulted in 853 households. The information includes household head characteristics, family characteristics, planting conditions, social capital, collective action, agriculture production as well as government support policy.

\subsubsection{Methodology}

Research question 1 is answered in Chapter 2 where Instrumental Variable (IV) Probit Model was utilized to estimate the relationship between socio-economic heterogeneity and social dilemma of farmers' attitude-behaviour paradox in participation in collective action. A theoretical framework was developed for the relationship between socio-economic heterogeneity and collective action. We examine the effects of social network heterogeneity (i.e., weak tie and strong tie) and relative income positions on farmers' attitude-behaviour paradox. Given the potential endogeneity of social network, distance to highways and whether family members work in a metropolitan city were selected as instrumental variables.

Question 2 is answered in Chapter 3 by using social capital theory as the theoretical framework. Because of the multi-dimensional nature of social capital, using various indicators to categorize them into a few components with clear information becomes an important task. Taking advantages of exploratory factor analysis, we convert the potentially correlated indicator variables into a set of linearly uncorrelated variables (Karamizadeh et al., 2013), which is subsequently used to measure the four components of social capital (i.e., social network, social trust, social reciprocity and social participation). Logistic model is employed to investigate the influence of four components of social capital on farmers' participative behaviour in collective action for small-scale irrigation facilities.

Chapter 4 answers question 3 by examining how economic heterogeneity affects the willingness of farmers to cooperate in collective action. A theoretical framework for social capital and collective action is extended to capture the role of economic heterogeneity in collective action. Because of the unique feature of structural equation modelling (SEM) in combining regression analysis and factor analysis, and because of its ability to estimate the 
relationship between latent and observed variables simultaneously, SEM is recruited to explore the underlying mechanisms of social capital components and farmers' willingness to cooperate in collective action. A multi-group analysis is employed to measure the effects of economic heterogeneity on the relationship between social capital components and farmers' willingness to cooperate in collective action.

Chapter 5 answers question 4 where SEM is used again to explore how trust and control mechanisms directly and indirectly influence farmers' participation and cooperative performance in commons governance for collective action for small-scale irrigation facilities. We construct a theoretical framework for studying how trust and control mechanisms affect the commons governance with explicit inclusion of organizational heterogeneity. We hypothesize that the selection of trust or control mechanism to promote participation in commons governance in order to sustain collective action is based on the relative costs associated with different group sizes. Group size in commons governance could be a good variable for organizational heterogeneity. Therefore, the multi-group analysis is utilized to examine how trust and control mechanisms affect the commons governance for different group sizes.

\subsection{Outline}

The rest of the thesis is organized as follows. The outline of the thesis is demonstrated in Figure 1.3. In Chapter 2 we explore how social network heterogeneity and relative income position influence farmers' attitude-behaviour paradox in resolving social dilemmas in collective action for small-scale irrigation facilities. Chapter 3 studies the relationship between social capital components and farmers' participative behaviour in collective action. Chapter 4 examines whether relationships between social capital components and farmers' willingness to cooperate in collective action is moderated by farmers' income levels. Chapter 5 studies how contrasting effects of the group size exerts on trust and control mechanisms in achieving farmers' participation degree and cooperative performance in commons governance. Chapter 6 makes a synthesis on different chapters into a complete framework of collective action for small-scale irrigation facilities. 


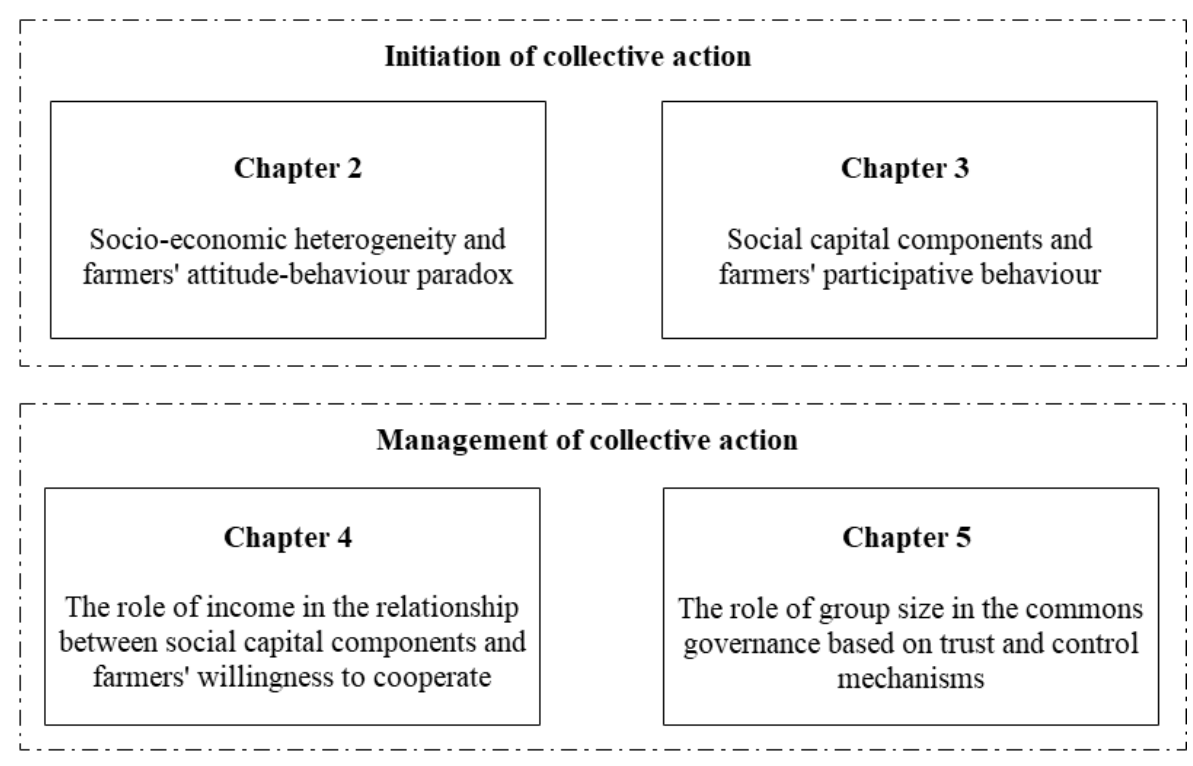

Figure 1.3 The outline of the thesis 


\section{References}

Adhikari, K.P., Goldey, P. 2010. Social capital and its downside: the impact on sustainability of induced community-based organizations in Nepal. World Development, 38(2): 184-194.

Aggarwal, R.M., Narayan, T.A. 2004. Does inequality lead to greater efficiency in the use of local commons? The role of strategic investments in capacity. Journal of Environmental Economics and Management, 47(1):163-182.

Agrawal, A. 2014. Studying the commons, governing common-pool resource outcomes: some concluding thoughts. Environmental Science \& Policy, 36(2): 86-91.

Anderies, J.M., Janssen, M.A., Lee, A., Wasserman, H. 2013. Environmental variability and collective action: experimental insights from an irrigation game. Ecological Economics, 93(9):166-176.

Araral, E. 2009. What explains collective action in the commons? Theory and evidence from Philippines. World Development, 37(3): 687-697.

Baland, J.-M., Platteau, J.-P. 1997. Wealth inequality and efficiency in the commons. Part I: the unregulated case. Oxford Economic Papers, 49 (4): 451-482.

Baldwin, E., McCord, P., Dell'Angelo, J., Evans, T. 2018. Collective action in a polycentric water governance system. Environmental Policy and Governance, 28 (4): 212-222.

Bardhan, P. 2000. Irrigation and cooperation: an empirical analysis of 48 irrigation communities in South India. Economic Development and Cultural Change, 48(4): 847-865.

Bardhan, P., Ghatak, M., Karaivanov, A. 2002. Inequality, market imperfections and the voluntary provision of collective goods. Working paper, MacArthur network on the effects of inequality on economic performance. http://globetrotter.berkeley.edu/macarthur/inequality/papers/Bardhan 2002.

Basili, M., Franzini, M. and Vercelli, A. (Eds.) 2006. Environment, Inequality and Collective Action, RFF Press, Washington, DC.

Bednarik, P., Linnerooth-Bayer, J., Magnuszewski, P., Dieckmann, U. 2019. A game of common-pool resource management: effects of communication, risky environment and worldviews. Ecological Economics, 156(2): 287-292.

Berger, U. 2011. Learning to cooperate via indirect reciprocity. Games and Economic Behavior, 72 (2):30-37.

Burlando, R.M., Guala, F. 2005. Heterogeneous agents in public goods experiments. Experimental Economics, 8(1):35-54.

Das, T.K., Teng, B.S. 2001. Trust, control, and risk in strategic alliances: An integrated framework. Organization Studies, 22(2):251-283.

Dayton-Johnson, J., Bardhan, P. 2002. Inequality and conservation on the local commons: a theoretical exercise. The Economic Journal, 112(481): 577-602.

Dayton-Johnson, J. 2000. Determinants of collective action on the local commons: a model with evidence from Mexico. Journal of Development Economics, 62(1): 181-208.

de Oliveira, A.C., Croson, R.T., Eckel, C. 2015. One bad apple? Heterogeneity and information in public 
good provision. Experimental Economics, 18 (1):116-135.

Edelenbos, J., Eshuis, J. 2012. The interplay between trust and control in governance processes: A conceptual and empirical investigation. Administration and Society, 44 (6): 647-674.

Ervin, D.E., Breshears, E.H., Frisvold, G.B., Hurley, T., Dentzman, K.E., Gunsolus, J.L., Jussaume, R.A., Owen, M.D., Norsworthy, J.K., Al Mamun, M.M., Everman, W. 2019. Farmer attitudes toward cooperative approaches to herbicide resistance management: A common pool ecosystem service challenge. Ecological Economics, 157(3): 237-245.

Futemma, C., De Castro, F., Silva-Forsberg, M.C., Ostrom, E. 2002. The emergence and outcomes of collective action: An Institutional and Ecosystem Approach. Society and Natural Resources, 15 (6): 503-522.

Gehrig, S., Schlüter, A. Hammerstein, P. 2019. Sociocultural heterogeneity in a common pool resource dilemma. PloS One, 14(1): p.e0210561.

Guido, A., Robbett, A., Romaniuc, R. 2019. Group formation and cooperation in social dilemmas: A survey and meta-analytic evidence. Journal of Economic Behaviour and Organization, 159(3): 192-209.

Halimatussadiah, A., Resosudarmo, B.P., Widyawati, D. 2017. Social capital to induce a contribution to environmental collective action: results from a laboratory experiment in Indonesia. International Journal of Environment and Sustainable Development, 16(4): 397-414.

Hardin, G. 1968. The tragedy of the commons. Science, 162(3859):1243-1248.

Iliopoulos, C., Valentinov, V. 2017. Member preference heterogeneity and system-life world dichotomy in cooperatives: An exploratory case study. Journal of Organizational Change Management, 30 (7) : 1063-1080.

Ishihara, H., Pascual, U. 2013. Re-Politicizing Social Capital: Revisiting Social Capital and Collective Action in Common Pool Resource Management, UNU-IAS Working Paper No. 170, United Nations University, Tokyo.

Iravani, M. R. 2010. Role of social capital on development. Journal of Alternative Perspectives in the Social Sciences, 2(2):966-978.

Janssen, M.A., Anderies, J.M., Joshi, S.R. 2011. Coordination and cooperation in asymmetric commons dilemmas. Experimental Economics, 14 (4): 547-566.

Janssen, M.A., Bousquet, F., Cardenas, J.C., Castillo, D., Worrapimphong, K. 2012. Field experiments of irrigation dilemmas. Agricultural Systems, 109(6): 65-75.

Karamizadeh, S., Abdullah, S., Manaf, A., Zamani, M., Hooman, A. 2013. An Overview of principal component analysis. Journal of Signal and Information Processing, 4(3): 173-175.

Kelly, E., Lee, K., Shields, K., Cronk, R., Behnke, N., Klug, T., Bartram, J. 2017. The role of social capital and sense of ownership in rural community-managed water systems: Qualitative evidence from Ghana, Kenya, and Zambia. Journal of Rural Studies, 56(11):156-166.

Kerr, N.L. 1983. Motivation losses in small groups: A social dilemma analysis. Journal of Personality and Social Psychology, 45(4):819-828. 
Kollock, P. 1998. Social dilemmas: The anatomy of cooperation. Annual Review of Sociology, 24(1): 183-214.

Kurian, M., Dietz, T. 2013. Leadership on the Commons: Wealth distribution, co-provision and service delivery. Journal of Development Studies, 49 (11): 1532-1547.

Lane, M.B., McDonald, G. 2005. Community-based environmental planning: operational dilemmas, planning principles and possible remedies. Journal of Environmental Planning and Management, 48(5):709-731.

Lins, K.V., Servaes, H., Tamayo, A. 2017. Social capital, trust, and firm performance: The value of corporate social responsibility during the financial crisis. The Journal of Finance, 72(4): 17851824.

López-Gunn, L. 2012. Groundwater governance and social capital. Geoforum, 43(6): 1140-115.

Mccarthy, N., Kilic, T. 2015. The nexus between gender, collective action for public goods and agriculture: Evidence from Malawi. Agricultural Economics (United Kingdom), 46 (3): 375402.

Mojo, D., Fischer, C., Degefa, T. 2017. The determinants and economic impacts of membership in coffee farmer cooperatives: recent evidence from rural Ethiopia. Journal of Rural Studies, 50(2): 84-94.

Molinas, J.R., 1998. The impact of inequality, gender, external assistance and social capital on locallevel cooperation. World Development, 26(3): 413-431.

Nagrah, A., Chaudhry, A.M., Giordano, M. 2016. Collective action in decentralized irrigation systems: Evidence from Pakistan. World Development, 84(8): 282-298.

Nakamaru, M., Shimura, H., Kitakaji, Y., Ohnuma, S. 2018. The effect of sanctions on the evolution of cooperation in linear division of labour. Journal of Theoretical Biology, 437(1): 79-91.

Naidu, S.C. 2009. Heterogeneity and collective management: Evidence from common forests in Himachal Pradesh, India. World Development, 37(3): 676-686.

Narain, V. 2018. Urbanization and Water. Globalization of Water Governance in South Asia, 195. Routledge, Taylor \& Francis Group.

Nitzan, S., Ueda, K. 2018. Selective incentives and intragroup heterogeneity in collective contests. Journal of Public Economic Theory, 20 (4): 477-498.

Oliver, P., Marwell, G. Teixeira, R. 1985. A theory of the critical mass. I. Interdependence, group heterogeneity, and the production of collective action. American journal of Sociology, 91(3): $522-556$.

Olson, M. 1965. The Logic of Collective Action: Public Goods and the Theory of Groups. Harvard University Press, Cambridge, Mass.

Ostrom, E., 1990. Governing the Commons: the Evolution of Institutions for Collective Action. Cambridge University Press.

Ostrom, E., 1994. Constituting social capital and collective action. Journal of Theoretical Politics, 6(4): 
$527-562$.

Ostrom, E. 2000. Social capital: a fad or a fundamental concept? in Dasgupta, P. (Eds.): Social Capital: A Multifaceted Perspective, World Bank, Washington, DC, 172-215.

Ostrom, E., Ahn, T. K. 2003. Introduction, in Ostrom, E. et al. (Eds.): Foundations of Social Capital, Publishing Limited, Cheltenham, 1-24.

Paavola, J., Adger, N. 2005. Institutional ecological economics. Ecological Economics, 53(3): 353-368.

Panchanathan, K., BoydIndirect, R. 2004. Reciprocity can stabilize cooperation without the secondorder free rider problem. Nature, 432 (11): 499-502.

Pilkiene, M., Alonderiene, R., Chmieliauskas, A., Simkonis, S., Muller, R. 2018. The governance of horizontal leadership in projects. International Journal of Project Management, 36 (7):913-924.

Poteete, A.R., Ostrom, E. 2004. Heterogeneity, group size and collective action: the role of institutions in forest management. Development and Change, 35(3): 435-461.

Putnam, R. D., Leonardi, R, Nanetti, R. Y. 1994. Making Democracy Work: Civic Traditions in Modern Italy. Princeton University Press.

Putnam, R.D. 1995. Tuning in, tuning out: The strange disappearance of social capital in America. Political Science \& Politics, 28(4): 664-683.

Putnam, R.D., 2000. Bowling alone: America's declining social capital. In Culture and politics (pp. 223-234). Palgrave Macmillan, New York.

Qu, F., Kuyvenhoven, A., Shi, X. Heerink, N. 2011. Sustainable natural resource use in rural China: recent trends and policies. China Economic Review, 22(4):444-460.

Rand, D.G., Armao, J.J.T., Nakamaru, M., Ohtsuki, H. 2010. Anti-social punishment can prevent the co-evolution of punishment and cooperation. Journal of Theoretical Biology, 265 (4):624-632.

Remmington, G. 2018. Transforming tradition: The aflaj and changing role of traditional knowledge systems for collective water management. Journal of Arid Environments, 151(4): 134-140.

Rockmann, K. W., Northcraft, G.B. 2018. The dilemma portfolio: A strategy to advance the study of social dilemmas in organizations. Academy of Management Annals, 12(2): 494-509.

Rudd, M.A. 2000. Live long and prosper: collective action, social capital and social vision. Ecological Economics, 34(1): 131-144.

Sasaki, T., Uchida, S., Chen, X. 2015. Voluntary rewards mediate the evolution of pool punishment for maintaining public goods in large populations. Scientific Reports, 5 (3):8917.

Sharp, E.A., Thwaites, R., Curtis, A. Millar, J. 2013. Trust and trustworthiness: conceptual distinctions and their implications for natural resources management. Journal of Environmental Planning and Management, 56 (8):1246-1265.

Sigmund, K., De Silva, H., Traulsen, A., Hauert, C. 2010. Social learning promotes institutions for governing the commons. Nature, 466 (7308): 861-863.

Six, F. 2013. Trust in regulatory relations: How new insights from trust research improve regulation theory. Public Management Review, 15 (2):163-185.

Stoop, J., van Soest, D., Vyrastekova, J. 2018. Rewards and cooperation in social dilemma games. 
Journal of Environmental Economics and Management, 88(3): 300-310.

Takayama, T., Matsuda, H., Nakatani, T. 2018. The determinants of collective action in irrigation management systems: Evidence from rural communities in Japan. Agricultural Water Management, 206(7): 113-123.

Talo, C. 2018. Community-based determinants of community engagement: A meta-analysis research. Social Indicators Research, 140 (2): 571-596.

Totin, E., Leeuwis, C., van Mierlo, B., Mongbo, R.L., Stroosnijder, L., Kossou, D.K. 2014. Drivers of cooperative choice: canal maintenance in smallholder irrigated rice production in Benin. International Journal of Agricultural Sustainability, 12 (3):334-354.

Vallentin, S., Thygesen, N. 2017. Trust and control in public sector reform: Complementarity and beyond. Journal of Trust Research, 7 (2):150-169.

Van Oel, P.R., Mulatu, D.W., Odongo, V.O., Willy, D.K., Van der Veen, A. 2019. Using data on social influence and collective action for parameterizing a geographically-explicit agent-based model for the diffusion of soil conservation efforts. Environmental Modelling and Assessment, 24 (1):1-19.

Varoutsa, E., Scapens, R.W. 2018. Trust and control in evolving inter-organisational relationships: Evidence from the aerospace industry. Accounting, Auditing and Accountability Journal, 31 (1): $112-140$.

Varughese, G., Ostrom, E. 2001. The contested role of heterogeneity in collective action: Some evidence from community forestry in Nepal. World Development, 29(5): 747-765.

Wang, J., Huang, J., Rozelle, S., Huang, Q, Rozelle, S. 2010. Water governance and water use efficiency: the five principles of WUA management and performance in China. Journal of the American Water Resource Association, 46(4):665-685.

Wang, Y., Chen, C., Araral, E. 2016. The effects of migration on collective action in the commons: Evidence from rural China. World Development, 88(12): 79-93.

Wangel, M., Blomkvist, H. 2013. Rural forest management in Sierra Leone: The role of economic (In)equality in facilitating collective action. Journal of Development Studies, 49 (11): 15641578 .

Xiao, B., Cui, B., Li, D., Chang, X. 2017. Temporal and spatial variations of precipitation in different climatic regions of the Loess Plateau. Science of Soil and Water Conservation, 1: 007.

Yu, H.H., Edmunds, M., Lora-Wainwright, A., Thomas, D. 2016. Governance of the irrigation commons under integrated water resources management-A comparative study in contemporary rural China. Environmental Science and Policy, 55 (1): 65-74.

Zhang, L., Zhu, X., Heerink, N. and Shi, X. 2014. Does output market development affect irrigation water institutions? Insights from a case study in northern China. Agricultural Water Management, 131(1):70-78. 


\title{
CHAPTER 2
}

\section{Why Farmers Don't Fit Their Deeds to Their Words? The Attitude-behaviour Paradox in Small-scale Irrigation Facilities Collective Action ${ }^{3}$}

\begin{abstract}
Farmers' participative behaviour is an important step for initiating collective action. This study investigates why farmers, who have a positive attitude towards small-scale irrigation collective action, do not transform into real participative choices or who do not have the attitude, yet have real participative behaviour, i.e., the attitude-behaviour paradox. The instrumental variable Probit model is employed to investigate how social network heterogeneity and relative income position influence the farmers' attitude-behaviour paradox. The findings demonstrate that social network heterogeneity, measured in the form of weak tie and strong tie, as well as relative income position, have significant negative effects in explaining the farmers' attitude-behaviour paradox. We incorporate an interaction term of social network and relative income position in the analysis and find that it has significant negative effects on the farmers' attitude-behaviour paradox. After dividing the farmers' paradox into "having attitude but no behaviour" and "having behaviour but no attitude", we find that a weak tie within a social network as well as interaction effects have negative impact on the farmers' paradox for "having behaviour but no attitude", while relative income position has negative impact on the farmers' paradox for "having attitude but no behaviour". Gaining insight into these explanations contribute to our understanding of heterogeneous effects social network and relative income position played in addressing the farmers' attitude-behaviour paradox, it also has policy implications for future development to overcome such social dilemmas.
\end{abstract}

Key words: collective action; attitude-behaviour paradox; relative income position; social network heterogeneity; Instrumental Variable Probit model

${ }^{3}$ This chapter is based on:

Miao, S., Heijman, W., Zhu, X.Q., Lu, Q., 2019. Why Farmers Don't Fit Their Deeds to Their Words? The Attitude-behavior Paradox in Small-scale Irrigation Facilities Collective Action. Under review, Journal of Rural Studies 


\subsection{Introduction}

Initiating collective action is difficult, as actors must overcome obstacles to integrating their preferences, distribution of interests and incentives associated with common-pool resources. This statement mirrors the arguments of Olson (1965) about "why groups of individuals with a common interest may not achieve that interest due to individual incentives" and "why one observes behaviour that appears inconsistent with the absence of collective action predicted by standard models" (Ahn et al., 2003). Currently, the vast majority of theory tries to explain why initiating collective action was successful in some places, while why it failed in some other places is rarely addressed. Normally, the willingness to cooperate is the main underpinning of cooperative behaviour. Based on the theory of planned behaviour, Ajzen (1985) postulated that attitudes---among other factors---influence behaviour. In the context of sustainable resource management, a positive attitude does not emerge as a good predictor of making irrigation facilities cooperative choices or having cooperative behaviour. Farmers' positive attitude and belief often fail to transform into real participative behaviour in common pool resource management. Or rather, farmers without the willingness of cooperation will indeed participate in collective action and show their behaviour. This inconsistency between farmers' expressed intention and their actual lack of action or the reverse is normally referred to as the attitude-behaviour gap/paradox (Claudy et al., 2013). For small-scale irrigation facilities, collective action is important to increase agricultural output and improve rural households' welfare. Therefore, overcoming social dilemmas and initiating collective action for small-scale irrigation facilities depend on how to reduce farmers' attitude-behaviour paradox; thus, farmers' attitude and behaviour could be integrated and consonant to support the conduct of common pool resource management. Overall, an insight into the factors that influence farmers' inconsistency between attitude and behaviour has important implications for policy interventions.

Previous studies concentrated on individual's attitude-behaviour paradox in the domains of sustainable tourism, environment, consumption, safety and study behaviour, etc. from the perspectives of psychology and sociology (Downey et al., 2009; Banwari, 1988; Caruana et al., 2016; Juvan and Dolnicar, 2014; Redondo and Puelles, 2017). This attitude-behaviour paradox can be attributed to the theory of planned behaviour, the attribution theory, the value-beliefnorm theory and the cognitive dissonance theory. Previous research demonstrates that the behaviour of others influences one's decision-making process in a number of domains (Nolan et al., 2008; Schultz et al., 2007). Attitudes, social norms and perceived behaviour control lead to the dissonance between attitude and behaviour (Juvan and Dolnicar, 2014). However, people 
prefer congruence to dissonance. This congruence is maintained by changing behaviour to correspond with attitude or vice versa. Another possible explanation may originate from Stern (2000), who argued that an individual's awareness of consequence and ascription of responsibility being inconsistent leads to the attitude-behaviour paradox. Although these studies tried to provide an answer to this question from their own perspective (Ajzen, 2002), none of the studies identifies reasons from the heterogeneity of socio-economics for the existence of the attitude-behaviour paradox in common pool resource management. Heterogeneity plays a significant role in addressing dilemmas of cooperation (Santos et al., 2006), as heterogeneity is composed of economic inequality and social-cultural differences (Ruttan, 2008), which could be an innovative theoretical perspective for illuminating farmers' attitude-behaviour paradox in collective action for small-scale irrigation facilities.

\subsection{Heterogeneity and collective dilemma: A theoretical background}

Neoclassical economic theory addresses the importance of economic incentives to promote collective behaviour for rational individuals pursuing profit maximization, while coevolutionary theory maintains that social incentives are critical for pro-social behaviour. The individual decision-making process is not only incentivized by evaluating costs and benefits but also made in social interaction contexts (Gintis et al., 2008; Henrich et al., 2005). These decisions are embedded in the social interaction process and are interplayed across different incentives, moving from individual income differentials and social networks towards mutual dynamics (Bebbington, 1999; Adger, 2003). Therefore, a model for the determinants of farmers' attitude-behaviour paradox that incorporate income and social network heterogeneity are developed.

Heterogeneity plays a critical role in initiating common pool resources management (Celia et al., 2002; Munoz et al., 2007). Just as Ahn et al. (2003) pointed out, "investigation to the members' heterogeneity of cooperatives is the key to explain the social dilemma of collective action, and it is also a hot and contentious terrain in current behaviour economics research". Thus, social-cultural backgrounds and economic attributes are intensively discussed and explored. The opposing viewpoint between Olson and Ostrom on how individuals' heterogeneity impact collective action attracts the interests of scholars. However, a consistent conclusion on heterogeneity's contribution is not reached (Olson, 1965; Varughese and Ostrom, 2001; Poteete and Ostrom, 2004; Dayton-Johnson, 2002; Naidu, 2009).

A flurry of studies suggest that people have a low propensity to cooperate in order to resolve collective action issues in more heterogeneous communities (Alesina et al., 1999; 
Alesina and La Ferrara, 2000), while some others argue that heterogeneity is conducive to collective action (Baland and Platteau, 1997). For example, Varughese and Ostrom (2001) demonstrate that wealth inequality is negatively related to collective forest management, while when wealthy participants pay more of the cost and gain more of the positive externalities, it has positive effects (Ruttan, 2008). In rural decentralised decision-making processes, wealthy farmers who are proponents of shared resources usually act as leaders in collective action and play an active role in the initial launch phase (Baland and Platteau, 1997). However, by analysing the situation of irrigation systems in Mexico and southern India, a 'U-curve' relationship between heterogeneity and resource sharing was identified (Dayton-Johnson and Bardhan, 2002). Moreover, Molinas (1998) contended that a moderate level of inequality is related to better cooperative performance, but a higher level of inequality makes it more difficult for cooperatives to work efficiently. Nevertheless, how to define a "moderate and higher" level of inequality still needs to be discussed.

Individuals do not live in a vacuum. Just as Gaspart and Platteau (2007) indicated, income inequality is advantageous to set up management authority, while social network, political status, reciprocity and other similar factors are also motivations to promote elites to undertake the cost of collective action. Social contexts have a great influence on individuals' decisionmaking process (Gould, 1991; Peter, 1994; McAdam and Paulsen, 1993; Opp and Gern, 1993; Siegel, 2009). "Participants were much more likely than withdrawal to have had ties--especially strong ties---to other volunteers" (McAdam, 1986, 80). Since networks could cooperate and transfer resources through information exchange by altering people's perceptions of costs and benefits (Verba et al., 1995). Moreover, network has a direct influence on changing individual's interests and internal motivations toward participation by social pressure (Klofstad, 2007; Oliver and Myers, 2003). Despite the identification that a social network is important for collective action (Marwell et al., 1988), the role of weak ties and strong ties within a social network should be deeply explored to resolve farmers' attitudebehaviour paradox, in the interest of increasing the prospects for common pool resource management.

\subsubsection{Economic heterogeneity}

Economic heterogeneity has complex effects on collective action (Varughese and Ostrom, 2001; Heckathron, 1993), as the differences in endowments may or may not lead to farmers' objectives and interests to coincide. Normally, economic endowments include income, assets, and farm size or wealth heterogeneity. Its lumpiness leads to the role of economic heterogeneity in its ambiguity (Ruttan, 2008). Therefore, it is critical to distinguish different heterogeneity, 
especially in regards to endowment, wealth and economic interests (Baland and Platteau, 1996). For example, Kant (2000) found that with an increase in income inequality, forest users product preferences are more diversified, rich people address the importance of producing biomass, while poor people pay attention to immediate consumption. Somanathan et al. (2002) found a positive relationship between income inequality and the frequency of meetings. However, Tang (1994) maintained that low income heterogeneity prompts irrigation collective action, provided that sufficient information was available. As inequality in wealth or income is often regarded as the main indicator for economic heterogeneity, and annual income is easily observed at the household level, the household's relative income position is employed to measure income inequality (Zhao, 2012):

$$
R I_{i}=\frac{x_{i}-X_{a v e}}{X_{\max }-X_{\min }}
$$

$R I_{i}$ stands for household relative income position in the community, $x_{i}$ denotes household $i$ 's annual income, $X_{\text {ave }}$ is the average value of survey data. $X_{\min }$ is the minimum value of the survey data and $X_{\max }$ is the maximum value of the survey data. Therefore, we propose hypothesis 1 :

H1: Relative income position is set as an a priori and may be positively or negatively related to farmers' attitude-behaviour paradox.

\subsubsection{Social network heterogeneity}

Social networks have been proven to be an important framework to analyse individuals' choice behaviour since it enables farmers to find interaction with different agents in the network. Social networks are heterogeneous because no identical network exists among different individuals (Mcevily and Zaheer, 1999). Normally, social network can be divided based on its relational and structural characteristics that are attributed to relational aspects (i.e. strong ties and weak ties) and structural aspects (i.e. core networks and periphery networks). Because "each individual has a particular, heterogeneous network of ties, and thus differences can be observed by attitude and behaviour (Molina-Morales and Martinez-Fernandez, 2009)", we select strong ties and weak ties to indicate the heterogeneity of a social network (Granovetter, 1973).

Strong ties represent a dense network that can be delineated as the active transmission of information and knowledge. It has the advantage of high-quality information exchange and strong social norms as well as sanctions generated in this process for exerting control mechanisms (Coleman, 1990). On the other hand, weak ties can be characterized as common 
or ordinary circulation or exchange of information and knowledge among remote connections (Molina-Morales and Martinez-Fernadez, 2009). The merit of weak ties is its ability to access new, exclusive information or opportunities to interpret people's behaviours (Granovetter, 1973). Based on Centola and Macy (2007), "weak ties connect acquaintances who interact less frequently, are less invested in the relationship, and are less readily influenced by one another. Strong ties connect close friends or kin whose interactions are frequent, affectively charged, and highly salient to each other". The difference between a strong tie and a weak tie is whether it could "generate information benefits when it is a bridge over a structural hole (Burt, 1992:28)". Therefore, a strong tie is measured by "the number of people you could ask for help", and a weak tie is measured by "the number of people in your daily contacts and acquaintances". Both of them are measured on a 5-point scale which takes the value 1 if the respondent replies one to three, 2 if they reply "four to seven", 3 if "eight to eleven", 4 if "twelve and fifteen" and 5 if " 16 and more". In general, based on the above analysis of strong ties and weak ties, we propose hypothesis 2 :

H2: Weak ties and strong ties of social network are negatively associated with the farmers' attitude-behaviour paradox.

\subsection{Study area and methods}

\subsubsection{Study area and variables}

In order to test the hypotheses of social network and relative income position on farmers' attitude-behaviour paradox, a household survey was conducted in the Xichen village, Donggou village, Zhaizigou village, Beizhao village and Qiaodi village of Xianyang city, Shaanxi Province of China between April and June in 2011. The study area was selected to the villages that carried out collective action for small-scale irrigation facilities. These villages belong to Jing Huiqu irrigation districts. The irrigated area included the Jingyang County, Sanyuan County, Gaoling County, Lintong County and Yanliang County for 1350 thousand mu. It is a gravity irrigation project combined with well irrigation facilities that connect to the Jing River. The irrigated areas are flat, and within those areas, the soil is fertile. The main crops are wheat, corn, cotton and vegetables. The study area is located in semi-arid districts with a continental monsoon climate, where the average annual rainfall is 399 millimetres; however, the rainfall is mainly concentrated in summer and autumn seasons. The uneven distribution of the rainfall often resulted in drought in summer. The survey contained information on social-demographics, management conditions of irrigation, social capital, social network and farmers' attitude on collective action for small-scale irrigation facilities. The order and wording of the questions 
are carefully designed to ensure unbiased identification. 308 valid questionnaires were selected after excluding those with incomplete responses from 350 copies of the survey. "A weakness of much of this research is the distinction between what survey respondents say and what they actually ask for or do" (Miller, 2003, P19). In order to account for this weakness and avoid social desirability bias, the information on participation behaviour was collected from the list of irrigation managing committee personnel after the survey interview.

Contextual elements and personal factors have been identified in order to analyse the attitude-behaviour paradox of individuals. Normally the contextual elements referred to are institutional constraints, social norms, social pressure or regulatory incentives (Jackson, 2005), while the personal factors relate to attitudes, attribute constraints, habits or personal competencies (Stern, 2005). Therefore, we select farmers' attitude-behaviour paradox as the independent variable. The core explanatory variables are the weak tie and strong tie of a social network as well as relative income position. The control variables are farmers' social demographics, rules and institutions as well as community environment. Community rules and atmosphere are selected to reflect the attributes of the community environment that can influence the behaviour and attitude in human-interactive situations (Richerson and Boyd, 2005). Previous studies have demonstrated that the sustainability of common-pool resource management is more inclined in a community with shared norms (Ostrom, 2014). We select past experiences of water stealing and water use conflicts to reflect the real level of rules-inuse for structuring human-interaction conditions, as the rules are critical for small-scale irrigation facilities construction and maintenance, especially for the rules-in-use by the participants (Ostrom, 2014).

\subsubsection{Methods}

To evaluate the effects of social network heterogeneity and relative income position on farmers' attitude-behaviour paradox for collective action for small-scale irrigation facilities, we estimate the following system of equations using a two-stage instrument variable Probit model (IVProbit) (Das, 2015):

$$
Y_{i}=\alpha+\beta X_{i}+\chi S N_{i}+\not R I_{i}+\varepsilon_{i}
$$

Where $Y_{i}$ is the binary variable that indicates 1 for inconsistency between attitude and behaviour and 0 for consistency between attitude and behaviour. This variable was computed by taking the absolute value of the difference score between attitude and behaviour. $X_{i}$ is the vector of variables controlling for socio-demographic variables. $S N_{i}$ is the social network that has the potential of endogeneity. $R I_{i}$ denotes the relative income position. Due to the 
difficulty of finding an appropriate regression methodology that can evaluate binary or continuous variables with endogenous variables (Angrist et al., 2010; Mont and Nguyen, 2013); a linear structure to the endogenous variable was recruited to estimate the model. Following this structure, the second stage model takes $S N_{i}$ as the endogenous variable. The first stage of the IV Probit model is shown as follows:

$$
S N_{i}=\delta+\phi C_{i}+\eta Z_{i}+v_{i}
$$

Where $C_{i}$ is a vector of exogenous variables, $Z_{i}$ is the vector of instruments, which are highly correlated with the social network but non-correlated with the error term, $\varepsilon_{i}$. Under the assumption of heterogeneity, the instrument variable should predict social network, but it should be uncorrelated with outcomes other than through social network. If $\operatorname{Cov}\left(\operatorname{SN}_{i}, \varepsilon_{i}\right) \neq 0$, it means social network under the program is endogenous.

We use the Bivariate Probit model to test for the necessity of recruiting instrument variables. The Bivariate Probit model has the function to test for endogeneity of social network variable to the outcome variable by estimating $\operatorname{Cov}\left(S N_{i}, \varepsilon_{i}\right) \neq 0$ or $\operatorname{Cov}\left(S N_{i}, \varepsilon_{i}\right)=0$. If $\operatorname{Cov}\left(S N_{i}, \varepsilon_{i}\right)=0$, then we cannot reject the null of exogeneity, and simple Probit estimation would be sufficient to gauge the impact. However, if $\operatorname{Cov}\left(S N_{i}, \varepsilon_{i}\right) \neq 0$, then the endogeneity conditions hold; IV Probit estimation can provide consistent estimates of the impact.

We evaluate the impact of social network as well as income heterogeneity on farmers' paradox by the outcome. Equation (1) and equation (2) are the first stage regressions for measuring the instruments of social networks as well as other control variables in the outcome equation. We develop three pairs of models:

Pair A is estimated with the Bivariate Probit model for strong tie and weak tie separately.

Pair B is estimated with the IV Probit model for strong tie and weak tie separately.

Pair $\mathrm{C}$ is estimated with the IV Probit model for strong tie $\times$ relative income position and weak tie $\times$ relative income position separately.

Since Zhou et al. (2014) have identified interaction effects between social capital and income disparity, the interaction item constructed is to evaluate the interactive effects of income and social network heterogeneity.

\subsubsection{Instrument variable of social networks}

Endogeneity of social network has been validated by a vast amount of literature (Hassan and Birungi, 2011; Durlauf and Fatchamps, 2004; Maweijie and Holden, 2014). This is mainly because social network and participation in collective action has reverse causality relationships. 
For example, farmers with voluminous social network channels are more inclined to participate in collective action, while farmers in cooperatives who benefit from information exchange and knowledge sharing as well as improved income levels, their inclination for further participation are thus increased. Moreover, it is more difficult about residual confounding, as some other unobserved variables, e.g. personality and family background, may also correlate with social network when it cannot be argued that explanatory variables are not correlated with the error term. Therefore, it is important to select a decent instrumental variable for two prerequisites to be satisfied: the instrumental variable should be correlated with the endogenous dependent variable, and it should not be correlated with the independent variable other than through endogenous variables. Therefore, a valid instrumental variable in our case should be correlated with social network but have no direct effects on the attitude-behaviour paradox other than through social network. Thus, we use instrumental variable methods for parameter estimation:

Distance to the provincial or national highway. It is selected to reflect the relationship between distance and social network. The Spearman correlation demonstrates that distance is not correlated with farmers' attitude-behaviour paradox (Spearman's $\rho=-0.074 ; \mathrm{P}=0.195$ ), but is correlated with social network (Spearman's $\rho=0.112 ; \mathrm{P}=0.049$ ), implying that distance to the provincial or national highway is independent of the attitude-behaviour paradox.

Whether the family member goes to a metropolitan city for migrant working. The selection of the instrumental variable fit for the criteria relevance and exogeneity, because a farmer with out-migration working experience helps himself to enlarge his social network with other migrant workers, but has no direct relationship with the attitude-behaviour paradox. Spearman correlation analysis indicates migrant working experience insignificantly correlated with the paradox (Spearman's $\rho=-0.045 ; \mathrm{P}=0.428$ ), while it is significantly correlated with social network (Spearman's $\rho=0.194 ; \mathrm{P}=0.001$ ).

\subsection{Results}

\subsubsection{Total effects of the attitude-behaviour paradox}

Table 2.1 summarises the sample descriptive statistics. $64.94 \%$ of respondents have willingness to participate in collective action for small-scale irrigation facilities; however, only $49.03 \%$ of respondents have real participative behaviour. $64.6 \%$ of respondents show attitudebehaviour paradox. Among this group, $23.7 \%$ of respondents do not have the attitude but do have real participative behaviour, while $40.9 \%$ show the willingness without any real participative behaviour. $80.84 \%$ of respondents received a primary and secondary education. 
The average cultivated area for every household is 3.517 acres. Past experiences of water stealing and water use conflicts are on a medium level, specifically 3.6 and 2.5 respectively compared to the maximum level of 5 . Respondents have comparatively dense networks regardless of weak tie and strong tie, for which the mean values are 4.47 and 3.58 respectively. Respondents have a high evaluation concerning their community environment, for which the mean value is above 3.6 .

Table 2.1 Descriptive statistics of main variables

\begin{tabular}{|c|c|c|c|c|c|}
\hline Variable & Description & Minimum & Maximum & Mean (S.D.) & $\begin{array}{c}\text { Expected } \\
\text { effects }\end{array}$ \\
\hline \multicolumn{6}{|l|}{ Independent variables } \\
\hline Paradox & $\begin{array}{l}\text { Paradox between attitude and behaviour } \\
\qquad(\text { paradox }=1, \text { no paradox }=0)\end{array}$ & .00 & 1.00 & $\begin{array}{l}.6396 \\
(.4809)\end{array}$ & \\
\hline \multicolumn{6}{|l|}{ Dependent variables } \\
\hline Weak tie & $\begin{array}{l}\text { The number of people in your daily contacts and } \\
\text { acquaintances( } 1=1-3 ; 2=4-7 ; 3=8-11 ; 4=12-15 ; \\
5=\text { above } 16)\end{array}$ & 2.00 & 5.00 & $\begin{array}{l}4.4740 \\
(.7716)\end{array}$ & - \\
\hline Strong tie & $\begin{array}{c}\text { The number of people you could ask for } \\
\text { help }(1=1-3 ; 2=4-7 ; 3=8-11 ; 4=12-15 ; 5=\text { above } \\
16)\end{array}$ & 1.00 & 5.00 & $\begin{array}{c}3.5812 \\
(1.1052)\end{array}$ & - \\
\hline $\begin{array}{l}\text { Relative income } \\
\text { position }\end{array}$ & Based on the computation & -.37 & .73 & $\begin{array}{l}-.0080 \\
(.7160)\end{array}$ & $+/-$ \\
\hline Cultivated area & Real cultivated area $(\mathrm{mu})$ & .00 & 11.00 & $\begin{array}{r}3.5170 \\
(2.0520)\end{array}$ & $+/-$ \\
\hline Water stealing & $\begin{array}{c}\text { The frequency of water stealing happened }(1= \\
\text { never; } 2=\text { occasionally; } 3=\text { sometimes; } 4= \\
\text { frequently; } 5=\text { always })\end{array}$ & 1.00 & 5.00 & $\begin{array}{r}3.6100 \\
(1.2081)\end{array}$ & $+/-$ \\
\hline Water use conflict & $\begin{array}{l}\text { The frequency of water use conflicts }(1=\text { never; } \\
\begin{aligned} 2=\text { occasionally; } 3=\text { sometimes; } 4=\text { frequently; } \\
5=\text { always })\end{aligned}\end{array}$ & 1.00 & 5.00 & $\begin{array}{c}2.5377 \\
(1.0100)\end{array}$ & $+/-$ \\
\hline Community rules & $\begin{array}{l}\text { The village's rules and regulations executive } \\
\text { conditions ( } 1=\text { very bad; } 2=\text { bad; } 3=\text { neither bad } \\
\text { nor good; } 4=\text { good; } 5=\text { very good })\end{array}$ & 2.00 & 5.00 & $\begin{array}{l}4.6753 \\
(.6135)\end{array}$ & $+/-$ \\
\hline $\begin{array}{l}\text { Community } \\
\text { atmosphere }\end{array}$ & $\begin{array}{l}\text { What is the community's atmosphere (1=very } \\
\text { bad; } 2=\text { bad; } 3=\text { neither bad nor good; } 4=\text { good; } \\
5=\text { =ery good })\end{array}$ & 1.00 & 4.00 & $\begin{array}{l}3.6169 \\
(.5898)\end{array}$ & $+/-$ \\
\hline Instrumental Variable 1 & $\begin{array}{l}\text { The village's distance to the highway? } 1=1-2 \\
\text { kilometres; } 2=3-5 \text { kilometres; } 3=6-8 \\
\text { kilometres; } 4=9-12 \text { kilometres; } 5=\text { above } 12\end{array}$ & 1.00 & 5.00 & $\begin{array}{l}3.6331 \\
(.9088)\end{array}$ & \\
\hline Instrumental Variable 2 & $\begin{array}{l}\text { kilometres } \\
2 \text { Whether family member work in } \\
\text { metropolitan city ( } 1=\text { =work; } 2=\text { no work })\end{array}$ & .00 & 1.00 & $\begin{array}{c}.3604 \\
(.4809)\end{array}$ & \\
\hline
\end{tabular}


The statistical results for the instrumental variable Probit (IV Probit) model that address the potential endogeneity problem of social network are shown in table 2.2. The listing in 3 columns allows for the comparison of the results of the Bivariate Probit model and IV Probit model. In the first bivariate model, all the household controls are used except for the instrumental variables. In the second specification, weak tie and strong tie are evaluated separately for which instrumental variables are included in the IV Probit model. For the third specification, interaction effects of social network and relative income positions are included. The results show that both of the instrumental variables of (1) distance to main provincial and country highway, and (2) whether a family member work in the metropolitan city, have significant effects on social network, indicating that both of these instrumental variables are highly associated with farmer's networks. Moreover, the F value of the first stage regression is above 10, demonstrating that the weak instrument problem does not exist (Staiger and Stock, 1997). The Wald test of exogeneity shows a $P$ value less than 0.1 , implying that we can reject the null of exogeneity at the $10 \%$ level of significance. Thus, the Probit regression with endogenous regressor ensures the accuracy to gauge the impact of social network and relative income position on farmers' attitude-behaviour paradox. 
Table 2.2 Estimation results of attitude-behaviour paradox

\begin{tabular}{|c|c|c|c|c|c|c|}
\hline & \multicolumn{2}{|c|}{ Bivariate model } & \multicolumn{2}{|c|}{ IV Probit model } & \multicolumn{2}{|c|}{$\begin{array}{c}\text { IV Probit model with social } \\
\text { network*relative income position }\end{array}$} \\
\hline & Model 1 & Model 2 & Model 3 & Model 4 & Model 5 & Model 6 \\
\hline $\begin{array}{l}\text { Social network1 } \\
\text { (weak tie) }\end{array}$ & $\begin{array}{l}-0.213 \\
(0.176)\end{array}$ & & $\begin{array}{l}-1.885^{*} \\
(1.143)\end{array}$ & & & \\
\hline $\begin{array}{l}\text { Social network2 } \\
\text { (strong tie) }\end{array}$ & & $\begin{array}{c}0.312 * * * \\
(0.111)\end{array}$ & & $\begin{array}{l}-0.688^{* *} \\
(0.335)\end{array}$ & & \\
\hline Social & & & & & & \\
\hline $\begin{array}{l}\text { Network } 1 \text { *relati } \\
\text { ve income } \\
\text { position }\end{array}$ & & & & & $\begin{array}{c}-0.388^{* * * *} \\
(0.151)\end{array}$ & \\
\hline Social & & & & & & \\
\hline $\begin{array}{l}\text { Network } 2 * \text { relati } \\
\text { ve income } \\
\text { position }\end{array}$ & & & & & & $\begin{array}{c}-0.524 * * * \\
(0.183)\end{array}$ \\
\hline $\begin{array}{l}\text { Relative income } \\
\text { position }\end{array}$ & $\begin{array}{c}-1.862 * * * \\
(0.667)\end{array}$ & $\begin{array}{c}-1.994 * * * \\
(0.702)\end{array}$ & $\begin{array}{c}-2.073 * * * \\
(0.778)\end{array}$ & $\begin{array}{c}-2.171 * * * \\
(0.836)\end{array}$ & & \\
\hline Education & $\begin{array}{l}-0.266^{*} \\
(1.452)\end{array}$ & $\begin{array}{l}-0.036^{* *} \\
(0.059)\end{array}$ & $\begin{array}{l}-0.109 \\
(0.199)\end{array}$ & $\begin{array}{l}-0.275 \\
(0.181)\end{array}$ & $\begin{array}{c}-0.289 * * \\
(0.144)\end{array}$ & $\begin{array}{c}-0.294 * * \\
(0.149)\end{array}$ \\
\hline Cultivated area & $\begin{array}{l}-0.017 \\
(0.057)\end{array}$ & $\begin{array}{l}-0.036 \\
(0.059)\end{array}$ & $\begin{array}{l}-0.031 \\
(0.066)\end{array}$ & $\begin{array}{c}0.007 \\
(0.073)\end{array}$ & $\begin{array}{l}-0.013 \\
(0.057)\end{array}$ & $\begin{array}{l}-0.020 \\
(0.058)\end{array}$ \\
\hline Agriculture year & $\begin{array}{c}0.006 \\
(0.011)\end{array}$ & $\begin{array}{c}0.006 \\
(0.011)\end{array}$ & $\begin{array}{c}0.019 \\
(0.015)\end{array}$ & $\begin{array}{l}-0.004 \\
(0.013)\end{array}$ & $\begin{array}{l}-0.004 \\
(0.11)\end{array}$ & $\begin{array}{l}-0.003 \\
(0.011)\end{array}$ \\
\hline Water stealing & $\begin{array}{c}1.290 * * * \\
(0.147)\end{array}$ & $\begin{array}{c}1.251 * * * \\
(0.138)\end{array}$ & $\begin{array}{c}1.366 * * * \\
(0.159)\end{array}$ & $\begin{array}{c}1.692 * * * \\
(0.218)\end{array}$ & $\begin{array}{c}1.256 * * * \\
(0.132)\end{array}$ & $\begin{array}{c}1.295 * * * \\
(0.136)\end{array}$ \\
\hline $\begin{array}{l}\text { Water use } \\
\text { conflicts }\end{array}$ & $\begin{array}{c}0.299 * * * \\
(0.112)\end{array}$ & $\begin{array}{l}0.225^{*} \\
(0.116)\end{array}$ & $\begin{array}{c}0.367 * * * \\
(0.139)\end{array}$ & $\begin{array}{l}0.354 * * \\
(0.146)\end{array}$ & $\begin{array}{l}0.282^{* *} \\
(0.110)\end{array}$ & $\begin{array}{c}0.266^{* *} \\
(0.111)\end{array}$ \\
\hline Community & -0.261 & $-0.455^{* *}$ & 0.813 & $-0.515 * *$ & $-0.430 * *$ & $-0.429 * *$ \\
\hline rules & $(0.240)$ & $(0.216)$ & $(0.773)$ & $(0.263)$ & $(0.212)$ & $(0.213)$ \\
\hline $\begin{array}{l}\text { Community } \\
\text { atmosphere }\end{array}$ & $\begin{array}{l}-0.314 \\
(0.199)\end{array}$ & $\begin{array}{l}-0.300 \\
(0.208)\end{array}$ & $\begin{array}{l}-0.456^{*} \\
(0.248)\end{array}$ & $\begin{array}{c}-0.699 * * \\
(0.282)\end{array}$ & $\begin{array}{l}-0.311 \\
(0.199)\end{array}$ & $\begin{array}{l}-0.341^{*} \\
(0.206)\end{array}$ \\
\hline Cons & $\begin{array}{l}-0.812 \\
(1.302)\end{array}$ & $\begin{array}{l}-1.483 \\
(1.405)\end{array}$ & $\begin{array}{c}1.066 \\
(1.971)\end{array}$ & $\begin{array}{c}1.927 \\
(1.994)\end{array}$ & $\begin{array}{l}-0.694 \\
(1.329)\end{array}$ & $\begin{array}{l}-0.636 \\
(1.325)\end{array}$ \\
\hline $\begin{array}{l}\text { Pseudo R- } \\
\text { squared }\end{array}$ & 0.5836 & 0.6006 & & & & \\
\hline Log-likelihood & -83.826 & -80.406 & & & & \\
\hline F Statistics & & & 11.59 & 13.15 & 465.33 & 385.88 \\
\hline $\begin{array}{l}\text { Wald test of } \\
\text { exogeneity }\end{array}$ & & & $\begin{array}{c}\text { Chi } 2(1)=3.09 \\
\text { Prob }>\text { chi } 2= \\
0.079\end{array}$ & $\begin{array}{c}\text { Chi } 2(1)=13.11 \\
\text { Prob }>\text { chi } 2= \\
0.0003\end{array}$ & $\begin{array}{c}\text { Chi } 2(1)=0.30 \\
\text { Prob }>\text { chi } 2= \\
0.5858\end{array}$ & $\begin{array}{c}\text { Chi } 2(1)=1.51 \\
\text { Prob }>\text { chi } 2= \\
0.2199\end{array}$ \\
\hline R-squared & & & 0.2811 & 0.3249 & 0.9336 & 0.9285 \\
\hline Adj R-squared & & & 0.2544 & 0.2998 & 0.9316 & 0.9264 \\
\hline
\end{tabular}

Note: $* * *, * *, *$ denote $1 \%, 5 \%, 10 \%$ of significance level, respectively 
The coefficient of weak tie (-1.885) is dramatically lower than strong tie (-0.688), both of which are negatively and significantly related to the farmers' attitude-behaviour paradox. It demonstrates that social network could reduce attitude-behaviour inconsistencies and thus initiate collective behaviour. One possible explanation for this result could be that social learning promotes information exchange and knowledge sharing in social contexts. Thus farmers' beliefs and ideas alter accordingly in response to these interactions. However, herd effects will arise in a social context as networks transmit social pressure and influence, related to the idea that "you are safer the more others join your actions" (Centola and Macy, 2007; Siegel, 2009). Weak tie is important in reducing farmers' attitude-behaviour paradox, as it can build upon more connections with others and fill up structural holes. Compared to the close circle and high communication cost of strong tie, weak tie is beneficial for searching new opportunities. Furthermore, the IV Probit regression of instrumental variables indicates that the instrumental variable selection is appropriate in addressing the farmers' attitude-behaviour paradox. Appendix 2A is the result of the first stage Probit regression, which validates for social network instruments.

Relative income position is negatively and significantly related to the farmers' attitudebehaviour paradox at the $1 \%$ level of significance. It means that the relative income differential will reduce the farmers' attitude-behaviour paradox. This finding is consistent with Olson (1965) as well as Baland and Platteau (1999), who argued that higher income individuals would like to participate in collective action as they can have higher benefits and more easily internalize their costs. Moreover, economic attributes lead to distinction for farmers' motives to participate in collective action. Normally, wealthy farmers are proponents and leaders of shared resources in collective action and play an active role in the initial launch phase.

The interaction items of social network and relative income position exerts a negative and significant relationship with the farmers' attitude-behaviour paradox. Our finding demonstrates that social network and relative income position could mutually reinforce each other by reducing the dilemmas of collective action. Social network heterogeneity and relative income positions are not static conditions. Rather, their interaction is a dynamic process that reflects the interactions between elites and other stakeholders within certain constraints and attributes. Also, "the dynamic interaction reflects how various forms of heterogeneity intensify and coincide and create motives for action among influential groups". This statement implies that the heterogeneity issue must be contextualised and conditionally studied as a dynamic process related to changes in social relationships (Douglas, 1986).

Experience of water stealing and water use conflicts are positively and significantly 
associated with the farmers' attitude-behaviour paradox. This statement can be corroborated by Poteete and Ostrom (2004), who addressed the importance of institutions and rules on reducing transaction costs to sustain collective action. It indicates that an array of efficient and fair rules and institutions are critical for the resonance of farmers' attitudes and behaviours. Community rules and atmosphere are negatively and significantly related to the farmers' paradox. It indicates that community environment plays a critical role in farmers' attitude and participative behaviour. A community with clear rules and norms are more inclined to overcome difficulties in farmers' participating or sustaining behaviour.

\subsubsection{Separate effects of the attitude-behaviour paradox}

Heterogeneous effects of income and social network have been identified by analysing the farmers' attitude-behaviour paradox. More tailored policy intervention is needed to address farmers' different types of paradox. Therefore, we divide this paradox into two types: "having behaviour but no attitude" and "having attitude but no behaviour", to explore the accurate role of different factors played in framing farmers' attitude-behaviour paradox. The results are demonstrated in Table 2.3. 
Table 2.3 Comparison between "having behaviour but no attitude" and "having attitude

but no behaviour"

\begin{tabular}{|c|c|c|c|c|c|c|c|c|}
\hline & \multicolumn{4}{|c|}{ Having behaviour but no attitude } & \multicolumn{4}{|c|}{ Having attitude but no behaviour } \\
\hline & \multicolumn{2}{|c|}{ IV Probit model } & \multicolumn{2}{|c|}{$\begin{array}{l}\text { IV Probit model } \\
\text { Network*relative } \\
\text { income position }\end{array}$} & \multicolumn{2}{|c|}{ IV Probit model } & \multicolumn{2}{|c|}{$\begin{array}{l}\text { IV Probit model } \\
\text { Network*relative } \\
\text { income position }\end{array}$} \\
\hline $\begin{array}{l}\text { Social network1 } \\
\text { (weak tie) }\end{array}$ & $\begin{array}{l}-2.781^{*} \\
(1.657)\end{array}$ & & & & $\begin{array}{l}-1.340 \\
(1.061)\end{array}$ & & & \\
\hline $\begin{array}{l}\text { Social network2 } \\
\text { (strong tie) }\end{array}$ & & $\begin{array}{l}1.048 \\
(1.011)\end{array}$ & & & & $\begin{array}{l}0.324 \\
(0.736)\end{array}$ & & \\
\hline $\begin{array}{l}\text { Social network } \\
1 * \text { relative } \\
\text { income position }\end{array}$ & & & $\begin{array}{l}-0.821 * * * \\
(0.241)\end{array}$ & & & & $\begin{array}{l}-0.241 \\
(0.168)\end{array}$ & \\
\hline $\begin{array}{l}\text { Social network } \\
2 * \text { relative } \\
\text { income position }\end{array}$ & & & & $\begin{array}{l}-1.145^{* * *} \\
(0.351)\end{array}$ & & & & $\begin{array}{l}-0.394 \\
(0.267)\end{array}$ \\
\hline $\begin{array}{l}\text { Relative income } \\
\text { position }\end{array}$ & $\begin{array}{l}-3.652^{* * *} \\
(1.370)\end{array}$ & $\begin{array}{l}-3.633^{* * * *} \\
(1.188)\end{array}$ & & & $\begin{array}{l}-1.440^{*} \\
(0.788)\end{array}$ & $\begin{array}{l}-1.202 * \\
(0.720)\end{array}$ & & \\
\hline Education & $\begin{array}{l}-0.143 \\
(0.369)\end{array}$ & $\begin{array}{l}-0.438 * \\
(0.244)\end{array}$ & $\begin{array}{l}-0.523^{* *} \\
(0.217)\end{array}$ & $\begin{array}{l}-0.493 * * \\
(0.218)\end{array}$ & $\begin{array}{l}-0.139 \\
(0.191)\end{array}$ & $\begin{array}{l}-0.204 \\
(0.178)\end{array}$ & $\begin{array}{l}-0.249 \\
(0.161)\end{array}$ & $\begin{array}{l}-0.248 \\
(0.162)\end{array}$ \\
\hline Cultivated area & $\begin{array}{l}0.018 \\
(0.111)\end{array}$ & $\begin{array}{l}0.060 \\
(0.089)\end{array}$ & $\begin{array}{l}0.063 \\
(0.079)\end{array}$ & $\begin{array}{l}0.054 \\
(0.078)\end{array}$ & $\begin{array}{l}-0.022 \\
(0.066)\end{array}$ & $\begin{array}{l}-0.048 \\
(0.068)\end{array}$ & $\begin{array}{l}-0.028 \\
(0.063)\end{array}$ & $\begin{array}{l}-0.024 \\
(0.063)\end{array}$ \\
\hline Agriculture year & $\begin{array}{l}0.041 \\
(0.026)\end{array}$ & $\begin{array}{l}0.021 \\
(0.018)\end{array}$ & $\begin{array}{l}0.014 \\
(0.015)\end{array}$ & $\begin{array}{l}0.015 \\
(0.151)\end{array}$ & $\begin{array}{l}0.008 \\
(0.015)\end{array}$ & $\begin{array}{l}0.002 \\
(0.014)\end{array}$ & $\begin{array}{l}-0.003 \\
(0.012)\end{array}$ & $\begin{array}{l}-0.003 \\
(0.012)\end{array}$ \\
\hline Water stealing & $\begin{array}{l}1.567 * * * \\
(0.264)\end{array}$ & $\begin{array}{l}1.002 * * * \\
(0.357)\end{array}$ & $\begin{array}{l}1.342 * * * \\
(0.186)\end{array}$ & $\begin{array}{l}1.344 * * * \\
(0.187)\end{array}$ & $\begin{array}{l}1.344^{* * * *} \\
(0.162)\end{array}$ & $\begin{array}{l}1.179 * * * \\
(0.256)\end{array}$ & $\begin{array}{l}1.261 * * * \\
(0.148)\end{array}$ & $\begin{array}{l}1.280 * * * \\
(0.150)\end{array}$ \\
\hline $\begin{array}{l}\text { Water use } \\
\text { conflicts }\end{array}$ & $\begin{array}{l}0.404 * \\
(0.234)\end{array}$ & $\begin{array}{l}0.330 * \\
(0.189)\end{array}$ & $\begin{array}{l}0.220 \\
(0.146)\end{array}$ & $\begin{array}{l}0.223 \\
(0.146)\end{array}$ & $\begin{array}{l}0.375^{* * * *} \\
(0.145)\end{array}$ & $\begin{array}{l}0.345^{* *} \\
(0.171)\end{array}$ & $\begin{array}{l}0.292 * * \\
(0.124)\end{array}$ & $\begin{array}{l}0.293 * * \\
(0.124)\end{array}$ \\
\hline $\begin{array}{l}\text { Community } \\
\text { rules }\end{array}$ & $\begin{array}{l}1.014 \\
(1.041)\end{array}$ & $\begin{array}{l}-0.493 * \\
(0.297)\end{array}$ & $\begin{array}{l}-0.682 * * * \\
(0.246)\end{array}$ & $\begin{array}{l}-0.610^{* * *} \\
(0.240)\end{array}$ & $\begin{array}{l}0.807 \\
(0.914)\end{array}$ & $\begin{array}{l}-0.183 \\
(0.310)\end{array}$ & $\begin{array}{l}-0.317 \\
(0.270)\end{array}$ & $\begin{array}{l}-0.275 \\
(0.270)\end{array}$ \\
\hline $\begin{array}{l}\text { Community } \\
\text { atmosphere }\end{array}$ & $\begin{array}{l}-0.459 \\
(0.409)\end{array}$ & $\begin{array}{l}-0.359 \\
(0.323)\end{array}$ & $\begin{array}{l}-0.305 \\
(0.283)\end{array}$ & $\begin{array}{l}-0.259 \\
(0.282)\end{array}$ & $\begin{array}{l}-0.412 * \\
(0.236)\end{array}$ & $\begin{array}{l}-0.340 \\
(0.219)\end{array}$ & $\begin{array}{l}-0.360 \\
(0.221)\end{array}$ & $\begin{array}{l}-0.389^{*} \\
(0.223)\end{array}$ \\
\hline Cons & $\begin{array}{l}2.240 \\
(2.894)\end{array}$ & $\begin{array}{l}-3.566 \\
(3.392)\end{array}$ & $\begin{array}{l}-0.306 \\
(1.664)\end{array}$ & $\begin{array}{l}-0.855 \\
(1.658)\end{array}$ & $\begin{array}{l}-1.417 \\
(1.711)\end{array}$ & $\begin{array}{l}-2.965 \\
(3.216)\end{array}$ & $\begin{array}{l}-1.255 \\
(1.634)\end{array}$ & $\begin{array}{l}-1.422 \\
(1.626)\end{array}$ \\
\hline F Statistics & 6.24 & 4.81 & 240.18 & 152.52 & 12.55 & 6.15 & 372.00 & 178.07 \\
\hline $\begin{array}{l}\text { Wald test of } \\
\text { exogeneity }\end{array}$ & $\begin{array}{l}\text { Chi2(1) } \\
=5.21 \\
\text { Prob }>\text { chi } 2 \\
=0.022\end{array}$ & $\begin{array}{l}\text { Chi2(1) } \\
=1.26 \\
\text { Prob }>\text { chi } 2 \\
=0.2622\end{array}$ & $\begin{array}{l}\text { Chi2 }(1) \\
=0.12 \\
\text { Prob }>\text { chi2 } \\
=0.7241\end{array}$ & $\begin{array}{l}\text { Chi2(1) } \\
=1.08 \\
\text { Prob }>\text { chi } 2 \\
=0.2991\end{array}$ & $\begin{array}{l}\text { Chi2(1) } \\
=1.10 \\
\text { Prob }>\text { chi2 } \\
=0.2946\end{array}$ & $\begin{array}{l}\text { Chi2(1) } \\
=0.00 \\
\text { Prob }>\text { chi } 2 \\
=0.9561\end{array}$ & $\begin{array}{l}\text { Chi2 }(1) \\
=0.13 \\
\text { Prob }>\text { chi } 2 \\
=0.7184\end{array}$ & $\begin{array}{l}\text { Chi2 }(1) \\
=0.21 \\
\text { Prob }>\text { chi2 } \\
=0.6445\end{array}$ \\
\hline R-squared & 0.2651 & 0.2176 & 0.9255 & 0.8875 & 0.3591 & 0.2153 & 0.9370 & 0.8769 \\
\hline Adj R-squared & 0.2226 & 0.1724 & 0.9216 & 0.8817 & 0.3305 & 0.0 .1803 & 0.9345 & 0.8720 \\
\hline
\end{tabular}

Note: $* * *, * *, *$ denote $1 \%, 5 \%, 10 \%$ of significance level, respectively 
For the first type of paradox, i.e. farmers having behaviour but no attitude, the weak tie of social network plays negative and significant effects in explaining this kind of inconsistency. This result is consistent with the proposition set forward by Granovetter (1973), who argued that weak tie has cohesive power to integrate into communities, while "strong ties, breeding local cohesion, lead to overall fragmentation". In reality, there is no difference in terms of good or bad networks between strong and weak ties, as "both may be useful in explaining different types of benefits that corresponds to different strategic objectives (Molina-Morales and Martinez-Fernandex, 2008)". Interaction effects of income and social network heterogeneity are also identified for this type of paradox. Since information and resources are distributed unevenly in pyramid structures, those at the top of pyramid are more inclined to acquire the important and new information. Thus this information and resource could be utilized to create new opportunities. Weak tie of social network plays a complementary effect for reducing the farmers' attitude-behaviour paradox. It is also noted that education has significant negative effects on the farmers' paradox "having behaviour but no attitude", which addresses the importance of education in altering farmers' choice.

On the other hand, the relative income position has significantly negative effects on the farmers' paradox for "having attitude but no behaviour". This result demonstrates that when relative income position increases, farmers who have a positive attitude will have a higher inclination to participate in collective action to undertake social roles. Since farmers develop a positive attitude when income increases, they will have viable options to participate in collective action. Farmers' choice is explicitly weighed by costs and benefits. The higher the income farmers have, the higher their ability to undertake the costs of collective action and get higher benefits from it. Therefore, the economic incentive is the key to reducing this kind of paradox. In this regard, farmers' perception of cost and benefits and how interests distributed are crucial for addressing this social dilemma.

\subsection{Conclusions}

Collective action for small-scale irrigation facilities plays a pivotal role in semi-arid rural areas. However, some groups succeed in collective action, while "some others experience an unravelling of collective action after initial success" (Poteete and Ostrom, 2004). Farmers are the main actors in the specific demographic, economic and social environments for participating in or sustaining these co-operations. Due to the very fact that farmers show inconsistencies between their attitude and behaviour, the study aims to shed light on this attitude-behaviour paradox in regards to participating in collective action. Social network and 
relative income position are identified as key factors influencing the farmers' attitudebehaviour paradox. Specifically, we divide the paradox into having behaviour but no attitude and having attitude but no behaviour. In order to investigate the factors separately from the perspective of social network and relative income positions, the instrumental variables are employed to reflect the farmers' social networks.

Our findings indicate that weak ties within a social network play a critical role in addressing farmers' having behaviour but no attitude, whereas relative income positions have substantive effects on farmers' having attitude but no behaviour. Therefore, weak ties are better predictors for initiating participative behaviour, as they bridge obstacles in order to incorporate everyone into social structures (Marwell et al., 1988). Its successful transformation lies in how different network structural properties promote positive or negative motivations to collectively act toward a common pool resource management. Since people who have intrinsically low motivations---and more information exchange and resource transfer are necessary---can be promoted by structural strength of weak ties to transform the attitude-behaviour paradox into consistencies.

In essence, people's collective behaviour aims "not only at economic goals but also at sociability, approval, status and power (Granovetter, 1985). Heterogeneous motivations originate from farmers' different responses to information, social interaction as well as their attribute and interests, all of which have a substantial impact on the farmers' attitude-behaviour paradox (Siegel, 2009; Granovetter and Soong, 1983; Kim and Bearman, 1997). The structural properties of the social network farmers are embedded in leads them to weigh their costs and benefits differently, thus producing motivations or demotivation for altering their behaviour, or rather to decide whether to integrate their attitude and behaviour consistently (Crespo et al., 2014).

Moreover, our findings verify that rules and institutions are contextual constraints that influence farmers' inconsistencies. Because institutions and rules-in-use could strengthen order-obeying and reduce free-riding, it is to some extent reduces the farmers' attitudebehaviour paradox. The devising and crafting of institutions to resolve conflicts and interests are foundations for collective action, just as Poteete and Ostrom (2004) asserted that the design of institutions and rules are very important for a group to be effective and fair in initiating and sustaining collective action. In this view, institutions play a prominent role in heterogeneity and the farmers' attitude-behaviour paradox. Finally, community environment matters not only for their biophysical attributes of stability but also their breeding of norms and cultural atmosphere. 
The identification of social network and relative income position contributes to our understanding of the attitude-behaviour gap in collective action for small-scale irrigation facilities. It provides the opportunity for policy interventions to promote different kinds of social groups, cooperatives and networks that would serve as a channel for information exchange and social learning. As for economic heterogeneity, interventions could be directed to enhance relative income differentials to promote elites' contribution to collective action. However, targeting to set optimal income differential still needs further research. It is also possible for us to check the other dimensions of social capital, such as social trust and social reciprocity, for their role in addressing the farmers' attitude-behaviour paradox in the future. 


\section{Appendix Tables}

Table 2A The first stage result of the IV Probit model

\begin{tabular}{|c|c|c|c|c|}
\hline & \multicolumn{4}{|c|}{ Dependent variables } \\
\hline & Social network1 & Social network2 & $\begin{array}{l}\text { Social } \\
\text { network1 } 1 \text { relative } \\
\text { income position }\end{array}$ & $\begin{array}{l}\text { Social } \\
\text { network } 2 * \text { relative } \\
\text { income position }\end{array}$ \\
\hline $\begin{array}{l}\text { Length to main } \\
\text { provincial or national } \\
\text { highway }\end{array}$ & $\begin{array}{l}0.056 \\
(0.043)\end{array}$ & $\begin{array}{l}0.482 * * * \\
(0.060)\end{array}$ & $\begin{array}{l}1.133 * * * \\
(0.023)\end{array}$ & $\begin{array}{l}0.934 * * * \\
(0.019)\end{array}$ \\
\hline $\begin{array}{l}\text { Whether the family } \\
\text { member go to } \\
\text { metropolitan city for } \\
\text { migrant working }\end{array}$ & $\begin{array}{l}0.204 * * \\
(0.082)\end{array}$ & $\begin{array}{l}-0.107 \\
(0.115)\end{array}$ & $\begin{array}{l}0.403 * * * \\
(0.147)\end{array}$ & $\begin{array}{l}0.089 \\
(0.123)\end{array}$ \\
\hline Education & $\begin{array}{l}0.085 * * * \\
(0.049)\end{array}$ & $\begin{array}{l}0.032 \\
(0.069)\end{array}$ & $\begin{array}{l}-0.008 \\
(0.016)\end{array}$ & $\begin{array}{l}-0.015 \\
(0.013)\end{array}$ \\
\hline Cultivated area & $\begin{array}{l}-0.005 \\
(0.019)\end{array}$ & $\begin{array}{l}0.046^{*} \\
(0.027)\end{array}$ & $\begin{array}{l}0.004 \\
(0.006)\end{array}$ & $\begin{array}{l}-0.004 \\
(0.005)\end{array}$ \\
\hline Agriculture year & $\begin{array}{l}0.009^{* *} \\
(0.004)\end{array}$ & $\begin{array}{l}-0.003 \\
(0.005)\end{array}$ & $\begin{array}{l}-0.001 \\
(0.001)\end{array}$ & $\begin{array}{l}0.0004 \\
(0.001)\end{array}$ \\
\hline Water stealing & $\begin{array}{l}0.035 \\
(0.033)\end{array}$ & $\begin{array}{l}0.264 * * * \\
(0.046)\end{array}$ & $\begin{array}{l}-0.0007 \\
(0.010)\end{array}$ & $\begin{array}{l}0.017 * \\
(0.009)\end{array}$ \\
\hline Water use conflicts & $\begin{array}{l}0.020 \\
(0.040)\end{array}$ & $\begin{array}{l}0.110^{* *} \\
(0.056)\end{array}$ & $\begin{array}{l}-0.013 \\
(0.013)\end{array}$ & $\begin{array}{l}-0.021 * * \\
(0.010)\end{array}$ \\
\hline $\begin{array}{l}\text { Relative income } \\
\text { position }\end{array}$ & $\begin{array}{l}-0.055 \\
(0.224)\end{array}$ & $\begin{array}{l}-0.102 \\
(0.314)\end{array}$ & & \\
\hline Community rules & $\begin{array}{l}0.602 * * * \\
(0.065)\end{array}$ & $\begin{array}{l}-0.047 * * \\
(0.092)\end{array}$ & $\begin{array}{l}-0.056^{* * * *} \\
(0.020)\end{array}$ & $\begin{array}{l}-0.004 \\
(0.017)\end{array}$ \\
\hline $\begin{array}{l}\text { Community } \\
\text { atmosphere }\end{array}$ & $\begin{array}{l}-0.058 \\
(0.066)\end{array}$ & $\begin{array}{l}-0.252 \\
(0.093)\end{array}$ & $\begin{array}{l}0.027 \\
(0.021)\end{array}$ & $\begin{array}{l}-0.050^{* * * *} \\
(0.018)\end{array}$ \\
\hline Cons & $\begin{array}{l}1.005 * * \\
(0.446)\end{array}$ & $\begin{array}{l}1.607 * * \\
(0.627)\end{array}$ & $\begin{array}{l}0.219 \\
(0.136)\end{array}$ & $\begin{array}{l}0.228 * * \\
(0.114)\end{array}$ \\
\hline R-squared & 0.281 & 0.307 & 0.934 & 0.929 \\
\hline F-statistics & 11.59 & 13.15 & 465.33 & 430.10 \\
\hline
\end{tabular}

Note: $* * *, * *, *$ denote $1 \%, 5 \%, 10 \%$ of significance level, respectively 


\section{References}

Ahn, T., Ostrom, E., Walker, J. 2003. Heterogeneous preference and collective action. Public Choice, 117(3-4): 295-314.

Ajzen, I. 1985. From Intentions to Actions: A Theory of Planned Behavior. In J. Kuhl \& J. Beckmann (Eds.), Action-control: From cognition to behavior (pp. 11-39). Heidelberg: Springer.

Ajzen, I. 2002. Consumer attitudes and behavior, in Handbook of Consumer Psychology, Curtis P. Haugtvedt, Paul M. Herr, and Frank R. Cardes, eds., New York: Lawrence Erlbaum Associates, 525-548.

Alesina, A, Baqir, R, Easterly, W. 1999. Public goods and ethnic divisions. Quarterly Journal of Economics, 114(4):1243-1284.

Alesina, A, La Ferrara, E. 2000. Participation in Heterogeneous Communities. Quarterly Journal of Economics, 115(3): 847-904.

Angrist, J. D., Lavy, V., Schlosser, A. 2010. Multiple experiments for the causal link between the quantity and quality of children. Journal of Labor Economics, 28(4): 773-824.

Baland, J.-M. and J.-P. Platteau. 1996. Halting Degradation of Natural Resources: Is There A Role for Rural Communities? Rome: Food and Agriculture Organization of the United Nations.

Baland, J-M, Platteau, J-P. 1999. The ambiguous impact of inequality on local resource management. World Development, 27(5):773-788.

Banwari, M. 1988. Achieving Higher Seat Belt Usage: The role of habit in bridging the attitudebehavior gap. Journal of Applied Social Psychology, 18(12): 993-1016.

Burt, R.S. 1992. Structural Holes: The Social Structure of Competition. Cambridge, US: Harvard University Press.

Caruana, R., Carrington, M., Chatzidakis, A. 2016. Beyond the attitude-behaviour gap: novel perspectives in consumer ethics: introduction to the thematic symposium. Journal Of Business Ethics, 136(2): 215-218.

Centola, D., Macy, M. 2007. Complex contagions and the weakness of long ties. American Journal of Sociology, 113(3): 702-734.

Claudy, M., Peterson, M., O'Driscoll, A. 2013. Understanding the attitude-behavior gap for renewable energy systems using behavioral reasoning theory. Journal of Macro-marketing, 33(4): 273287.

Coleman, J. 1990. Foundation of Social Theory. Harvard University Press, Cambridge, MA.

Crespo, J., Requier-Desjardins, D., Vicente, J. 2014. Why can collective action fail in local agri-food systems? A social network analysis of cheese producers in aculco Mexica. Food Policy, 46(6):165-177.

Das, U. 2015. Can the rural employment guarantee scheme reduce rural out-migration: Evidence from West Bengal, India. The Journal of Development Studies, 51(6): 621-641.

Dayton-Johnson, J., Bardhan, P. 2002. Inequality and conservation on the local commons: A theoretical exercise. The Economic Journal, 112(481): 577-602.

Douglas, M. 1986. How institutions think. London: Routledge \& kegan Paul. 
Downey, D. B., Ainsworth, J. W., Qian, Z. 2009. Rethinking the attitude-achievement paradox among blacks. Sociology of Education, 82(1): 1-19.

Durlauf, N., Fatchamps, M. 2004. Social Capital, working paper series No. 10485, National Bureau of Economic Research, Cambridge, Available at: www.nber.org/papers/w10485.

Futemma, C., Castro, F., Silva-Forsberg, M., Ostrom, E. 2002. The emergence and outcomes of collective action: An institutional and ecosystem approach. Society \& Natural Resources, 15(6): 503-522.

Gaspart, F., Platteau, J. 2007. Heterogeneity and Collective Action for Effort Regulation. Lessons from the Senegalese Small-scale Fisheries. In Inequality, cooperation and environmental sustainability, ed. J. M. Baland, P. Bardhan, and S. Bowles, 159-204 . New York: Russell Sage Foundation.

Gould, R. V. 1991. Multiple networks and mobilization in the Paris commune, 1871. American Sociological Review, 56(6):716-29.

Granovetter, M. S. 1977. The strength of Weak Ties. In Social networks (pp. 347-367). Academic Press.

Granovetter, M., Soong, R. 1983. Threshold models of diffusion and collective behavior. Journal of Mathematical Sociology, 9(3): 165-179.

Granovetter, M. 1985. Economic action and social structure: the problem of embeddedness. American Journal of Sociology, 91(3):481-510.

Hassan, R., Birungi, P. 2011. Social capital and poverty in Uganda. Development Southern Africa, 28(1): 19-37.

Heckathron, D. 1993. Collective action and group heterogeneity: voluntary provision versus selective incentives. American Sociological Review, 58(3):329-350.

Jackson, T. 2005. Motivating Sustainable Consumption: A Review of Evidence on Consumer Behavior and Behavioral Change, Report, London.

Juvan, E., Dolnicar, S. 2014. The attitude-behavior gap in sustainable tourism. Annals of Tourism Research, 48(9): 76-95.

Kant, S. 2000. A dynamic approach to forest regimes in developing economies. Ecological Economics, 32(2): 287-300.

Kim H. J., Bearman, P. S. 1997. The structure and dynamics of movement participation. American Sociological Review, 62(1):70-93.

Klofstad, C. 2007. Talk leads to recruitment: How discussions about politics and current events increase civic participation. Political Research Quarterly, 60(2):180-191.

Marwell, G., Oliver, E., Prahl, R. 1988. Social networks and collective action: A theory of the critical mass. American Journal of Sociology, 94(3): 502-534.

Maweijie, J., Holden, S. 2014. Does social network capital buy higher agriculture prices? A case of coffee in Masaka district, Uganda. International Journal of Social Economics, 41(7):573-585.

McAdam, D., Paulsen, R. 1993. Specifying the relationship between social ties and activism.” American Journal of Sociology, 99(3): 640-67.

McAdam, D.1986. Recruitment to high-risk activism-----the case of freedom summer. American 
Journal of Sociology, 92(1):64-90.

Mcdonal, R., Fielding, K., Louis, W. 2014. Conflicting norm highlight the need for Action. Environmental Behavior, 46(2):139-162.

Mcevily, B., Zaheer, A. 1999. Bridging ties: A source of firm heterogeneity in competitive capabilities. Strategic Management Journal, 20(12): 1133-1156.

Miller, G. 2003. Consumerism in sustainable tourism: A survey of UK consumers. Journal of Sustainable Tourism, 11(1): 17-39.

Molina-Morales, F., Martinez-Fernadez, M. 2009. Does homogeneity exist within industrial districts? A social capital-based approach. Regional Science, 88(1):210-229.

Mont, D., Nguyen, C. 2013. Does parental disability matter to child education? Evidence from Vietnam. World Development, 48(8): 88-107.

Muñoz, I., Paredes, M., Thorp, R. 2007. Group Inequalities and the Nature and Power of Collective Action: Case Studies from Peru. World Development, 35(11):1929-1946.

Naidu, S. 2009. Heterogeneity and collective management: Evidence from common forests in Himachal Pradesh, India. World Development, 37(3): 676-686.

Nolan, J. M., Schultz, P. W., Cialdini, R. B., Goldstein, N. J., Griskevicius, V. 2008. Normative social influence is underdetected. Personality and Social Psychology Bulletin, 34(7): 913-923.

Oliver, P. E., Myers, D. J. 2003. Social Movements and Networks: Relational Approaches to Collective Action. In Networks, Diffusion, and Cycles of Collective Action, ed. Mario Diani and Doug McAdam. New York: Oxford University Press, 173-203.

Olson, M. 1965. The Logic of Collective Action: Public Goods and the Theory of Groups. Cambridge, MA: Harvard University Press.

Opp, K., Gern, C. 1993. Dissident groups, personal networks, and spontaneous cooperation---The EastGerman revolution of 1989. American Sociological Review, 58(5): 659-80.

Ostrom, E. 2014. Do institutions for collective action evolve? Journal of Bioeconomics, 16(1): 3-30.

Peter, H. 1994. Contagious Collectivities---On the spatial diffusion of Swedish Trade---Unions, 18901940. American Journal of Sociology, 99(5):1157-79.

Poteete, A., Ostrom, E. 2004. Heterogeneity, group size and collective action: the role of institutions in forest management. Development and Change, 35(3): 435-461.

Redondo, I., Puelles, M. 2017. The connection between environmental attitude-behavior gap and other individual inconsistencies: a call for strengthening self-control. International Research in Geographical and Environmental Education, 26(2): 107-120.

Richerson, P. J., Boyd, R. 2005. Not by Genes Alone: How Culture Transformed Human Evolution. Chicago: University of Chicago Press.

Ruttan, M. 2006. Sociocultural heterogeneity and the commons. Current Anthropology, 47(5): 843-853.

Ruttan, M. 2008. Economic heterogeneity and the commons: effects on collective action and collective goods provisioning. World Development, 36(5): 969-985.

Santos, F., Pacheco, J., Lenaerts, T. 2006. Evolutionary dynamics of social dilemmas in structured heterogeneous populations. PNAS, 103(9):3490-3494. 
Schultz, P. W., Nolan, J. M., Cialdini, R. B., Goldstein, N. J., Griskevicius, V. 2007. The constructive, destructive, and reconstructive power of social norms. Psychological Science, 18(5): 429-434.

Siegel, D.A. 2009. Social Networks and Collective Action. American Journal of Political Science, 53(1): 122-138.

Somanathan, E., Prabhakar, R., Mehta, B. S. 2002. Collective Action for Forest Conservation: Does Heterogeneity Matter? New Delhi, India: Indian Statistical Institute.

Staiger, D., Stock, J. H. 1997. Instrumental variables regression with weak instruments. Econometrica, 65(3): 557-586.

Stern, P. C. 2000. Toward a coherent theory of environmentally significant behavior. Journal of Social Issues, 56(3): 407-424.

Tang, S.Y. 1994. Institutions and Performance in Irrigation Systems, in: E. Ostrom, R. Gardner \& J. Walker (Eds) Rules, Games, and Common-pool Resources (Ann Arbor, MI, University of Michigan Press).

Varughese, G., Ostrom, E. 2001. The contested role of heterogeneity in collective action: Some evidence from community forestry in Nepal. World Development, 29(5):747-65.

Verba, S., Schlozman, K. L., Brady H. E. 1995. Voice and Equality: Civic Voluntarism in American Politics. Cambridge, MA: Harvard University Press.

Zhao, K. 2012. Theory of farmers' professional cooperative heterogeneity and its quantitative determination method. Journal of South China Agricultural University (social science edition), 4: 57-66.

Zhou, G., Fan, G., Shen, G. 2014. Income disparity, social capital and health---A case study based on China family panel studies. Management World, 7:12-21. 


\title{
CHAPTER 3
}

\section{Social Capital Influences Farmer Participation in Collective Irrigation Management in Shaanxi Province, China $^{4}$}

\begin{abstract}
The purpose of this paper is to investigate the influence of social capital components on farmers' participative behaviour in collective actions for constructing and operating small-scale groundwater irrigation systems on the Guanzhong Plain, Shaanxi Province, China. The four components (social networks, social trust, social reciprocity and social participation) were derived by employing exploratory factor analysis. A Logistic model was used to examine the influence of these components on farmers' participative behaviour. We find that higher levels of social trust and social participation lead to a higher propensity for collective action, while social reciprocity reduces the probability of participation. A consideration of the different components of social capital allows for a more precise understanding of farmers' participative behaviour. Other socio-economic factors and farming characteristics such as education levels, cultivated area, cropping patterns and grain subsidies also have a significant positive impact. The findings suggest creating favourable conditions for communication and information exchanges between farmers, which enhance their trust in each other, encourage farmers to participate in collective action. Moreover, supportive rules are necessary for the future development of collective action. The results of this study also have implications for national irrigation plans for small-scale irrigation systems in other developing countries.
\end{abstract}

Key words: common pool resources; groundwater; rural household behaviour; participatory irrigation management; exploratory factor analysis

${ }^{4}$ This chapter is based on:

Miao, S., Heijman, W., Zhu, X.Q., Lu, Q., 2015. Social capital influences farmer participation in collective irrigation management in Shaanxi Province, China. China Agricultural Economic Review 7 (3): 448-466. 


\subsection{Introduction}

Due to the increasing demand for water resources in recent years, China's water shortage is becoming more serious (Liu et al., 2009). The Chinese government has promoted the reform of the property rights of small-scale irrigation facilities. A collective small-scale irrigation system in rural areas is being advocated to solve the water shortage problems of rural communities in arid and semi-arid areas (Zhang et al., 2014). However, some field surveys and research indicate that it is difficult to rely on collective action to resolve the problems of irrigation water supply, mainly because social capital strongly influences the behaviour of participants in the collective action, and therefore the social outcomes (Ostrom, 2007). It is important to understand the role of social capital in explaining participative behaviour, as social capital affects the path, scale and nature of collective action (Baker, 1998; Lam, 1998; Ostrom, 2000). Several researchers have argued that a combination of different components of social capital might be more effective in addressing common dilemmas and enhancing general wellbeing (Woolcock and Sweetser, 2002; Pretty, 2003). To design effective agricultural policies, policymakers need insights into how social capital and its components influence farmers' participative behaviour in collective action, particularly for irrigation water systems in arid and semi-arid areas. Empirical results which reveal the impact of social capital components on participative behaviours in collective action for irrigation systems are therefore of current interest.

Several researchers have identified social capital as a key factor in collective action (Gutierrez et al., 2011; Gorton et al., 2010). However, social capital remains a "vague idea" and "casual empiricism" (Solow, 1999), although the role of social capital is emphasised in terms of its cognitive and structural elements (Jones et al., 2010; Polyzou et al., 2011). Previous studies have focused primarily on one or several indicators and have led to various measurement approaches. Some authors equate social capital with trust and trustworthiness, while others appear to regard social capital as a form of social network (Steven, 2002). The incorporation of individual elements or components of social capital (such as trustworthiness, networks, or institutional affiliation) into a collective action framework is a frequent approach in these narratives, but is less frequent in analytically-rigorous formal models. The failure to conceptualise the components of social capital as separate terms is ultimately likely to compromise the clarity of outcome when answering empirical questions. Unless the separate components of social capital are identified, neither the interactions between different components of social capital nor the aggregate social capital can be systematically explored (Newton, 1997). 
Collective actions may result in success or failure, which is consistent with conditional cooperation, because these actions occur within local networks, organisations, or other relationships among individuals. Therefore, since both positive and negative impacts can be expected a priori, the actual impact of social capital components, as well as their aggregate value on collective actions for establishing small-scale irrigation facilities, is a topic for empirical investigation.

This paper aims to identify the important components of social capital and to understand the effects of these components on collective action for irrigation systems. For this purpose, we conduct an empirical study on the Guanzhong Plain, Shaanxi Province of China, where collective small-scale groundwater irrigation facilities have been promoted by the government. First, we elaborate on a conceptual framework which addresses potential factors for collective action, in order to analyse the elements of social capital. Second, we use a factor analysis approach, which resolves the problem of close relationships between different elements (Stone, 2001). Our goal is to categorise these potential elements into four principal components of social capital. Third, we use a Logistic model to investigate the influence of social capital as a whole and its four principal components on farmers' participative behaviour in collective action for the groundwater irrigation system in the study area, combined with other socioeconomic factors.

\subsection{Theoretical background on the relationship between social capital and collective action}

Social capital was first systematically conceptualised by Coleman (1988). Following this, Putnam (1993) found a strong correlation between measures of civic engagement and government quality, which promoted social capital research into its current widespread and lively phase of development. Since then, many scholars have made significant contributions to this literature. Commonly, social capital is viewed as a person's social characteristics (Glaeser et al., 2002; Carpenter et al., 2004; Karlan, 2005), but some other scholars define social capital as the common property of a group that facilitates collective action for the mutual benefits of its group members (Putnam, 2000; Krishna, 2002).

As Ostrom (1990) remarks, "Cooperation is fundamental when humans develop successful management institutions for public goods including natural resources". Seen as the third capital, in addition to physical and human capital (Putnam, 2000; Krishna, 2002), social capital plays an important role in the cooperative management of irrigation systems (Pretty, 2003; Ostrom and Ahn, 2009; Gorton et al., 2010; Jones et al., 2010; Gutiérrez et al., 2011). 
Social capital is, to some extent, understood as a resource or attribute of individuals that enables them to enhance their collective action by lowering transaction costs and accumulating social learning (Ostrom and Ahn, 2009). The empirical relationship between social capital and collective action has been discussed intensively (Gorton et al., 2010; Gutiérrez et al., 2011).

However, there is a gulf between our understanding of social capital and how social capital has been measured in most of the empirical work to date. Part of the problem lies in the conflation of institutions with different forms of social capital (Dasgupta and Serageldin, 2000). The complex relationships across hierarchical levels of institutional change, between institutional arrangements within a single setting and newly created incentives, impact on human decisions and resource-related outcomes. This lack of consensus leads to different ways of constructing a set of social capital indices. For example, Putnam (1995) defines social capital in terms of networks. Bowles and Gintis (2002) argue that the expression "social capital" should be replaced by the concept of community, which 'focuses on what groups do rather than what people own'. Moreover, Coleman (1990) viewed social capital as a community-level attribute. DiPasquale and Glaeser (1999) and Alesina and La Ferrara (2000) remark that social capital tends to focus on highly specific aspects, such as home ownership or ethnic heterogeneity. A number of qualitative studies have suggested that social capital is crucial to participative behaviour in collective actions for common pool resource management (Ostrom and Ahn, 2009). Most previous quantitative studies on the relationship between social capital and collective action have used networks, norms of trust or reciprocity as indicators of social capital. Although practical in some ways, this variety of indicators of social capital in research has led to considerable confusion about what exactly social capital is. In addition, some studies (e.g. Coffé and Geys, 2005) have used social capital as a comprehensive index and are therefore unable to show how the different components of social capital can explain farmers' participative behaviour.

Based on Stone's classification of social capital (Stone, 2001), we use indicators which relate to its principal or core components-social networks, trust, participation and reciprocity—in order to avoid tautology (Portes, 1998; Durlauf, 1999; Ostrom and Ahn, 2009). Motivated by the contributions of Ostrom (1998), Stolle (1998), Putnam (2000), Uslaner et al. (2003), Szreter and Woolcock (2004), we include all possible elements, which are closely related to social capital, and then apply exploratory factor analysis to decide which elements could represent these four attributes.

A social network consists of the formal and informal connections developed within a community (Putnam, 2000). It may be divided into informal and formal networks (Putnam, 1998). Being part of more social networks is usually accompanied by a higher level of 
collective action, because those people who participate more actively in social networks are expected to be more involved in collective actions.

The related concept of social trust refers to trust in other people, either in general or in specific groups (Stolle, 1998; Uslaner et al., 2003). It is anticipated that where a higher level of social trust exists, communities will also be more willing to act collectively for public goods.

Social reciprocity constitutes an internalised, personal, moral norm as well as a pattern of social exchange (Putman, 1984). It includes the 'effort to identify who else is involved and an assessment of the likelihood that others are conditional co-operators', indicating that a collective action is likely to occur, or at least be maintained, if group members are reciprocated or abide by the norms of reciprocity as they participate in cooperative activities (Ostrom, 1998).

Social participation is an important component of social capital, especially participation through voting in elections and attendance at public affairs (Putnam, 2000). It provides opportunities for individuals to gain access to resources to which they might not otherwise have had access (Szreter and Woolcock, 2004). As more people participate in these activities, more information is expected to be acquired about joint objectives, the processes to be followed in achieving these objectives, and how one process feeds into another, thus improving the probability of successful collective actions.

The relationship between the different components of social capital and collective action can be summarised as follows. Here, social network, participation, trust, and reciprocity form a self-reinforcing quartet, and each component can be explicitly measured. The measurement system is divided into four levels: the overall target level, the sub-target level, the sub-goal level and the operational level (Liebowitz, 2005). The overall target level is expressed by the aggregate social capital. The sub-target and sub-goal levels rely on specific elements of social capital. For example, social network depends on social scale, network density and network difference (Bourdieu, 1993), while social trust reflects the degree of trust. Likewise, social reciprocity invokes interactions and prestige, and social participation includes election participation and public participation (Putnam, 2000). At the operational level, a series of specific interview questions attempted to assess every element of social capital are used (see Table 3.1).

\subsection{The model specification}

\subsubsection{Factor analysis for measuring social capital}

Social capital is multidimensional in nature. In order to operationalise the number of independent variables in the Logistic model, we categorised the indicators of social capital into 
four principal components using factor analysis.

Factor analysis is a mathematical modelling technique used to examine a wide range of data sets. It proposes an explicit underlying model that attempts to interpret correlations among a set of $n$ observed elements or variables $\left(X_{1}, X_{2}, X_{3} \ldots, X_{n}\right)$ through a linear combination of a few latent (unobserved) random factors $(F)$. In the case of a single factor $F$, the underlying model for any variable $X_{i}$ is defined as:

$$
X_{i}=\lambda_{i} F+e_{i}
$$

Where $\lambda_{i}$ is the loading factor associated with the observed variable $X_{i}$ and $e_{i}$ is the error term. This procedure allows the estimation of factor loadings, as well as the approximation of the unobserved factor $F$ for each sub-group, $F$ being retained as the synthetic indicator. Loading factors, on the other hand, provide information about the weights and correlation between each variable and a common factor: the higher the load, the more relevant the primary variable is in defining the dimensionality of a factor (Clark et al., 2004).

In the process of factor extraction, a Principal Component Analysis (PCA) is used to construct new variables (called Principal Components, PCs), from a set of initial variables. PCs are linear combinations of the initial variables and can be calculated as:

$$
P C=C_{1} X_{1}+C_{2} X_{2}+\ldots+C_{i} X_{i}
$$

Where $P C$ denotes 'score for a principal component', $C_{i}$ is the weight of element $i$ which is the share of its variance in the sum of variances of relevant variables and $X_{i}$ is the value of element $i$.

\subsubsection{Logistic analysis for measuring participative behaviour}

A critical facet of farmers' propensity to participate in collective action is the nature and degree of social capital. Through factor analysis, social capital components and an aggregate value may be obtained. Four PCs were created to represent social network, social trust, social reciprocity and social participation. Aggregate social capital is a linear combination of the four principal components, for which equation (2) was used (these four components were interpreted as composite measures of aggregate social capital).

In order to apply the continuously-valued independent variables to a discrete-valued dependent variable, we use a Logistic model that classifies farmers into two groups, one with participative behaviour (e.g., they pay for the irrigation fee or contribute to the labour force) and the other without participative behaviour. The Logistic model for addressing a dichotomous choice variable reads: 


$$
P(Y=1 \mid X=x)=\Phi\left(x^{\prime} \beta\right)
$$

Where $P$ denotes the probability of farmers' participative behaviour to construct and run small-scale irrigation facilities, $Y$ is a binary outcome variable defined as 1 if a farmer exhibits participative behaviour (e.g., they pay for the irrigation fee or contribute to labour force) and 0 if otherwise, $X$ is a vector of the explanatory variables including social capital components and other socio-economic variables which will be detailed in section $4, \Phi$ is the cumulative distribution function, and $\beta$ is a vector of parameters. The parameters $\beta$ are estimated by the maximum likelihood method.

\subsection{Study area and data}

\subsubsection{Study Area}

We selected the Guanzhong Plain of Shaanxi Province, China for our study. This area has 697,550 hectares and a population density of 409 per $\mathrm{km}^{2}$. The plateau is composed mainly of small and fragmented farming fields. The annual average precipitation on the Guanzhong Plain is $603.5 \mathrm{~mm}$. The rainfall occurs mainly during summer and autumn in short storms, accounting for $60 \%$ of the total precipitation. The study area is situated in arid and semi-arid regions in north-west China, where surface water is insufficient to support agriculture. Most farmers use groundwater for irrigation, and about $75 \%$ of the arable land is irrigated. The primary cropping pattern includes winter wheat and summer corn, while some of the farmers intercrop kiwis, tomatoes, apples, and other fruits and vegetables. Corn is grown during the rainy season, while wheat is grown in the dry season, thus requiring more irrigation water than corn.

Currently, there are three ways to collectively manage irrigation in the study area: village council management, contracts, and water user associations. Most of the investment and maintenance is organised by collectively managed irrigation systems or contracts. In the case of village council management, village leaders are responsible for almost all management activities, including tube well drilling, facility maintenance, and water fee collection. Contracting is a system by which village leaders hire a manager to oversee canals and pumps, in return for payment. Water user associations are organized by local farmers, and property rights are owned by water user associations after construction completed. Specialized water managers are appointed by the water user associations.

Collective action for irrigation facilities prevails in the study area primarily because it is not possible for individual farmers to invest 104,000 to 170,000 RMB (USD 17,333 to 28,333) required for the pump and tube well installation. Additionally, the average cost of drilling a 
deep tube well $(90 \mathrm{~m})$ is five times greater than the cost of a shallow well $(37 \mathrm{~m})$, due to overdrilling and the unavailability of shallow aquifers (for example, due to saltwater intrusion). As a result, the central government advocates local control over small-scale irrigation systems, in the form of collectively owned irrigation systems.

In the study area, there are three rounds of irrigation per year. The tariff rates are about 40 to 65 yuan RMB per hour and normally include a management fee and an electricity fee. Pumping and drilling equipment are loaned at a discounted rate. Water is transported utilizing plastic pipelines from the pump house to farmers' fields. The pipelines are monitored by managers and neighbours, and are usually checked every day for leaks and theft. The prospect of free-riding is not relevant in such a system. However, there exists a strong externality in using the irrigation system. If one farmer turns on the pump, it will affect the other farmers whose cultivated area is under irrigation, due to the low water table of groundwater. This may result in disputes between farmers. As a result, in rural areas with intensive social interactions, most farmers comply with the basic rules for irrigation. Therefore, collective action in the study area seems a way to promote the efficient use of water resources.

Notably, with the reform of irrigation systems, there has been a trend in which management changes from village council to contracting, and finally to a water user association. In the survey villages, $32 \%$ are under contracting management, and $46 \%$ have water user associations. Since the cancellation of the agricultural tax and the ensuing insufficiency of maintenance funds, the government has not maintained facilities in a timely way, and village management does not bring a high level of satisfaction to farmers. Under the contracted management operation, efficiency is higher than under the village council management, but it is more expensive because the contractors allocate the higher management cost to farmers. Under water user associations, farmers can easily coordinate their interests to achieve the common goal of ensuring the efficient operation of small-scale irrigation facilities. In the study area, the formation of water user associations relies on rural elites (rich people, village leaders or patriarchs), with the support of the local governments, and also on the World Bank projects.

\subsubsection{Data}

We conducted a household survey between April and June of 2011, using a multi-strata sampling procedure to ensure that all townships and zones were properly represented. We first identified six agricultural zones by considering two important parameters: villages with ownership and construction of small-scale irrigation facilities, and social capital. The six zones are: Fengxiang, Qishan, Meixian, Fufeng, Wugong and Zhouzhi. The level of organisation and their collective action initiatives were also considered. We then selected random samples of 20 
to 25 farmers in each village. All of the farmers are water users, although some of them do not participate in these collective actions. Thus, our initial sample included 20 villages with 422 farmers. After discarding 29 incomplete response profiles, we obtained a sample of 393 farmers. Two-thirds of these farmers participated in collective action for irrigation facilities by paying fees or providing labour for the irrigation system, while the other farmers irrigated their cultivated areas by their facilities or lent from the others. Participation in these three collectively managed irrigation systems is voluntary.

We used two semi-structured questionnaires. The first pertains to factors that might influence collective action for small-scale irrigation facilities, including: (i) socio-demographic characteristics of farmers such as gender, age, and education. (ii) agricultural production history and cropping pattern. (iii) policy issues, such as government subsidies and (iv) service and maintenance of irrigation infrastructure. 
Table 3.1 Descriptive statistics regarding elements of social capital

\begin{tabular}{|c|c|c|}
\hline & Mean & Std dev. \\
\hline \multicolumn{3}{|l|}{ Social network } \\
\hline 1.1 People whom you normally contact (number of people) & 7.42 & 0.65 \\
\hline 1.2 People from whom you could get help in difficulties (number of people) & 4.67 & 0.63 \\
\hline 1.3 Frequency of contact with friends & 4.53 & 0.69 \\
\hline 1.4 Frequency of contact with relatives & 3.48 & 0.84 \\
\hline 1.5 Frequency of contact with village leaders & 4.40 & 0.65 \\
\hline 1.6 Frequency of contact with neighbours & 3.58 & 0.83 \\
\hline 1.7 Frequency of contact with agricultural organizations & 2.90 & 0.89 \\
\hline 1.8 Frequency of contact with family members & 4.84 & 0.75 \\
\hline 1.9 Occupation of best friends ( $\%$ in farming) & 63.1 & 0.34 \\
\hline 1.10 Income status of best friends & 3.25 & 0.64 \\
\hline 1.11 Family members' occupation ( $\%$ in farming) & 51.2 & 2.21 \\
\hline 1.12 Income status of your family members & 3.21 & 0.62 \\
\hline 1.13 Primary relatives' occupation (\% in farming) & 48.9 & 0.62 \\
\hline 1.14 Income status of primary relatives & 2.98 & 0.75 \\
\hline \multicolumn{3}{|l|}{ Social trust } \\
\hline 2.1 Trust level to close friends & 4.32 & 0.76 \\
\hline 2.2 Trust level to close relatives & 4.32 & 0.70 \\
\hline 2.3 Trust level to village leaders & 3.20 & 0.95 \\
\hline 2.4 Trust level to respectful farmer & 3.64 & 0.66 \\
\hline 2.5 Trust level to agricultural organization & 3.39 & 1.27 \\
\hline 2.6 Trust level to family member & 2.94 & 0.78 \\
\hline 2.7 Trust level to acquaintances & 4.68 & 0.62 \\
\hline 2.8 Trust level to strangers & 2.75 & 0.77 \\
\hline 2.9 Trust level to neighbours & 1.83 & 0.88 \\
\hline \multicolumn{3}{|l|}{ Social reciprocity } \\
\hline 3.1 Your friends come to help in case of wedding ceremony & 1.84 & 0.88 \\
\hline 3.2 When others have important affairs to decide, they turn to you for discussion & 3.61 & 0.82 \\
\hline 3.3 In harvesting season, others come to help & 2.96 & 0.86 \\
\hline 3.4 The villagers respect you & 3.17 & 0.84 \\
\hline 3.5 When you build a house, your friends come over and help & 2.73 & 0.39 \\
\hline 3.6 When others have domestic conflicts, they turn to you for help & 2.88 & 0.10 \\
\hline \multicolumn{3}{|l|}{ Social participation } \\
\hline 4.1You ask other farmers to solve the issues together when the village has them & 2.44 & 0.91 \\
\hline 4.2 You participate in group activities in the village & 4.60 & 0.51 \\
\hline 4.3 You participate in the village cadre's election & 2.39 & 1.02 \\
\hline 4.4 You propose suggestions or opinions when deciding public affairs in the village & 4.19 & 0.39 \\
\hline 4.5 You participate in "one project, one discussion" & 2.07 & 1.07 \\
\hline
\end{tabular}

Note: Measurements for variables except for 1.1 and 1.2 are in the scale of 1 to 5 (1-very low, 2-low, 3-neither low nor high, 4-high, 5-very high) except for those explicitly given. 
The second questionnaire addresses the individual's social capital elements. According to the theoretical framework, we designed a survey with 34 questions for the elements of social network, social trust, social reciprocity and social participation. All social capital elements are multivariate variables based on social capital measurement studies and field observations (e.g. Scott, 1991; Putnam, 1995; Glaeser et al., 2000; Krishna and Uphoff, 2003). These variables were mostly measured using a Likert-type scale. Table 3.1 gives detailed information on these elements.

The characteristics of farmers are shown in Table 3.2. Among the respondents, $49.2 \%$ were male and $50.8 \%$ were female, $42.5 \%$ had at least a junior high school education level, and $89.2 \%$ were mainly engaged in agricultural production. Only $10.8 \%$ of respondents were purely non-agricultural producers.

Table 3.2 Households' characteristics in proportions, by item

\begin{tabular}{cccccccc}
\hline \multicolumn{2}{c}{ Gender (\%) } & \multicolumn{2}{c}{ Age (years) } & \multicolumn{2}{c}{ Education (years) } & \multicolumn{2}{c}{ Occupation (\%) } \\
\hline \multirow{2}{*}{ Male } & 49.2 & $\leq 16$ & 0.3 & 0 & 7.6 & Farming & 89.2 \\
Female & 50.8 & $17-30$ & 10.2 & $1-6$ & 38.4 & No farming & 10.8 \\
& & $31-45$ & 39.0 & $6-9$ & 42.5 & & \\
& $46-60$ & 41.3 & $9-12$ & 10.5 & \\
& $61-75$ & 9.2 & $12-15$ & 0.6 & \\
\hline
\end{tabular}

Many factors, such as rules and regulations, can affect the collective actions. Groundwater irrigation is largely available on the Guanzhong Plain. Thus, there is little need for complex rules and regulations regarding this irrigation, because groundwater irrigation greatly increases the excludability and reduce the possibility of free riding. Therefore, we focus our analysis on some important factors that influence participative behaviour in collective action for smallscale irrigation facilities, including farmers' socioeconomic characteristics (Gorton et al., 2010). Ostrom (2011) suggests that "knowledge is essential for collective action problems solving." Thus, we include education as an explanatory variable in our analysis. Institutional factors such as governance systems and rules also can influence collective actions (e.g. Mildred, 2001). Thus, we include grain subsidy as an explanatory variable. Servicing and maintenance of infrastructure affect the reliability and timeliness of irrigation service and, consequently, water use efficiency (ADB, 2001). 
Furthermore, water use disputes are the main concern of local farmers in our survey. Proper planning and management of irrigation are vital in achieving high profitability and sustaining livelihoods for groundwater irrigation. Maintaining an irrigation volume suitable for cropping patterns is an important factor for the maximisation of net return. Besides, different plants have different water requirement. The cropping pattern is therefore another variable in our model. In sum, we define five major categories ( social-economic characteristics, institutional factors, servicing and maintenance, social capital, farming) of 12 independent variables, with the participative behaviour in collective action for small-scale irrigation facilities as the dependent variable. Table 3.3 gives detailed information on these variables, including their statistical description and expected effects.

Table 3.3 Descriptive statistics of model variables and the expected signs of their impacts on participation in collective action

\begin{tabular}{|c|c|c|c|}
\hline & Mean & Std. dev. & $\begin{array}{c}\text { Expected } \\
\text { effect }\end{array}$ \\
\hline \multicolumn{4}{|l|}{ Dependent variable } \\
\hline Participative behaviour $($ yes $=1$, no $=0$ ) & 0.66 & 0.473 & \\
\hline \multicolumn{4}{|l|}{ Independent variables } \\
\hline $\begin{array}{l}\text { Education }(1-6: 0 \text { year }=1,1-6 \text { years }=2,7-9 \text { years }=3,10-12 \text { years }=4 \text {, } \\
13-15 \text { years }=5, \geq 16 \text { years }=6)\end{array}$ & 2.59 & 0.826 & $+/-$ \\
\hline Cultivated area (acre) & 3.55 & 2.069 & $+/-$ \\
\hline Production history (years) & 24.29 & 11.273 & + \\
\hline Cropping pattern (cash crop $=1$, others crop $=0$ ) & 2.09 & 0.60 & + \\
\hline Grain subsidies (yuan) & 284.01 & 591.97 & + \\
\hline $\begin{array}{l}\text { Timing of maintenances }(1-5 \text { : very untimely }=1 \text {, untimely }=2 \text {, neither } \\
\text { untimely nor timely }=3 \text {, timely }=4 \text {, very timely }=5 \text { ) }\end{array}$ & 3.59 & 1.206 & + \\
\hline $\begin{array}{l}\text { Water use disputes }(1-4 \text { : never }=1 \text {, occasionally }=2 \text {, sometimes }=3 \text {, } \\
\text { frequently }=4)\end{array}$ & 2.33 & 0.99 & + \\
\hline Aggregated social capital & 0.37 & 0.30 & + \\
\hline Social network & 0.20 & 0.17 & + \\
\hline Social trust & 0.39 & 0.29 & + \\
\hline Social reciprocity & 0.42 & 0.34 & - \\
\hline Social participation & 0.53 & 0.36 & + \\
\hline
\end{tabular}




\subsection{Results}

We first apply factor analysis to our survey data, to identify elements of social capital for inclusion in our econometric analysis. We then use the selected elements in our Logistic model to determine which components are better predictors for farmers' participative behaviour.

\subsubsection{Factor analysis of social capital}

We used all 34 initial variables of social capital to create the draft scale for assessing the factorability of the correlation matrices. We then conducted a diagnostic factor analysis to define the sub-group of variables to be considered for each aggregate indicator. We repeated this procedure on the sub-groups to estimate the common factor. We evaluated the correlation matrix to determine whether it was factorable through both visual inspection and statistical procedures for all 34 variables. The Kaiser-Meyer-Olkin measure of sampling adequacy was 0.789, while Bartlett's test of Sphericity (approximated Chi-Square equal to 4128.148) had a P-value less than 0.01 . Hence, we concluded that the correlation matrix was a reliable identity matrix. We then performed a diagnostic factor analysis on four groups of primary variables: social network, social trust, social reciprocity, and social participation. Our goal was to identify the sub-groups or primary elements within these four groups that are highly correlated, so that each primary element could be exclusively mapped to an aggregate indicator (Table 3.4).

In the second step, we ran four separate factor analysis procedures on each of the four subgroups identified in the first step, with a single estimated factor retained by the data. In this process, Principal Component Analysis was selected to reduce every subgroup's dimensionality in order to construct principal components. Out of a set of initial variables/elements, if the cumulative variance was more than $80 \%$ or had an eigenvalue above 1 , the set of elements was selected as principal components. The initial elements scoring above 0.3 capture the main information of each factor. Then, we applied varimax rotation to the factor loading matrix to obtain a simple loading structure and improve the interpretation. The coefficients for the four new components of social capital are computed such that the first principal component (PC1) accounts for the largest share of its variance in the sum of the variances of all the original variables, and the second principal component (PC2) is chosen to account for the largest share of the remaining variables, and so on. 
Table 3.4 Factor loadings in the elements of four components of social capital

\begin{tabular}{|c|c|c|c|}
\hline Elements & Factor loadings & Mean & Std. dev. \\
\hline \multicolumn{4}{|l|}{ Social network } \\
\hline \multicolumn{4}{|c|}{$\mathrm{KMO}=0.658$ Cronbach's alpha $=0.603$ Explained variance $=60.61 \%$} \\
\hline 1.1 & 0.677 & 3.876 & 0.314 \\
\hline 1.2 & 0.606 & 4.667 & 0.634 \\
\hline 1.3 & 0.601 & 4.529 & 0.689 \\
\hline 1.4 & 0.708 & 3.484 & 0.836 \\
\hline 1.5 & 0.567 & 4.400 & 0.651 \\
\hline 1.6 & 0.656 & 3.578 & 0.830 \\
\hline 1.7 & 0.420 & 2.898 & 0.892 \\
\hline 1.8 & 0.518 & 4.840 & 0.747 \\
\hline 1.9 & 0.679 & 2.473 & 1.961 \\
\hline 1.10 & 0.523 & 3.255 & 0.636 \\
\hline 1.11 & 0.697 & 2.964 & 2.215 \\
\hline 1.12 & 0.538 & 3.211 & 0.626 \\
\hline 1.13 & 0.622 & 2.221 & 1.007 \\
\hline 1.14 & 0.502 & 2.977 & 0.747 \\
\hline \multicolumn{4}{|l|}{ Social trust } \\
\hline \multicolumn{4}{|c|}{$\mathrm{KMO}=0.761 \quad$ Cronbach's alpha $=0.746$ Explained variance $=60.32 \%$} \\
\hline 2.1 & 0.698 & 4.316 & 0.761 \\
\hline 2.2 & 0.706 & 4.316 & 0.701 \\
\hline 2.3 & 0.682 & 3.204 & 0.953 \\
\hline 2.4 & 0.575 & 3.641 & 0.663 \\
\hline 2.5 & 0.477 & 3.392 & 1.273 \\
\hline 2.6 & 0.586 & 2.944 & 0.784 \\
\hline 2.7 & 0.493 & 4.679 & 0.618 \\
\hline 2.8 & 0.544 & 2.753 & 0.771 \\
\hline 2.9 & 0.606 & 1.835 & 0.881 \\
\hline \multicolumn{4}{|c|}{ Social reciprocity } \\
\hline \multicolumn{4}{|c|}{$\mathrm{KMO}=0.738$ Cronbach's alpha $=0.745$ Explained variance $=61.65 \%$} \\
\hline 3.1 & 0.614 & 3.611 & 0.823 \\
\hline 3.2 & 0.733 & 2.964 & 0.862 \\
\hline 3.3 & 0.712 & 3.165 & 0.843 \\
\hline 3.4 & 0.600 & 2.733 & 0.687 \\
\hline 3.5 & 0.761 & 2.878 & 1.000 \\
\hline 3.6 & 0.682 & 2.443 & 0.910 \\
\hline \multicolumn{4}{|c|}{ Social participation } \\
\hline \multicolumn{4}{|c|}{$\mathrm{KMO}=0.709 \quad$ Cronbach's alpha $=0.758$ Explained variance $=71.18 \%$} \\
\hline 4.1 & 0.715 & 4.601 & 0.506 \\
\hline 4.2 & 0.842 & 2.387 & 1.019 \\
\hline 4.3 & 0.745 & 4.191 & 0.393 \\
\hline 4.4 & 0.843 & 2.071 & 1.074 \\
\hline 4.5 & 0.741 & 2.176 & 1.041 \\
\hline
\end{tabular}


Four composites were created to represent social network, social trust, social reciprocity and social participation. Aggregate social capital is a linear combination of the four principal components, for which equation (2) was used. These four components were interpreted as composite measures of aggregate social capital. The results of four principal components of social capital and the aggregate social capital are given in Table 3.4 and Table 3.5.

Table 3.5 Extracted components of aggregated social capital

\begin{tabular}{lcccc}
\hline & Component 1 & Component 2 & Component 3 & Component 4 \\
\hline VAR 00001 & .585 & -.601 & .451 & .307 \\
VAR 00002 & .436 & .781 & .438 & .093 \\
VAR 00003 & .784 & -.107 & -.047 & -.609 \\
VAR 00004 & .720 & .131 & -.580 & .358 \\
\hline
\end{tabular}

\subsubsection{Predicting participative behaviour from social capital}

We first used the aggregate social capital as an independent variable to estimate equation (3), combined with socio-economic variables (model 1). Since the aggregate indicator for social capital contains much information on a wide range of individual elements and components, it is interesting to examine how the principal components of the social capital influence farmers' participative behaviour. Therefore, we also took each of the four components as an independent variable for the estimation of equation (3), combined with the socioeconomic variables (model 2).

We estimated the model using ML method with Stata 10. To correct for the heteroscedasticity problem, we recruit a robust test to revise it. The estimation results for the two models are shown in Table 3.6. The goodness of fit is 0.8241 and 0.6514 respectively. 
Table 3.6 Estimation results of the Logistic model (with aggregate social capital and four components of social capital)

\begin{tabular}{|c|c|c|c|c|c|c|}
\hline & \multicolumn{3}{|c|}{ Model 1 (with aggregate social capital) } & \multicolumn{3}{|c|}{ Model 2 (with four components of social capital) } \\
\hline & Coefficient & $\begin{array}{l}\text { Robust } \\
\text { Std. Err. }\end{array}$ & $\mathrm{P}$ value & Coefficient & $\begin{array}{l}\text { Robust Std. } \\
\text { Err. }\end{array}$ & $\mathrm{P}$ value \\
\hline Education & 0.8379 & 0.2230 & 0.506 & 0.9439 & 0.4617 & 0.906 \\
\hline Cultivated area & 0.9574 & 0.1062 & 0.695 & 1.1966 & 0.1473 & 0.145 \\
\hline Production history & 1.0143 & 0.0234 & 0.539 & 1.0231 & 0.0375 & 0.534 \\
\hline Cropping pattern & $7.3319 * * *$ & 3.3061 & 0.000 & $8.9874 * * *$ & 6.6371 & 0.003 \\
\hline Grain subsidies & $0.9993 * * *$ & 0.0002 & 0.001 & $0.9958 * * *$ & 0.0015 & 0.006 \\
\hline Timing of maintenance & $11.9406 * * *$ & 3.8378 & 0.000 & $15.9113^{* * *}$ & 9.4908 & 0.000 \\
\hline Water use disputes & $1.9249 * *$ & 0.4928 & 0.011 & $2.8190 * *$ & 6.1827 & 0.014 \\
\hline \multicolumn{7}{|l|}{ Social capital } \\
\hline Social network & & & & 12.4648 & 22.1586 & 0.156 \\
\hline Social trust & & & & $127.6915^{* * *}$ & 159.7895 & 0.000 \\
\hline Social reciprocity & & & & $-0.1851 * * *$ & 0.1049 & 0.003 \\
\hline Social participation & & & & $7.5430 * *$ & 6.1827 & 0.014 \\
\hline $\begin{array}{l}\text { Aggregated social } \\
\text { capital }\end{array}$ & $7.30 \mathrm{e}-17 * * *$ & $7.07 e-16$ & 0.000 & & & \\
\hline \multirow[t]{5}{*}{ Constant } & $0.0332 * * *$ & 0.3631 & 0.000 & & & \\
\hline & \multicolumn{3}{|c|}{ Log pseudolikelihood $=-35.42$} & \multicolumn{3}{|c|}{ Log pseudolikelihood =-70.18 } \\
\hline & \multicolumn{3}{|c|}{ Wald chi2 $(8)=72.93$} & \multicolumn{3}{|c|}{ Wald chi2 $(11)=70.17$} \\
\hline & \multicolumn{3}{|c|}{ Prob $>$ chi $2=0.000$} & \multicolumn{3}{|c|}{ Prob $>$ chi $2=0.000$} \\
\hline & \multicolumn{3}{|c|}{ Pseudo R2 $=0.8241$} & \multicolumn{3}{|c|}{ Pseudo R2=0.6514 } \\
\hline
\end{tabular}

Our estimation shows that aggregate social capital and three of the four components of social capital (social participation, social trust, and social reciprocity) are statistically significant (see Table 3.6). Socio-economic variables such as the size of the cultivated area, cropping pattern, grain subsidies, and service and maintenance of irrigation system also are statistically positive and significant.

Aggregate social capital has a significant influence on farmer participation in the collective groundwater irrigation system in the study area. This is consistent with the literature on the role of social capital in collective action. For example, Masahiko (2001) argued that social exchange (a form of social capital) eased the incentive compatibility conditions for cooperation among farmers. 
Considering the rich information of principal components of social capital and the heterogeneity of these components, now we focus our discussion on the results from the second model. Social participation has a significant and positive influence on farmers' participative behaviour in the collective action for underground water irrigation system in the study area. This result confirms some previous findings: the importance of the participation of public actors in the provision of access to key resources (Mildred, 2001). This can be explained by the fact that the on-going involvement in social public affairs and the desire to contribute to the village community can encourage relatively higher degrees of collective participation (Weale, 1992). This result verifies the importance of social involvement in close-knit rural societies like Guanzhong Plain, Shaanxi Province, China. As the literature (see e.g. Collier, 1998; Rudd, 2000) point out, regular participation increases the flow of information. Continuous and regular face-to-face exchanges of information-an essential requirement for overcoming collective action problems - can enhance knowledge about the behaviour of others and reduce risk and transaction costs (Ostrom, 2000). Furthermore, information, knowledge, influence and funding are fundamental elements of the participation process, thus affects the incentives for collective action (Rydin and Pennington, 2010). Therefore, we observe that social participation becomes a contributing factor that promotes collective action for the sustainable and healthy development of small-scale irrigation facilities.

Our result shows that social trust has a significantly positive influence on the collective action for groundwater irrigation system in the Guanzhong Plain, Shaanxi Province. This is consistent with the literature (e.g. Ostrom, 2010; Jones et al., 2010). A possible explanation is that in the study area, collective irrigation is managed mainly by water user associations and contractors. Thus, the manager and contractor that responsible for groundwater irrigation are centrally important, and collective action depends on whether the manager or contractor can enforce the completion of the irrigation task. The ways by which management determines human choices are critically important in understanding and solving problems of collective action (Vollan, 2011). Trust among farmers is an important factor for collective action (Rydin and Pennington, 2010). In addition, evidence from studies of regional economies suggests that various aspects of social capital can support different activities at different stages of development (Beugelsdijk and Smulders, 2003; Inkpen and Tsang, 2005). More specifically, social trust with strong internal ties and bonding is especially helpful in developing small-scale local initiatives (Woodhouse, 2006). In the social context of our study area, people are not used to the total freedom of choices. Instead, trust in other farmers is a common phenomenon, which could potentially explain the significant coefficient of trust in our result. 
The component of social reciprocity has a significant negative impact on participative behaviour. This demonstrates that the more the reciprocity between farmers, the lower the possibility of participative behaviour in collective action. This is congruent with the bounded generalised reciprocity theory. Farmers' participative behaviour in collective action for irrigation is determined by self-interest. That is, people will behave in a manner that maximises their own outcome as compared to the overall outcome of their group. Farmers' reciprocity is bounded to a small range which includes family members, relatives, friends and so on. With this grading structure, farmers will behave positively toward those who are expected to reciprocate such behaviours; it will effectively protect and further one's self-interests. In this regard, farmers' naturally expect close connected members to reciprocate positive behaviours (such as family members and relatives), while irrigation cooperatives' members will not (i.e., the Group Heuristic).

Further explanation is that irrigation cooperatives involve generalised, rather than personal, exchanges between two individuals who expect direct reciprocity. "Generalised reciprocity occurs when one's giving is not reciprocated by the recipient, but by a third party (Ekeh, 1974)". When farmers have the ability to demonstrate their disapproval at some personal cost, for the violation of widely-held norms (e.g., free-riding), they will intervene immediately to take revenge rather than relying on the collective management. The issue of free-riding is not explicitly studied in this paper, because it is not easy to free-ride within a groundwater irrigation system in the study area, as every pipeline is constructed directly to the cultivated area. Since free-riding is not an issue, social reciprocity is not relevant in collective action for farmers to control their opportunism (Gulati, 1995).

Cropping patterns are significantly associated with the odds of farmers' participative behaviour, since cash crops normally need more water to be irrigated, and that irrigation agriculture is expected to have more output. A recent study from 1998 to 2009 in China's 31 provinces found that when the irrigation efficiency increases $1 \%$, the per unit area yield of grain will be increased by $0.0875 \%$ (Feng, et al., 2012). It is demonstrated that the more farmers dependent on arable land and irrigation for livelihood, the more odds for their participation in collective action. Since irrigation is valuable to farmers who grow specific irrigated crops, it is the interest of farmers to participate in the collective irrigation system. This is consistent with Oliver (1980) that collective action depends upon the specific functions of the collective goods to the individuals.

Farmers' participative behaviour is positively and significantly related to grain subsidies. As first-generation collective action theories argues that individuals could not achieve joint benefits without the intervention of external authority (Olson, 1965; Hardin, 1968), while the 
national policy and local practices reveal that only if the external policy interventions are embedded and consistent with the local practices, the farmers' participative behaviour will be promoted. In this area, 'grain subsidy' provides a certain means for farmers to pay the participation fee in the collective irrigation system. As an external policy, farmers may also link the compliance condition of receiving grain subsidy to the irrigation system.

Service and maintenance of the irrigation system contribute to farmers' participative behaviour in the collective irrigation system in the study area. This can be explained by the fact that the service and maintenance of the groundwater irrigation system is the concern of the farmers because irrigation water is a common pool resource in this case, and the rules and regulations are conductive to the success of common pool resource management (Ostrom, 2000; Baland and Platteau, 1996). The empirical result reflects that cooperation in the collective action greatly reduces negotiation and organisational costs. The established rules can internalise willingness to participate in cooperatives as the rational choice. Therefore, timely and efficient maintenance of small-scale irrigation facilities not only resolves farmers' doubts about operation efficiency but also increases their enthusiasm for participation and sense of ownership.

Water use disputes among farmers are insignificant in the model. A possible explanation is that groundwater irrigation system with deep wells and piping technology in the study area greatly reduces the possibility of water use disputes, especially under the mutual surveillance of the farmers themselves. Therefore, water use disputes do not influence the participation in the collective action for the groundwater irrigation system.

\subsection{Discussion and conclusions}

We have analysed the impact of principal components of social capital on farmers' participative behaviour in collective action for small-scale irrigation systems, based on data collected from a household survey of 393 farmers in the Guanzhong Plain of Shaanxi Province in 2011. Our goal was to examine under which conditions collective action is likely to occur in a traditional small-holder society. The empirical results demonstrate that participative behaviour will be forthcoming in rural communities where two components of social capitalnamely social trust and social participation-play positive and significant roles. However, social reciprocity will reduce the probability of collective action. This result reflects the heterogeneity of social capital dimensions: some components have a positive role in collective action, while some others deter the probability of collective action. Moreover, well-organised service and maintenance of irrigation systems can greatly promote farmers' participative 
behaviour and boost the healthy and sustainable development of rural specialised cooperatives.

In conclusion, a consideration of the different components of social capital allows for a more precise understanding of farmers' participative behaviour. Multiple facets of social capital should be cultivated to support collective action. However, the negative effects of social capital should be avoided, since bounded generalised reciprocity will lead to the failure of collective action. This result suggests that irrigation participation with a helpful teammate can confirm expectations of group members to reciprocate and lead to sustainable participative behaviours between participants. Policy interventions that aim to build social capital require a due attention to different dimensions of social capital. National policies to create local resource management institutions are likely to lead to highly uncertain results at the local level due to significant variations in different dimensions of social capital. In this regard, how to cultivate multidimensional social capital is the core of this issue. Social space is the precondition of social capital formation, therefore, it is necessary to create favourable conditions for communication and information exchanges between farmers, through frequent interaction and contacts in social environment such as canteens, public squares, stages and sports centres, these social networks were developed over time, during which a basis for cooperation and collective action had been established. Wood et al. (2012) also stressed the importance of social networks for farmers' uptaking behaviours and diffusion of irrigation collective action in developing countries. From this study, social participation and awareness of public affairs emerged as very important factors, as it could be nurtured by setting up clubs and voluntary associations. However, it needs long term education and democracy atmosphere infiltration to have positive effects for collective action. Further, for policy intervention and planning, social capital could be generated within the local community by means of voluntary works, this could initiate local development and execute social and state strategy. The role of the state in such development policy is essential as it assists local societies not only economic assistance, but more importantly the organisational assistance.

Collective action initiatives can be perceived as an important strategy for linking smallholders to irrigation facilities which contribute to their economic and social development. For long term operation and maintenance of small-scale irrigation collective actions, challenges are inequalities in the distribution of water resources rather the negative dimensions of social capital. Within China's collective water use status quo, there are three ways that determine how water resources are managed and at what price, different village conditions could fit for different management ways. For future policy design, it should not only emphasize on cultivating multiple dimensions social capital, but also consider institution design to produce equal access to collective resources. In this regards, the mechanism designed should encourage 
farmers involved to have equal rights to water resources based on their contributions, then they have incentives to participate in these public issues deeply. As the first stage, a participatory process of all actors should be encouraged; policy interventions should foster local farmers mobilise "from below" rather than "from above", the economic incentive is expected by the state at the second stage for the launching of collective actions in a strategic plan.

Finally, we conclude by emphasising the importance of service and maintenance conditions for sustainability of collective actions. While multi-dimension social capitals predispose farmers towards cooperative behaviours, and thus enforcing collective efficacy (Hurtado et al., 2011). Decent service and maintenance rules could facilitate collective management of water resources. In terms of policy development and farmers' wellbeing improvement, binding of irrigation policies and nurturing of multi-dimension social capital are essentials for collective actions. Second-generation model based on evolutionary game theories (Gintis, 2000; Henrich, 2004) acknowledged the existence of multiple types of individuals as a core of modelling (Ostrom, 2005). Farmers' participative decisions are made not only with institutional arrangements but also multi-dimension social capitals. The results of this study may also have implications for national irrigation plans for small-scale irrigation facilities in other developing countries. 


\section{References}

Alesina, A., La Ferrara, E. 2000. Participation in Heterogeneous Communities. Quarterly Journal of Economics, 115 (3): 847-904.

Asia Development Bank (ADB). 2001. Water for All: The Water Policy of Asian Development Bank. Asian Development Bank, Manila.

Baker, J.M. 1998. The effect of community structure on social forestry outcomes: insights from Chota Nagpur, India. Mountain Research and Development, 18(1): 51-62.

Beugelsdijk, S., Smulders, S. 2003. Bridging and bonding social capital: Which type is good for economic growth? Paper presented at the European Regional Science Association Conference, Finland.

Bourdieu, P. 1993. Sociology in Question. London: Sage.

Bowles, S., Gintis, H. 2002. Social capital and community governance. The Economic Journal, 12(11): 419-436.

Carpenter, J.P., Daniere, A.G., Takahashi, L.M. 2004 Cooperation, trust and social capital in Southeast Asian Urban Slums. Journal of Economic Behaviour and Organization, 55(4):533-551.

Clark, X., Dollar, D., Micco, A. 2004. Port efficiency, maritime transport costs, and bilateral trade. Journal of Development Economics, 75(2): 417-450.

Coffé, H., Geys, B., 2005. Institutional performance and social capital: an application to the local government level. Journal of Urban Affairs, 27(5): 485-501.

Coleman, J. S., 1988. Social capital in the creation of human capital. American Journal of Sociology, 94: S95-S120.

Coleman, J. S. 1990. Foundation of Social Theory. Cambridge MA: the Belk nap Press of Harvard University.

Collier, P. 1998. Social Capital and Poverty. The World Bank, Social Capital Initiative Working Paper, Rep. No. 4(unpubl.).

DasGupta, P., Serageldin, I. 2000. Social Capital: A Multifaceted Perspective. World Bank, Washington DC.

DiPasquale, D., Glaeser, E. L. 1999. Incentives and social capital: are homeowners better citizens? Journal of Urban Economic, 45 (2): 354-84.

Durlauf, S. N., 1999. The case 'against' social capital. Focus, 20(3):1-5.

Ekeh, P.P. 1974. Social Exchange Theory: The Two Traditions. Cambridge. MA: Harvard University Press.

Feng, Y., Yao, S., Guo, Y. 2012. Irrigation efficiency of grain per unit area yield in China based on the panel data. Resources Science, 09: 1734-1740.

Gintis, H. 2002. Game Theory Evolving. Princeton, NJ: Princeton University Press.

Glaeser, E. L., Laibson, D.I., Scheinkman, J.A., Soutter, C.L. 2000. Measuring trust. The Quarterly Journal of Economics, 115(3):811-846.

Glaeser, E.L., Laibson, D.I., Sacerdote, B. 2002. An economic approach to social capital. The Economic 
Journal, 112, 483(11):437-458.

Gorton, M., Sauer, J., Peshevski, M. 2010. The Dimensions of Social Capital and Rural Development: Evidence from Water Communities in the Republic of Macedonia. European Association of Agricultural Economists, Paper prepared for presentation at the 118th seminar of the EAAE. Ljubljana, Slovenia, August 25-27.

Gulati, R. 1995. Social structure and alliance formation patterns: a longitudinal analysis. Administrative Science Quarterly, 40( 4): 619-652.

Gutiérrez, N.L., Hilborn, R., Defeo, O. 2011. Leadership, social capital and incentives promote successful fisheries. Nature, 470(7334):386-389.

Hardin, G. 1968. The tragedy of the commons. Science, 162(11):1243-1248.

Henrich, J. 2004. Cultural group selection, co-evolutionary processes and larger-scale cooperation. Journal of Economics Behaviour and Organizations, 53(1): 85-88.

Inkpen, A.C., Tsang E. W. K., 2005. Social capital, networks, and knowledge transfer. Academy of Management Review, 30 (1): 146-165.

Jones, N., Evangelinos, K., Halvadakis, C.P., Iosifides, S.T., Sophoulis, C.M. 2010. Social factors influencing perceptions and willingness to pay for a market-based policy aiming on solid waste management. Resources, Conservation and Recycling, 54 (9): 533-540.

Karlan, D.S., 2005. Using experimental economics to measure social capital and predict financial decisions. American Economic Review, 95(5): 1688-1699.

Krishna, A. 2002. Active Social Capital: Tracing the Roots of Development and Democracy. New York: Columbia University Press.

Krishna, A., Uphoff, N., 2003. Mapping and Measuring Social Capital through Assessment of Collective Action to Conserve and Develop Watersheds in Rajasthan. India. Pp85-124. Cambridge: Cambridge University Press.

Lam, W.F. 1998. Governing Irrigation Systems in Nepal: Institutions, Infrastructure, and Collective Action. San Francisco, CA: Institute for Contemporary Studies.

Liebowitz, J. 2005. Linking social network analysis with the analytic hierarchy process for knowledge mapping in Organizations. Journal of Knowledge Management, 9(1):76- 86.

Liu, Y., Huang, J.K., Wang, J.X., Rozelle, S. 2009. Factors affecting agricultural water-saving technology adoption decisions---based on the empirical study of 10 provinces in China. Watersaving and Irrigation. 10:1-5.

Masahiko, A. 2001. Toward a Comparative Institutional Analysis. Cambridge, MA: MIT Press.

Mildred, W. 2001. State policy under devolution: redistribution and centralization. National Tax Journal, 54(3): 541-56.

Newton, K. 1997. Social capital and democracy. American Behavioural Scientist, 140(5): 575-586.

Olson, M. 1965. The Logic of Collective Action. Cambridge: Harvard University Press.

Onyx, J., Bullen, P. 2000. Sources of Social Capital, in Winter, I. (ed.). Social Capital and Public Policy in Australia, Australian Institute of Family Studies, Melbourne, pp. 105-134. 
Ostrom, E. 1990. Governing the Commons: the Evolution of Institutions for Collective Action. Cambridge New York: University Press.

Ostrom, E. 1998. A behaviour approach to the rational choice theory of collective action. American Political Science Review, 92(1): 1-22.

Ostrom, E. 2000. Collective action and the evolution of social norms. Journal of Economic Perspective, 14(3): 137-158.

Ostrom, E. 2005. Understanding Institutional Diversity. Princeton, NJ: Princeton University Press.

Ostrom, E., Ahn, T.K. 2009. The Meaning of Social Capital and its Link to Collective Action. Pp. 1735 in Handbook of Social Capital---The Troika of Sociology, Political Science and Economics, edited by G.T. Svendsen and G. L. H. Svendsen. Northampton: Edward Elgar Publishing.

Ostrom, E. 2010. Beyond markets and states: polycentric governance of complex economic systems. American Economic Review, 100(6):1-33.

Ostrom, E. 2011. Reflections on 'Some Unsettled Problems of irrigation'. American Economic Review, 101(1):49-63.

Polyzou, E., Jones, N., Evangelinos, K.I., Halvadakis, C.P. 2011. Willingness to pay for drinking water quality improvement and the influence of social capital. The Journal of Socio-Economics, 40(1): 74-80.

Portes, A. 1998. Social capital: its origins and applications in modern sociology. Annual Review of Sociology, 24(1):1-24.

Pretty, J. 2003. Social capital and the collective management of resources. Science, 302(5652):19121914.

Putnam, R.D. 1993. The Prosperous community: social capital and public life. The American Prospect, 13:25-42.

Putnam, R.D. 1995. Bowling alone: American's declining social capital. Journal of Democracy, 6:6578.

Putnam, R.D. 1998. Foreword. Housing Policy Debate, 9(1):5-8.

Putnam, R.D. 2000. Bowling Alone: the Collapse and Revival of American Community. New York: Simmon \& Schuster Paperbacks.

Rozelle, S., Wang, J., Huang, J. 2002. Water Management Reform and the Poor: Impacts on Income, Output and Water Use in the Yellow River Basin, China. Friday Seminar Paper. International Water Management Institute, Colombo.

Rudd, M.A. 2000. Live longer and prosper: collective action, social capital and social vision. Ecological Economics, 34(234):131-144.

Rydin,Y., Pennington, M. 2010. Public participation and local environment planning: the collective action problem and the potential of social capital, local environment. The International Journal of Justice and Sustainability, (5)2: 153-169.

Scott, J. 1991. Social Network Analysis: A Handbook. London: Sage Publications. 
Solow, R.M. 1999. Notes on Social Capital and Economic Performance, in Partha Dasgupta and Ismail Serageldin(eds). Social Capital: A Multifaceted Perspective. Washington, DC: The World Bank, pp.6-9.

Steven, D. 2002. Symposium on social capital. The Economic Journal, 112(483): 417-418.

Stolle, D. 1998. Making Associations Work: Group Characteristics, Membership and Generalized Trust. In: Proceedings of the Annual Meeting of APSA, Boston, 9: 3-6.

Stone, W. 2001. Measuring social capital: towards a theoretically informed measurement framework for researching social capital in family and community life. Research Paper.

Szreter, S., Woolcock, M. 2004. Health by association? Social capital, social theory, and the political economy of public health. International Journal of Epidemiology, 33(4):650-667.

Uslaner, E.M., Conley, R.S. 2003. Civic engagement and particularized trust: the ties that bind people to the ethnic communities. American Political Research, 31 (4):331-360.

Vollan, B. 2011. The difference between kinship and friendship: (Field-) experimental evidence on trust and punishment. Journal of Social-Economics, 40(1):14-25.

Weale, A. 1992. The New Politics of Pollution. Manchester, Manchester: Manchester University Press.

Wood, S., Foster, J., Kols, A. 2012. Understanding why women adopt and sustain home water treatment: insights from the Malawi antenatal care program. Social Science and Medicine, 75(4): 634-642.

Woodhouse, A. 2006. Social capital and economic development in regional Australia: A case study. Journal of Rural Studies, 22 (1): 83-94.

Woolcock, M., Sweetser, A.T. 2002. Bright ideas: social capital---the bonds that connect. ADB Review, 34(2):26-27.

Zhang, L., Zhu, X., Heerink, N., Shi, X. 2014. Does output market development affect irrigation water institutions? Insights from a case study in northern China. Agricultural Water Management, 131(1): 70-78. 


\title{
CHAPTER 4
}

\section{Income Groups, Social Capital and Collective Action on Small-Scale Irrigation Facilities: A Multi-Group Analysis Based on a Structural Equation Model ${ }^{5}$}

\begin{abstract}
This paper examines whether relationships between social capital characteristics and the willingness of farmers to cooperate in collective action is moderated by the farmers' income level. A structural equation model was employed to analyse the influence of social capital components (social network, interpersonal trust, social reciprocity and social participation) on the willingness of farmers to cooperate in collective small-scale irrigation in the Guangling County, Shanxi Province of China. This analysis was complemented by a multi-group analysis to measure the potential variance effects across income groups. Our results show that low- and middle-income farmers give more importance to the aspects of social network, social reciprocity and social participation, while high-income farmers place emphasis on interpersonal trust and social participation. As such, the willingness of farmers to cooperate for the different income groups was influenced in different ways in relation to the various social capital components. Therefore, social capital and income differences have complex effects on the willingness of farmers to cooperate. In this regard, our research provides an alternative way to understand the complex process involved in the formation of collective action under the presence of increasing economic heterogeneity in local communities.
\end{abstract}

Key words: income differentials; social capital; small-scale irrigation facilities; willingness to cooperate; collective action

${ }^{5}$ This chapter is based on:

Miao, S., Heijman, W, Zhu, X., Qiao, D., and Lu, Q., 2018. Income Groups, Social Capital, and Collective Action on SmallScale Irrigation Facilities: A Multigroup Analysis Based on a Structural Equation Model. Rural Sociology, 83 (4): $882-911$. 


\subsection{Introduction}

Due to agricultural structural adjustment, industrialisation and urbanisation in northern China, an increasing demand for water and consequently an increasingly severe water shortage has occurred in recent years. Collective action to construct and operate small-scale irrigation infrastructure has become an effective way to cope with the water shortage problems encountered by rural farmers in arid and semi-arid areas (Iskandar et al., 2010), yet scaling up local collective actions for optimal impact remains problematic. To be successful, such projects are dependent on the willingness of farmers to cooperate and the coordination of their efforts. China has also been experiencing far-reaching social transformation, i.e. changing from a kinship society to a modern society. Such circumstances have led to inequality in socioeconomic factors, which has been growing continuously between the years 1991 and 2013 and become the main stumbling block for the realisation of collective action (Nie et al., 2015).

Social capital is recognized as a precursor for collective management of natural resources because of its importance in facilitating economic development (Coleman, 1990; Putnam, 1993; Jordan et al., 2010; Michelini, 2013; Munasib and Jordan, 2011; Woolcock, 1998). Generally speaking, social capital is a concept containing different components (Putnam, 1993; Brehm and Rahn, 1997). Despite the fact that several studies have empirically analysed the relationships between the multiple components of social capital and collective action (Jicha et al., 2011; Miao et al., 2015), the measurement of the different components of social capital in itself is difficult because social capital is embodied in the relations among persons (Coleman, 1990). Therefore, a more consistent and integrated measurement of the components of social capital based on comprehensive field work would be conducive to the extant literature (GomezLimon et al., 2014).

Beyond the consensus on social capital in relation to common-pool resource management, the theoretical issue of economic heterogeneity in connection to the willingness of farmers to cooperate in collective action is still highly contested (Varughese and Ostrom, 2001; Bharamappanavara et al., 2016). Because heterogeneity is multi-dimensioned, comprising social-cultural backgrounds, interests and endowments, a combination of different aspects of heterogeneity may increase the difficulty in achieving consensus in different circumstances. As "cooperation may possibly be enhanced by heterogeneous social structure except when such heterogeneity is tantamount to heterogeneity in economic interests and political power" (Varughese and Ostrom, 2001), the mechanisms by which difference among users or income differentials may influence the components of social capital, which then may affect collective action (Crespo et al., 2014), is yet to be fully explored and explained. Further, clarity is lacking as to whether income differentials affect collective action directly or whether given this 
attribute of heterogeneity farmers invest in the most useful components of social capital to maximize their benefit-to-cost ratio and thus realize collective action. Based on our knowledge to date, detailed empirical research of income differentials on social capital components among farmers and collective action is scarce. In particular, more attention needs to be paid to the interrelationship between structures of inequality, social capital and collective action.

It is no longer sufficient to empirically observe the presence of social capital and accept it as solely responsible for different forms of development. The body of work on heterogeneity has not been able to detect a uniform effect thereof on the organisation of collective action (Varughese and Ostrom, 2001). Specifically, little is known about the stage of initialising collective action. Moreover, the mechanism as to how income differentials may affect social capital components upon instigating willingness to cooperate has not yet been well explained. Normally, income inequalities are considered as a key element to explain the formation of social capital and the initialisation of collective action, but how these variables are interrelated and how they function still needs to be explored. Therefore, our contribution to the present literature is to clarify whether the relationship between social capital components and collective action varies across income groups and to reveal the mechanism of how income differentials expound commons management.

The objective of this paper is to examine whether the role played by social capital components in instigating cooperative willingness to collectively manage natural resources is different for distinct income groups. We first propose a multiple frameworks to explore the mechanism by which heterogeneity and dimensions of social capital influence the decision of farmers to participate in collective action. In particular, the application of social capital or heterogeneity theory to collective action problems accounts for a great quantity of the literature. However, a combination of social capital and heterogeneity theory in regard to collective action problems is scarce. Therefore, this framework is crucial to understanding the role heterogeneity plays in influencing the distribution of social capital as well as the farmers' willingness to cooperate. Moreover, it can also help with the organisation of collective action and interventions by informing future policies and programs.

\subsection{Theoretical background}

\subsubsection{Social capital and collective action}

The prominence of social capital theory in explaining and promoting collective action has been identified by many scholars. As the multidimensional nature of social capital was explored firstly by Putnam (1993), we follow his definition of the "features of social life — networks, 
norms, and trust - that enable participants to act together more effectively to pursue shared objectives". Putnam (1995) pointed out that social network, trust as well as norms of reciprocity has the function of promoting individuals to cooperate in order to attain collective goals. He also addressed the importance of participation in public affairs as conducive to collective action, making civic engagement the core of social capital (Putnam, 1993; Putnam, 2000; Brehm and Rahn, 1997). Therefore, social network, social trust, social reciprocity and social participation can be extracted as different components of social capital.

Based on Jicha et al. (2011) and Fulkerson and Thompson (2008), social capital can be divided into structural perspectives (social network and social participation) and normative perspectives (social trust and social reciprocity). Fulkerson and Thompson (2008) argue that integrated insights will be gained from both perspectives, otherwise "social capital may suffer the same fate as structural-functionalism". The structural perspective of social capital specifically describes the social interactions and civic engagement between individual members and organisations. This perspective explains how individuals through interaction with people or institutions gain access to resources, interests or other benefits (Gomez-Limon et al., 2014; Sabatini, 2009). Therefore, the key attribute of this perspective includes social network and social participation (Putnam, 1993).

In order to facilitate collective action with the aim of reaching mutual benefits among the individuals in a community, the normative perspective of social capital emphasizes the reciprocals transactions and values introjections in a social structure (Coleman 1988, 1990; Ainsworth, 2002; Putnam, 2002). In this vein, social capital is predisposed to collective action and economic development. This perspective is comprised of trust and norms of reciprocity (Putnam, 2000; Putnam et al., 1993). Previous studies have demonstrated the existence of social interaction effects and the correlations among structural, relational and cognitive social capitals (Jicha et al., 2011). We attempt to examine the structural-to-normative relationships of social capital. The demographic characteristics of farmers (sex, age and education) are also examined.

\subsubsection{Heterogeneity and collective action}

Collective action has become an important way to manage water resources and irrigation systems in rural contexts (Ostrom and Ahn, 2007). A series of studies suggest that people have a low propensity to cooperate or resolve collective action issues in more heterogeneous communities (Alesina et al., 1999; Alesina and La Ferrara, 2000). However, Olson (1965) maintained that group members' preference heterogeneity related to collective goods makes the initiation of collective action possible. Collectively, previous theoretical research has proven how heterogeneity is positively related, negatively related and U-shaped with respect 
to collective action (Johnson and Libecap, 1982; Bergstrom et al., 1986; Molinas, 1998).

To date, studies of heterogeneity and commons management have shown different and even contested results. According to Baland and Platteau (1994:302-312), inequality and heterogeneity do not necessarily reduce the likelihood of collective action on a common property resource. Based on the nature of the resource and the way it is exploited, social factors have intermediary effects on the externalities of collective goods. This complexity originates from the definition of heterogeneity itself. Since the term is used to mean both economic inequality and socio-cultural differences, in relation to income, wealth, asset, technology, preferences, skills, knowledge, gender and endowments (Baland et al., 2006; Habyarimana et al., 2009; La Ferrara, 2002; Johnson and Libecap, 1982; Bardhan \& Dayton-Johnson, 2002). For example, it is difficult to explore the way in which these factors act upon each other. Therefore, evaluating the important factors related to heterogeneity seems crucial to elucidate the mechanisms of collective action (Agrawal, 2001).

We take the factor of income differentials as our focus. Income differentials play a role in the willingness of farmers to participate in collective action. This relationship may be rooted in how each farmer's income group views benefits and cost differently (Sarin, 1996; Molinas, 1998; Agarwal, 1994). That is, farmers in low-income groups mainly rely on collective action for substance and due to economic restraint may also have a short time horizon. However, farmers in high-income groups may have incentives to take on the large costs of collective action; they also have access to other higher income channels while they recover from those costs. In this sense, their perception of the value of common pool resource may be different from that of low-income farmers. That is to say, how income differentials play a role in the participation in collective action is related to the economic position of farmers.

Income differentials may affect farmers' participation in collective action due to components of social capital (networks, participation, trust and reciprocity) or their social position within the social structure. Being in a specific income group that is structurally embedded in social capital leads farmers to weigh their own interests and gain opportunities for resource management cooperation. The multidimensionality of social capital has important implications for understanding the collective action behaviour of different income groups due to the different patterns of distributions social capital components can have among the various income groups (Crespo et al., 2014).

Social networks are integral to the structural component of social capital (Gesthuizen et al., 2013). Campbell et al. (1986) found that socioeconomic status has a positive effect on the range and composition of social networks. Individuals who are at the bottom of the social structure are also deprived of high-quality social networks, which leads to the underprivileged 
position of the poor (Letkia and Mierina, 2015; Lancee and van de Werfhorst, 2012; Pichler and Wallace, 2009). As inequality encourages people of different levels of social position to have diverse expectations of the access to resources and use of these social networks, high- and middle-income farmers are more inclined to participate in collective action because, compared to low income farmers, they can more easily mobilise resources through social networks.

A large quantity of literature shows that a low level of social participation is correlated with a low household income and society's overall income inequality level (Andersen and Fetner, 2008; Huisman and Oldehinkel, 2009). Low income individuals have less chance to participate in professional associations and political organisations because the "inequality of resources leads people in lower economic brackets to refrain from participating, either because they have fewer resources or because they believe that getting involved will be fruitless because the system is stacked against them (Uslaner and Brown, 2005)". Therefore, it is expected that social participation is positively associated with the willingness of middle- and high-income groups to cooperate.

Trust is an important component of social capital. It is composed of interpersonal trust and institutional trust (Nooteboom, 2007). A large number of studies demonstrate that inequality reduces people's generalized trust (Bjørnskov, 2008; Cozzolino, 2011; Freitag and Bühlmann, 2009; Wilkinson and Pickett, 2009; Zak and Knack, 2001). This finding can be explained by social psychological effects: low-income farmers experience more untrustworthy behaviour from others, making them inclined to be resentful and jealous when compared to high-income farmers.

The role of interpersonal trust for promoting collective action has also been verified by many studies (Dahal and Adhikari, 2008; Paraskevopoulos, 2010). Koutsou et al. (2014) found that young Greek farmers with enhanced interpersonal trust are more eager to participate in collective action. Therefore, it is expected that interpersonal trust is positively associated with high- and middle-income farmers' willingness to cooperate.

Based on social capital theory, social reciprocity is a component of social capital that could reduce risk, provide access to resources, supply information and achieve collective action (Grootaert, 1998). The function of social reciprocity is to form a reputation that will reduce transaction costs and thus free riding opportunism. Moreover, social reciprocity will facilitate instrumental and collective gains by encouraging participation in collective action (Ostrom, 1998). High-income farmers with an "elite role" expect to gain more benefits from participating in collective action than lower-income farmers (Bardhan et al., 2007). Further, rich farmers have more incentives to acquire a reputation than lower-income farmers (Ostrom, 1998). Put differently, lower-income farmers probably do not expect much from the collective actions. 
Therefore, it could be expected that social reciprocity is negatively related to middle- and lowincome farmers' willingness to cooperate.

How income differentials play a role in initiating collective action would be better explained by the interaction between the different components of social capital and their distribution in social structures based on income. Based on the theoretical background above, we make the following hypotheses to test how different income groups have different levels of willingness to cooperate in collective action via their social position reflected by the social capital components.

H1: Social network and social participation are positively related to middle- and lowincome farmers' willingness to cooperate, while social reciprocity is negatively related to middle- and low-income farmers' willingness to cooperate.

H2: Interpersonal trust and social participation are positively related to high-income farmers' willingness to cooperate.

\subsection{Data and methods}

\subsubsection{Context and data}

A survey was conducted in Guangling County in the Shanxi Province of China in 2012. Guangling is the district located at the lowest plateau in the northwest region of China. The natural environment is characterized by a semi-arid continental climate with dry weather and little precipitation. The annual rainfall is only around $380-400 \mathrm{~mm}$, and the average annual evaporation is $1,144 \mathrm{~mm}$. The rainy season is distributed unevenly between July and September, two irrigation seasons are arranged between spring (from April 1st to May 10th) and summer (from June 15th to August 10th). The main income of farmers comes from the agricultural industry and migrant work. Over $80 \%$ of its population depends on agriculture for their main livelihood. The cultivated crops are corn, sorghum, millet and beans for their subsistence. Usually, corn is the main irrigated crop, as its output is twice compared to other crops. Following the grass-roots political reform, the role of the local government in irrigation collective action is to protect the property rights of water user organisations, be responsible for fixing canals and construct as well as allocate the national reservoir quotas. Therefore, the local government exercises its soft power in the allocation of surface irrigation quotas, but it does not directly control collectives.

Irrigation collective action is organised into three channels: water user organisations (WUOs), contractors (the management and monitor rights are transferred to agents who are responsible for irrigation) and village councils. Different channels have their own set of 
regulations and rules for irrigation, violation punishment and irrigation maintenance.

Irrigation collective action in the Dong Jiaoshan village is organised by the Water User Organisation. It is a highly self-organised organisation, and the local government does not intervene in its internal management.

In the Xi Jiaoshan village and the Zhong Jiaoshan village, it is organised by the village councils. However, the village council's power is weakened as a result of the rural government's dissolution reform. Irrigation rights are transferred to agents who are responsible for getting quotas from the local government's water agencies, water allocation and surveillance. The water used in gravity irrigation comes from the state-owned reservoirs. As reservoir volume fluctuates according to the annual rainfall quantity and frequency, the quotas villagers receive are different year to year.

In the $\mathrm{Du}$ Jiazhuang village and the Yinjiazhuang village, it is organised through contracting organisations. The managers are responsible for water allocation and surveillance. They also usually have very good socio-political relationships with the local government and village leaders. The irrigation fee by way of contracting is the highest (RMB 120 per hour) when compared to the other two ways (WUOs and village councils). Typically, only powerful people can take on the responsibility of a manager because they can make use of their power to resolve delayed and delinquent payments of irrigation fees.

There are two ways for local residents to participate in collective action: money contribution and labour contribution. For the case of Dong Jiaoshan, the money contribution of the local residents includes the cost of electricity, repairs and the wages of management personnel. Dong Jiaoshan's irrigation collective action was initiated by a retired senior civil servant. The motor-pumped well was constructed by the local government, while the well maintenance is paid by local residents through fundraising (they have to employ professional repairman to fix and maintain it). Local residents contribute in labour by way of canal maintenance and repair before irrigation season, and also take on surveillance tasks when their fields are under irrigation in order to prevent water stealing. For the other 4 villages, the irrigation water comes from a state-owned reservoir, the management personnel are responsible for surveillance and water distribution, canal maintenance is undertaken by local residents.

Free riding problems rarely happen in the surveyed area. For the WUOs, underground irrigation water is transported from pump stations to farmlands via underground sub-lines via a switch. Usually, only one household can be irrigated at a time; therefore, if free riding were to happen, it would be quickly noticed by the farmer who is under irrigation because of the smaller volume available. Moreover, for farmers, there is not a strong incentive to free ride as there is a trade-off between saving money and saving reputation. In addition, the water price is 
low, such that farmers have little incentive to free ride. Thus, very few free riding cases were reported.

In the case of contractors, whenever free riding is detected, managers may use strict enforcement where deemed necessary. They would fine the accused 10 to 20 times the irrigation fee. In other words, managers hold a lot of power in local areas and exercise this power. For example, if farmers exit in the first round of irrigation (from April 1st to May 10th) because of the occurrence of rain, participation in the second round of irrigation in summer (from June 15th to August 10th) will be denied by the managers of the contracting organisations. This policy may cause a great reduction in corn output because of the lack of irrigation during the key growth period, but effectively control the exit options of farmers.

For the study, five villages (Dong Jiaoshan, Xi Jiaoshan, Zhong Jiaoshan, Du Jiazhuang and Yin Jiazhuang) were selected for a stratified random sampling of residents based on whether the village builds projects to solve farmland irrigation problems, such as farm irrigation, drainage projects and medium-sized pump stations. The sample was stratified by economic and cultural characteristics. The villages were selected based on their different economic development level and their propensity for adhering to rules and regulations.

Questionnaires were given to survey respondents and completed with the researchers present. The survey covers the social-demographics and social capital characteristics of farmers. Four hundred and twenty-eight copies of the survey questionnaires were collected through semi-structured interviews. After excluding those with incomplete responses, 390 valid questionnaires were selected, resulting in a response rate of $91.1 \% .53 \%$ of the respondents are male. The respondents' average education level is junior secondary school. The average annual income is RMB 9632.50 per household. Moreover, group discussions and key informant interviews were also employed as supplements. These methods were recruited to corroborate information and form a representative dataset to understand local irrigation collectives' management.

\subsubsection{Variables}

The willingness to cooperate defines those farmers who have the inclination to participate in collective action for small-scale irrigation facilities. A large amount of research reveals that perception and attitude are indicators of an individual's behaviour and can thus be used to predict real actions (Shibia, 2010; Tessema et al., 2010).

As for the indicators that reflect the attitudes of farmers, much literature demonstrates that local people's support of protected areas or community is closely associated with their perceptions of benefits and costs (Infield, 1998; Heinen, 1993; Fiallo and Jacobson, 1995; Ite, 
1996; De Boer and Baquette, 1998; Newmark et al., 1993). Similarly, based on Mehta \& Heinen (2001), the positive attitudes of farmers towards natural resource management are related to their perceptions of the benefits and costs. Hence, an evaluation of farmers' perceptions of benefits and costs could be used as an indicator to reflect their willingness to cooperate.

Moreover, recognition of the importance of collective action on small-scale irrigation facilities is selected as an indicator. This relation is based on Davis et al. (1989), who defined perceived usefulness as the "prospective user's subjective probability that using a specific application system will increase his or her job performance within an organisational context". Perceived usefulness as a predictor of farmers' attitudes was confirmed theoretically and empirically by other scholars (Bagozzi, 1992).

Ajzen \& Fishbein (1980, pp, 82-86) posited that an individual changing behaviour occurs mainly through beliefs and evaluations as well as the "subjective probability that performing the target behaviour will result in consequence". Previous studies also found that the farmers' tendencies to join agricultural cooperatives are closely connected with subjective judgements (Stallman and James, 2015). Thus, the satisfaction degree of farmers for collective action on small-scale irrigation facilities is incorporated into the index of farmers' willingness to cooperate. Therefore, the perceptions of benefits and costs, the importance attached to collective action on small-scale irrigation facilities and the degree of satisfaction are taken as indicators of farmers' willingness to cooperate.

A social network is a connection between behavioural agents. Also, the interactive mode between behaviour agents and external circumstances are formed in this network. Social networks influence one's perceptions when collecting and perceiving information. Therefore, the design of social network variables is primarily determined by the level of communication between different subjects. It is expected that if a farmer has a wider social network, the farmer's willingness to cooperate in collective action will be stronger.

According to the definition of Brehm \& Rahn (1997) and Jicha et al. (2011), interpersonal trust refers to trust in narrow surroundings and the level of trust inside one's close personal connections, consisting of family members and friends. According to China's grading structure of rural interpersonal relationships and different trust levels (from close relationships to acquaintances), it is expected that interpersonal trust has a positive impact on farmers' willingness to cooperate.

Social reciprocity is defined as "the desire to be kind to those who are kind to you and unkind to those who are unkind to you" (Dufwenberg and Patel, 2017). It reflects instances involving actual give-and-take situations in everyday interactions that guarantee the sustenance of cooperation and defecting punishment. Thus, social exchange continues if group members 
abide by the norms of reciprocity as they participate in cooperative activities. It is hypothesised that social reciprocity plays an effective role in instigating farmers' willingness to cooperate.

Social participation describes people's participation in different kinds of public activity, such as festivals, public issues and elections. The measurement index of civic engagement is designed mainly in relation to the frequency and degree of participation in public affairs. It is hypothesised that farmers involved more deeply in social public affairs will have a stronger willingness to cooperate, and they will be familiar with the processes needed to be followed in order to achieve these objectives as well as how one process is connected with another, thus improving the probability of successful collective action.

Annual household income reflects the natural endowments farmers own. Based on the economic model, income is one of the determinants for willingness to pay (Liebe, 2010). Farmers' willingness to cooperate is restrained by their disposable income when they consider participating in collective action. As for the relationship between income and collective action, previous literature has shown quite different or even opposing results for the effects of economic inequality on collective action (Baland and Platteau, 1997; Bardhan et al., 2007; Bergstrom et al., 1986; Cornes and Sandler, 1996; Heckathorn, 1993). A U-shaped relationship even exists between inequality and collective action (Johnson and Bardhan, 2002). Lanjouw et al. (2013) argue that as income inequality increases, collective action will be negatively affected. Therefore, income level may have either a positive or a negative effect on farmers' willingness to cooperate.

\subsubsection{Empirical model}

Structural Equation Modeling (SEM) is a multivariate statistical technique that fuses factor and path analysis. As a result, multivariate quantitative research is applied to the relationship between latent and observed variables. In order to analyse the factors that impact the willingness of farmers to participate in collective action on small-scale irrigation facilities, this paper uses the Structural Equation Model to verify the research hypotheses. The Structural Equation Model comprises the measurement model and the structural model (Tang et al., 2013).

The measurement model incorporates equations (1) and (2):

$$
\begin{aligned}
& y=\Lambda_{y} \eta+\varepsilon \\
& x=\Lambda_{x} \xi+\delta
\end{aligned}
$$

Where $y$ is a $p \times 1$ vector of the endogenous observed variables, including recognition of importance of collective action on irrigation facilities, degree of satisfaction and perception of 
benefits and costs. $x$ is a $q \times 1$ vector of exogenous observed variables. $\eta$ is a $m \times 1$ vector of latent endogenous variables (willingness to cooperate), and $\xi$ is a $n \times 1$ vector of latent exogenous variables, including social network, social trust, social reciprocity and social participation. $\Lambda_{y}$ and $\Lambda_{x}$ are $p \times m$ and $q \times n$ matrices of the coefficients (or loadings), respectively. At the end, $\varepsilon$ and $\delta$ are $p \times 1$ and $q \times 1$ vectors of measurement errors of $y$ and $x$, respectively.

The structural model is set as follows:

$$
\eta=B \eta+\Gamma \xi+\zeta
$$

Where $\eta$ and $\xi$ are defined in equations (1) and (2). B is a $m \times m$ matrix with $\beta_{i j}$ representing the effect of the $j$ th endogenous latent variable on the $i$ th endogenous latent variable. $\Gamma$ is an $m \times n$ matrix with $\gamma_{i j}$ representing the effect of the $j$ th exogenous latent variable on the $i$ th endogenous latent variable, and $\zeta$ is a $m \times m$ vector of disturbances.

SEM proceeds in two steps. First, the measurement model is analysed, by which observable variables are made to reflect latent variables. The second step is evaluating the structural model in order to indicate the relationship between latent variables. We test components of social capital on farmers' willingness to cooperate by employing AMOS 23.0. Next, we use the bootstrapping method to test the mediating effects of demographic variables. Finally, a multi-group analysis is utilized to analyse the role income groups play in formulating social capital components and farmers' willingness to cooperate.

\subsection{Empirical analysis}

\subsubsection{Statistics, validity test and confirmatory factor analysis}

Based on Miao et al. (2015), the components of social network, participation, trust and reciprocity are used to measure farmers' social capital, and these four factors consist of 13 variables. 
Table 4.1 Descriptive statistics and factor loadings of indicator variables

\begin{tabular}{|c|c|c|c|c|c|}
\hline Variables & Observable Variable & S.D. & Mean & Min. & Max. \\
\hline \multicolumn{6}{|l|}{ Exogenous variables } \\
\hline \multicolumn{6}{|l|}{ Social network } \\
\hline 1 & $\begin{array}{l}\text { Number of people you could ask for help when in } \\
\text { difficulty }\end{array}$ & .77434 & 4.4744 & 2 & 5 \\
\hline 2 & Frequency of contact with friends & .79571 & 4.3641 & 2 & 5 \\
\hline 3 & Frequency of contact with relatives & .82143 & 3.4487 & 2 & 5 \\
\hline 4 & Frequency of contact with neighbours & .78231 & 4.1513 & 2 & 5 \\
\hline 5 & Frequency of contact with village leaders & .81860 & 3.5462 & 2 & 5 \\
\hline \multicolumn{6}{|l|}{ Social trust } \\
\hline 6 & Trust level towards close friends & .87403 & 3.9538 & 1 & 5 \\
\hline 7 & Trust level towards prestigious farmer & .69975 & 3.5513 & 2 & 5 \\
\hline 8 & Trust level towards family members & .72726 & 3.0256 & 1 & 5 \\
\hline \multicolumn{6}{|l|}{ Social reciprocity } \\
\hline 9 & $\begin{array}{l}\text { When people have important affairs to decide on, } \\
\text { they ask you for suggestions }\end{array}$ & .89791 & 3.0308 & 1 & 5 \\
\hline 10 & Others come to help during harvest season & .84461 & 3.1641 & 1 & 4 \\
\hline 11 & Friends come to help when building a house & .84226 & 2.9897 & 1 & 5 \\
\hline $\begin{array}{l}\text { Social participation } \\
12\end{array}$ & Participates in the village cadre's election & .99274 & 2.9179 & 1 & 5 \\
\hline 13 & $\begin{array}{l}\text { Proposes suggestions when deciding about public } \\
\text { issues }\end{array}$ & 1.11292 & 2.8846 & 1 & 5 \\
\hline \multicolumn{6}{|c|}{$\begin{array}{l}\text { Endogenous variables } \\
\text { Cooperation willing }\end{array}$} \\
\hline 14 & Satisfaction with small-scale irrigation facilities & 1.19883 & 3.4667 & 1 & 5 \\
\hline 15 & Perception of benefits and costs & 1.09486 & 3.3641 & 1 & 5 \\
\hline 16 & Importance of small-scale irrigation facilities & 1.13117 & 3.3590 & 1 & 5 \\
\hline \multicolumn{6}{|l|}{ Socio-demographics } \\
\hline Gender & $1=\operatorname{man}, 0=$ woman & 0.50 & 0.53 & 0 & 1 \\
\hline Age & $\begin{array}{l}1=\text { under } 17,2=18-35 \text { years old; } 3=36-50 \text { years } \\
\text { old; } 4=51-65 \text { years old; } 5=\text { older than } 66\end{array}$ & 0.86 & 3.45 & 1 & 5 \\
\hline Education & $\begin{array}{l}1=\text { illiterate, } 2=\text { primary school, } 3=\text { junior } \\
\text { secondary school, } 4=\text { senior secondary school, } 5= \\
\text { technical school and above }\end{array}$ & 0.99 & 2.32 & 1 & 5 \\
\hline Income & & 9632.5 & 17633 & 2000 & 55000 \\
\hline
\end{tabular}

Table 4.1 presents the statistics of the observed variables. Based on the definition in Section 2, farmers' willingness to cooperate is measured by the following indicators: (1) farmers' degree of satisfaction (x14), (2) farmers' perception of benefits and costs (x15) and (3) the importance of small-scale irrigation facilities (x16). Each of the indicators is measured on a 5-point scale, specifically, strongly disagree, disagree; neither disagree nor agrees, agree and strongly agree. As seen in the statistical analysis in Table $4.1,72 \%$ of the respondents report that they attach importance to small-scale irrigation facilities for agricultural production. 
Regarding their perception of the benefits and costs, 59.7\% of the respondents agree and strongly agree on the benefits of participating in collective action. As for the degree of satisfaction with collective action on small-scale irrigation facilities, $60 \%$ were satisfied or strongly satisfied. The conclusion can be drawn that farmers have the inclination to cooperate in such collective action.

Five indicators that measure social network include: (1) number of people you could ask for help when in difficulty, (2) frequency of contact with friends, (3) frequency of contact with relatives, (4) frequency of contact with neighbours and (5) frequency of contact with village leaders. Indicator (1) is a categorical variable that takes the value 1 if the respondent replies "one to three", 2 if the reply is "four to seven", 3 if the reply is "eight to eleven", 4 if the reply is "twelve and fifteen" and 5 if the reply is "16 or more". Indicators (2), (3), (4) and (5) are defined as 1 if the respondent replies "one or two times a year or never", 2 if the reply is "one or two times a month", 3 if the reply is "one or two times a week", 4 if the reply is "three to five times a week" and 5 if the reply is "every day in a week".

The three indicators which measure interpersonal trust are: (1) trust level towards close friends, (2) trust level towards prestigious farmers and (3) trust level towards family members. All three indicators are measured on a 5-point scale: strongly distrust, distrust, neither distrust nor trust, trust and strongly trust.

Social reciprocity is measured by the following indicators: (1) when people have important affairs to decide on, they ask you for suggestions; (2) others come to help you during harvesting season and (3) friends come to help when building a house. All indicators are measured on a 5-point scale: never, rarely, sometimes, very often and always.

Social participation is measured by the following indicators: (1) participation in the village cadre's election and (2) proposal of suggestions when deciding public issues. Indicators are measured on a 5-point scale: never, rarely, sometimes, very often and always.

The reliability test indicates that a reliable index is when Cronbach's alpha for the whole model is 0.770 . For the aforementioned four components of social capital, it is between 0.577 0.776 (social network, 0.762; social trust, 0.577 ; social reciprocity, 0.641 ; social participation, 0.776). For the Cronbach's alpha, the ideal value is above 0.7 (Nunnaly, 1978, it is still acceptable if it is above the cut-off point of 0.4 (Pinheiro-Alves and Zambujal-Oliveira, 2012; McHorney et al., 1994). Moreover, the approximate statistics value of $\chi^{2}$ in the Bartlett test being 1263.146, the results of the KMO test being 0.738 and the significant coefficients of Sig $=0.000<0.05$ indicate a high reliability. The CR value of the observed variables was greater than 2, and all of the observed variables are significant between $95 \%$ and $99 \%$ confidence level. Therefore, the loading factors between observed variables and latent variables are significant. 
In order to avoid the common method bias problem, we designed an anonymous questionnaire and changed the questionnaire sequence to perform process control for the common method bias effect. In addition, the results of Harman's single factor model test for statistical control demonstrate that the first factor accounts for $30 \%$ of variance (not over $40 \%$ ). The factor analysis shows the presence of four distinct factors with an eigenvalue greater than 1.0, which verifies no one general factor accounts for the majority of the covariance in the measurement process. Finally, the unmeasured latent method factor technique is utilised. The results indicate that all loadings of the items on the unmeasured latent variable were not significant. Therefore, it can be concluded that common method bias is not a problem.

Based on the hypotheses mentioned above, we test the mediation effects of the demographics of farmers. For direct interpretation, the direct and total effects are reported in Table 4.2 as unstandardized estimates. We estimate the effects of the demographics of farmers on the components of social capital. Education is significantly and positively associated with social reciprocity. In other words, the social reciprocity of farmers will increase correspondingly by 0.057 per unit increase in education level. This finding indicates that education is important for increasing farmers' social reciprocity. However, it is not significant for other components of social capital. Age has negative and significant effects on social network, indicating that younger farmers are more active in social contexts. Sex is negatively and significantly related to social network. In other words, women are more likely than men to engage in social networking, which is consistent with Putnam's (1995) findings. The results of demographics suggest that being younger, women and higher educated is conducive to the formation of social capital.

Table 4.2 Direct and total effects of demographics on farmers' willingness to cooperate

\begin{tabular}{|c|c|c|c|c|c|c|c|c|}
\hline & Education & Age & Sex & $\begin{array}{c}\text { Social } \\
\text { participation }\end{array}$ & $\begin{array}{l}\text { Social } \\
\text { reciprocity }\end{array}$ & $\begin{array}{c}\text { Interpersonal } \\
\text { trust }\end{array}$ & $\begin{array}{c}\text { Social } \\
\text { network }\end{array}$ & $\begin{array}{l}\text { Willingness } \\
\text { to cooperate }\end{array}$ \\
\hline $\begin{array}{l}\text { Social } \\
\text { participation }\end{array}$ & $\begin{array}{c}-.044 \\
(0.042)\end{array}$ & $\begin{array}{c}.001 \\
(0.049)\end{array}$ & $\begin{array}{l}-.020 \\
(0.091)\end{array}$ & .000 & .000 & .000 & .000 & .000 \\
\hline $\begin{array}{l}\text { Social } \\
\text { reciprocity }\end{array}$ & $\begin{array}{l}.057 * * * \\
(0.022)\end{array}$ & $\begin{array}{c}-.031 \\
(0.025)\end{array}$ & $\begin{array}{c}-.035 \\
(0.044)\end{array}$ & .000 & .000 & .000 & .000 & .000 \\
\hline $\begin{array}{l}\text { Interpersonal } \\
\text { trust }\end{array}$ & $\begin{array}{c}.029 \\
(0.044)\end{array}$ & $\begin{array}{c}-.028 \\
(0.050)\end{array}$ & $\begin{array}{c}-.004 \\
(0.078)\end{array}$ & .000 & .000 & .000 & .000 & .000 \\
\hline $\begin{array}{l}\text { Social } \\
\text { network }\end{array}$ & $\begin{array}{l}-.049 \\
(0.035)\end{array}$ & $\begin{array}{l}-.087 * * \\
(0.043)\end{array}$ & $\begin{array}{c}-.222 * * * \\
(0.071)\end{array}$ & .000 & .000 & .000 & .000 & .000 \\
\hline $\begin{array}{l}\text { Willingness to } \\
\text { cooperate }\end{array}$ & $\begin{array}{c}.010 \\
(0.040)\end{array}$ & $\begin{array}{c}-.058 \\
(0.043)\end{array}$ & $\begin{array}{c}.099 \\
(0.073)\end{array}$ & $\begin{array}{c}1.023 * * * \\
(0.072)\end{array}$ & $\begin{array}{c}-.309 * * * \\
(0.118)\end{array}$ & $\begin{array}{l}.377 * * * \\
(0.107)\end{array}$ & $\begin{array}{l}.351 * * * \\
(0.070)\end{array}$ & .000 \\
\hline
\end{tabular}

${ }^{*} p<.05,{ }^{* *} p<.01, * * * p<.001$ using a one-tailed $t$-test. Standard errors are reported in parentheses. 
Social network and social participation positively and significantly influence farmers' willingness to cooperate (the structural model). Their respective coefficients of 0.351 and 1.023 are significant at the $99 \%$ level. These results support the hypothesis that the more involved the farmer is in public affairs and social networking, the more willingness to participate in small-scale irrigation facilities collective action the farmer shows. The interpersonal trust also positively impacts farmers' willingness to cooperate; the coefficient of 0.377 is significant at the $99 \%$ level. In contrast, social reciprocity negatively and significantly affects farmers' willingness to cooperate, with the coefficient of -0.309 being significant at the $99 \%$ level. In general, the total effects have the same results as the direct effects, which demonstrate that no indirect effects existed.

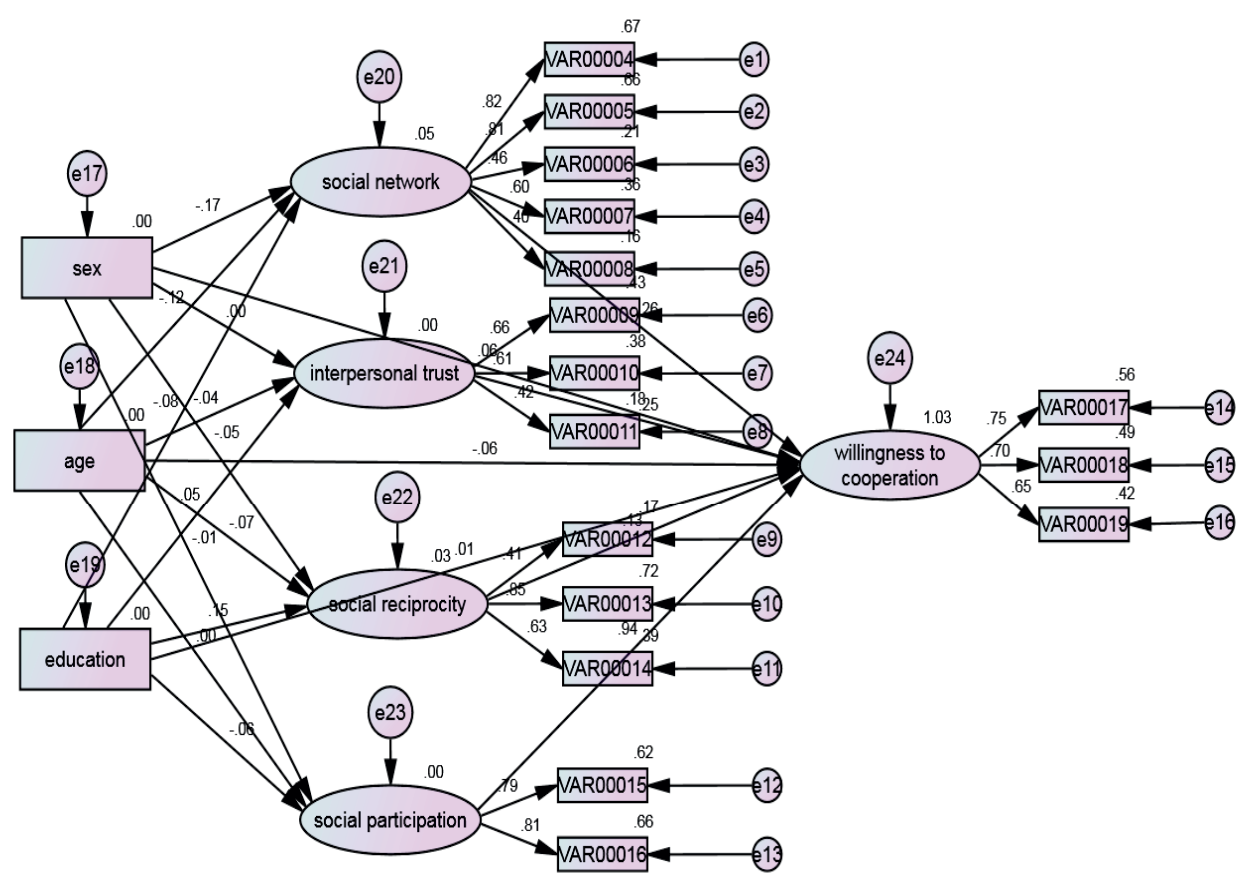

Figure 4.1 Estimates of the structural equation model on the relationship between components of social capital and farmers' willingness to cooperate 
The results of the Structural Equation Model that predict components of social capital and farmers' willingness to cooperate are shown in Figure 4.1. It is displayed to reflect the standardized relationships between latent and observed variables. The goodness of fit for the structural equation model is evaluated by $\chi^{2}(403.061, \mathrm{CMIN} / \mathrm{DF}=2.964)$, the root mean square error of approximation (0.071, RMSEA), the goodness of fit index $(0.896, \mathrm{GFI})$ and the comparative fit index $(0.863, \mathrm{CFI})$. Based on the recommended cut-off criterion for RMSEA (0.07), GFI and CFI (greater than 0.9) (Hooper et al., 2008), the model and data indicate a reasonably fair fit.

Social network positively and significantly impacts farmers' willingness to cooperate (0.263, P<0.01). Indicators X1, X2, X3, X4 and X5 are the most important ones for social network. Their standard factor loading coefficients are $0.818,0.810,0.460,0.601$ and 0.398 , respectively. Social networks have the function of communicating information and mobilising resources. In order to overcome the difficulties of daily life, farmers place emphasis on building and maintaining social networks. Through this network structure, information can flow easily by reducing transaction costs. Rural elites with a network of strong concentration and intensity can take advantage of network resources to aid in the organisation's development. Therefore, higher networking ability and lower networking costs promote collective action.

Interpersonal trust is positively and significantly associated with farmers' willingness to cooperate $(0.254, \mathrm{P}<0.01)$. X6 (trust towards close friends), X7 (trust towards prestigious farmers) and X8 (trust towards family members) are the most important indicators for interpersonal trust, of which the standard loading factors are 0.649, 0.622 and 0.419 , respectively. These loading factors reflect a transmission of the traditional trust logics of farmers, which are based on blood kinship and follow a sequence from intimate associates, to acquaintances, to strangers (Fei, 1947). Our results demonstrate that the trust logics of farmers transform from special into common trust in order to construct new economy-oriented relationships.

Social reciprocity has significant and negative effects on farmers' willingness to cooperate $(-0.136, \mathrm{P}<0.01) . \mathrm{X} 9, \mathrm{X} 10$ and $\mathrm{X} 11$ are the most important indicators, of which the standard loading factors are $0.413,0.839$ and 0.634 , respectively.

Social participation has positive and significant effects on farmers' willingness to cooperate $(0.938, \mathrm{P}<0.01)$. Among the indicators describing social participation, the standard loading factors of X12 and X13 are 0.786 and 0.812 , respectively. The interpretation of the loadings demonstrates that a standard deviation increase in social participation leads to a 0.786 increase in participation in the village cadre's election and a 0.812 increase in proposals of suggestions when deciding public issues. 


\subsubsection{Multi-group analysis based on income differences}

Multi-group analysis is utilised to examine income differentials in terms of path differences. Correspondingly, based on annual household income, farmers are classified into a low-income group (under RMB 10 thousand), a middle-income group (RMB 11-24 thousand) and a high-income group (more than RMB 25 thousand). The outcomes of the multi-group analysis for the model are shown in Table 4.3. Results demonstrate that the multi-group analysis has statistically significant differences among the different income groups when showing their willingness to cooperate in small-scale irrigation facilities collective action. The overall fit of the model was acceptable $(\mathrm{CFI}=0.914$, RMSEA $=0.039)$. Since we would like to capture the subtle differences between various income groups, we set 0.1 for the significance level, which is slightly different from the convention of 0.05 as the significance level.

Table 4.3 Estimated results of social capital components for willingness to cooperate by income group in multi-group analysis

\begin{tabular}{lcccccc}
\hline Willingness to cooperate & \multicolumn{2}{c}{ Low-income group } & \multicolumn{2}{c}{ Middle-income group } & \multicolumn{2}{c}{ High-income group } \\
& coefficient & C.R. & coefficient & C.R. & coefficient & C.R. \\
\hline Social Network & $0.216^{* *}$ & 2.319 & $0.200^{* *}$ & 2.366 & 0.169 & 1.325 \\
Interpersonal Trust & 0.184 & 1.432 & 0.120 & 1.228 & $0.245^{*}$ & 1.676 \\
Social Reciprocity & $-0.172^{*}$ & -1.772 & $-0.256^{* * *}$ & -2.794 & 0.017 & 0.177 \\
Social Participation & $0.811^{* * *}$ & 5.292 & $0.916^{* * *}$ & 7.285 & $0.807^{* * *}$ & 6.957 \\
\hline
\end{tabular}

Note: the C.R. (Critical Ratio) value is the value of $\mathrm{t} ; *$, ** and $* * *$ respectively represent the significance under the levels of $10 \%, 5 \%$ and $1 \%$.

Social network is more positively correlated to willingness to cooperate among lowincome farmers $(0.216 ; \mathrm{P}=0.02<0.05)$ than middle-income farmers $(0.200 ; \mathrm{P}=0.018<0.05)$. The $\mathrm{P}$ value is insignificant for the high-income group. A possible explanation for this result is that low-income farmers mainly rely on the help of neighbours or friends when facing difficulties since social network is an efficient way of investing in group relationships for farmers with limited resources. Therefore, with the aim of achieving coordination and communication between individuals through social ties, building social network creates possibilities to solve the dilemma of collective action. These results are in accordance with Zhao et al. (2007), who found that support from social network induces the rural income gap in China by $12.1 \%$ to $13.4 \%$. People have a strong motivation to construct and maintain social networks to reduce the income gap, which also confirms Grootaert's conclusion (2001) that social networks reduce farmers' transaction costs. 
Interpersonal trust is positively related to high-income farmers' willingness to cooperate in collective action $(0.245 ; \mathrm{P}=0.094<0.1)$. This result is consistent with Kemp-Benedict (2013), who contended that while social trust declines with rising income inequality, rising income is conducive to a higher level of social trust. The possible reason for this dynamic lies in the difference in trust type for low- and high-income farmers. As a general rule, low-income farmers mainly address family members, friends and the neighbours around them, which are defined as "special trust". High-income farmers have more widespread sources of networks, such as with agricultural organisations, village cadres and strangers, defined as "common trust". Also, high-income farmers have more resources to cope with failure and loss, which are the inherent risks of trust. The result of our tests related to interpersonal trust shows the existence of this chain of logic: high-income farmers have higher interpersonal trust, which leads to a higher willingness to cooperate.

Social reciprocity is more negatively associated with willingness to cooperate among middle-income farmers $(-0.256 ; \mathrm{P}=0.005<0.01)$ than among low-income farmers $(-0.172$; $\mathrm{P}=0.076<0.1)$. The $\mathrm{P}$ value is insignificant for the high-income farmers. This result can be explained by the fact that bounded reciprocity will satisfy low- and middle-income farmers' daily needs as they provide each other with assistance in agricultural tasks, such as mutual help during the harvesting season or building a house and so on. Therefore, due to their limited resources and short time preferences, low-income farmers are more inclined to disregard longterm benefits and reciprocate with those counterparts who can offer immediate give-and-take. Contrastingly, high-income farmers are more general reciprocal co-operators. Since their economic security is more realised, their motivation for pursuing long-term benefits is much higher compared to low-income farmers, as high-income farmers have "an incentive to acquire a reputation for keeping promises and performing actions with short-term costs but long-term net benefits" (Ostrom, 1998, p.12).

As a result of economic development, personal reciprocity is decreasing and being replaced by professional third parties. When farmers encounter harvesting or irrigation issues, they are more inclined to contact professional third parties to harvest or participate in cooperatives such as Water User Organisations to complete the agricultural task.

Social participation is more positively related to willingness to cooperate among middleincome farmers $(0.916 ; \mathrm{P}=0.01)$ compared to low- $(0.811 ; \mathrm{P}=0.01)$ and high-income farmers (0.807; $\mathrm{P}=0.01)$. An inverse U-shaped relationship was found among the different income groups. These results provide important insights into the importance of social participation for promoting opportunities for collective action. Three discrete findings emerged from this discovery. First, the benefit-cost ratio is the main consideration of middle- and low-income 
farmers. As atomised individuals, they are unable to bear the cost of the construction of smallscale irrigation facilities (between RMB 100,000 and RMB 200,000). Through joint participation, these costs are significantly reduced. Second, social participation brings certain social benefits like information and material resources. Furthermore, participating in public issues reduces the chance of being marginalised by community members, thus increasing the likelihood of social acceptance. Third, due to ubiquitous information asymmetry, participation in public affairs will strengthen the farmers' sense of involvement and empower them to supervise resource allocation and to organise operations better, in turn reducing the possibility of these aspects being controlled by the elite.

Overall, the multi-group analysis indicates a statistically significant difference between different income groups for integrating willingness to cooperate, due to farmers in different income groups placing emphasis on different social capital components. Farmers with low income pay more attention to social networks, social reciprocity and social participation. Medium-income farmers value social networks, social reciprocity and social participation, and high-income farmers emphasize interpersonal trust and social participation. The result indicates that social capital components are not equally distributed within the different income groups, or rather being an intangible capital, they also lack parity. In essence, the value of specific components of social capital depends on the farmers' socio-economic endowments, which are derived from their specific social structures and then employed to pursue their specific interests (Baker 1990, p. 619). As Ferragina (2010:75) points out, "individuals can exploit social capital of their networks to achieve private objectives".

\subsection{Discussion}

The study aims to address whether there are statistically significant differences between income groups when analysing the impact of social capital components on farmers' willingness to cooperate in irrigation collective action. The most important results demonstrate that membership of a specific income group affects the way in which farmers attach importance to social capital components and that these structural patterns in turn influence their willingness to cooperate. Therefore, collective action may possibly be enhanced in different ways by farmers of different income groups. This disparity can be explained by Tiewtoy et al. (2011), who addressed that farmers with their own identity are often motivated to use special components of social capital to maximize their personal benefits in a collective environment. In this regard, differences in income have leveraging effects that encourage farmers to allocate their social capital components in an efficient way. In general, the role of income groups in the 
willingness of farmers to cooperate lies in their income status, leading them to decide whether or not to invest in certain components of social capital. In other words, the willingness of farmers to cooperate is based on their economic endowments and each individual's goal to maximise their welfare at the lowest cost. On the other hand, because components of social capital exert diverse functions with regard to collective action, different social capital components to some extent simultaneously frame a favourable social structure that is conducive to successful collective action. Thus, when coupled with economic incentives to increase corn output, the willingness to cooperate is successfully integrated into the results of successful collective action.

Components of social capital influence collective action, but they influence it differently and even negatively when income differentials are at play. Evidence shows that low- and middle-income farmers highlight the importance of social networks, while high-income farmers do not. Interpersonal trust is positively related to high-income farmers, but not to low and middle-income farmers. This result is consistent with Jones (2004), who found that agricultural frontiers promote social trust in wealthy farmers during the initiation stage of cooperatives, but have negative impacts on the operation of collective action in the long run. Social reciprocity is negatively related to low- and middle-income farmers' willingness to cooperate, while it is not a significant feature for high-income farmers. This result can be explained by the fact that when encountering difficulties, disadvantaged farmers have short time horizons and focus on the daily give-and-take, while high-income farmers would sacrifice in the short-term for long-term benefits. This finding reflects that social capital also has a negative impact (Baron et al., 2000), which is a finding consistent with Adhikari \& Goldey (2010) and Field (2003), who studied the dark side of social capital. This result coincides with China's societal transformation and market-oriented economic reforms. Specifically, rural China has undergone a process in which it has changed from being a patriarchal society to new conditions where atomised individuals try to maximise their utilities through existing endowments, which include income, social-demographic conditions, social status and so on. Meanwhile, the transformation of society has accelerated the disparity between the different strata. Therefore, not all components of social capital are equally available. Farmers invest in those components of social capital that are most useful to their endowments and allow the farmers to make the most of them. This structuring has the potential to exceed the threshold of the positive aspects of social capital and contribute to the negative ones, leading to elite captures or clannish behaviours.

Finally, social capital and income differences have complex effects on farmers' willingness to cooperate. In this regard, our research provides an alternative way to understand 
the complex process involved in the formation of collective action under the presence of increasing economic heterogeneity in local communities. To quote Varughese and Ostrom (2001), "it is important to ask how these variables are embedded in situations that themselves vary substantially in regard to the benefit-cost calculus of those involved in negotiating and sustaining agreements". As a matter of fact, the success of collective action does not necessarily depend on possessing high levels of all the components of social capital. Rather, structural properties of social capital are key fundamentals for understanding the performances of cooperatives in transforming societies. Just as Crespo et al. (2014) contend, "hierarchical structure of social capital does not go against collective action since the presence of leading community members can be helpful for the diffusion of cooperative behaviours". Therefore, the structural properties between different components of social capital integrated into different income groups are collectively a key parameter for promoting willingness to cooperate.

\subsection{Conclusion and implications}

This article examines whether significant differences exist between farmers of different income groups in terms of social capital components and their willingness to cooperate in collective small-scale irrigation in the Guangling County, Shanxi Province of China. The results show that when different income groups are taken into the analysis, the influence of social capital components on farmers' willingness to cooperate depends on income differentials. Particularly, the study illuminates the role played by income inequality in forming social capital structural patterns. The probability of collective action relies on the availability of social capital structural properties, the degree of their distribution based on their specific endowments and the extent to which their structural properties favour the convergence of willingness.

In summary, our findings have important implications for understanding the black box of collective action initiation due to the different components of social capital and the effects they can have within a heterogeneous community. It is important to understand the role income differentials play in formulating social structures and attaining collective action. In this sense, the success of collective action largely relies on the social capital structural patterns formed based on the farmers' endowments, i.e. the income groups they belong to. The different patterns of interaction can complement each other, which then promote community adherence and thereby collective action. In short, studying social capital multiplicity and structural properties gives an insight into how to activate willingness to cooperate in collective action for farmers in varying income groups. In addition, the distribution and trade-off among different 
components of social capital embedded in social structures form the key for understanding the results of collective action. However, the degree to which hierarchy in income groups results in elite capture, in turn leading to the tragedy of commons, is as yet unknown.

There are also some limitations that may guide future work. First, the question of the optimal income gap still needs in-depth study. This paper simply conducts a cursory analysis which divides income level into low-income, middle-income and high-income. How to use quantitative analysis to measure income gap to an accurate degree still needs further study. Second, income heterogeneity is only one dimension of economic heterogeneity. Olson (1965) believes that economic heterogeneity includes multiple levels, such as wealth stock, asset size, income level and more. How to include different heterogeneities of economy into the analysis framework is therefore a direction for further study. Third, there are certain restrictions related to the sample size. Although concentrating on a sample in one area increases the representativeness of the research and eliminates the influence of different environmental factors, it also limits the scope of its application. Thus, local implementation of national policies requires a holistic and coherent framework suited to regional feature and economic conditions in order for water reforms to work synergistically. 


\section{References}

Adhikari, K, Goldey, P. 2010. Social capital and its "downside": the impact on sustainability of induced community-based organizations in Nepal. World Development, 38(2):184-194.

Agarwal, B. 1994. Gender and command over property: a critical gap in economic analysis and policy in South Asia. World Development, 22 (10): 1455-1478.

Ainsworth, J. 2002. Why does it take a village? The mediation of neighbourhood effects on educational achievement. Social Forces, 81(1): 117-152.

Ajzen, L., Fishbein, M. Understanding attitudes and predicting social behavior. Prentice-Hall, Englewood Cliffs, NJ, 1980.

Alesina A., Baqir R., Easterly W. 1999. Public goods and ethnic divisions. Quarterly Journal of Economics, 114(4): 1243-1284.

Alesina A., La Ferrara E. 2000. Participation in heterogeneous communities. Quarterly Journal of Economics, 115(3): 847-904.

Andersen, R., Fetner, T. 2008. Economic Inequality and Intolerance: Attitudes toward Homosexuality in 35 Democracies. American Journal of Political Science, 52(4): 942-958.

Bagozzi, R. P., Davis, F. D., Warshaw, P. R. 1992. Development and test of a theory of technological learning and usage. Human Relations, 45(7): 659-686.

Baker, W. 1990. Market networks and corporate behaviour. American Journal of Sociology, 96(3):589625.

Baland, J., Bowles, S., Bardhan, P. 2006. Inequality, Cooperation and Environmental Sustainability. Princeton, NJ: Princeton University Press.

Baland, J., Platteau, J. 1994. Halting Degradation of Natural Resources: Is There a Role for Rural Communities? Rome, FAO.

Baland, J-M., Platteau, J-P. 1997. Wealth inequality and efficiency in the commons: The unregulated case. Oxford Economic Papers, 49(4): 451-482.

Bardhan, P., Dayton-Johnson, J. 2002. Unequal Irrigators: Heterogeneity and Commons Management in Large-Scale Multi-variate Research. In E. Ostrom, T. Dietz, N. Dolsak, P. C. Stern, S. Stonich, \& E. U. Weber (Eds.), The Drama of the Commons (pp. 87-112). Washington, DC: National Academy Press.

Bardhan, P., Ghatak, M., Karaivanov, A. 2007. Wealth inequality and collective action. Journal of Public Economics, 91(9): 1843-1874.

Baron, S., Field, J., Schuller, T.(Eds.) Social Capital: Critical Perspective. Oxford: Oxford University Press, 2000.

Bergstrom, T., Blume, L., Varian, H. 1986. On the private provision of public goods. Journal of Public Economics, 29(1): 25-49.

Bharamappanavara, S.C., Hanisch, M., Rommel, J. 2016. The effect of heterogeneity and freedom of participation on collective action in rural self-help groups: Combining in-depth interviews with curve estimation. Journal of Mixed Methods Research, 10(2): 147-167. 
Bjørnskov, C. 2008. Social trust and fractionalization: A possible reinterpretation. European Sociological Review, 24 (3): 271-283.

Brehm, J., Rahn, W. 1997. Individual Level Evidence for the Causes and Consequences of Social Capital. American Journal of Political Science, 41 (3): 999-1023.

Coleman, J.S. 1988. Social capital in the creation of human capital. American Journal of Sociology, 94: S95-S120.

Coleman, J. 1990. Foundations of Social Theory. Cambridge, MA: The Belknap Press of Harvard University Press.

Cornes, R., Sandler, T. 1996. The Theory of Externalities, Public Goods and Club Goods. Cambridge: Cambridge University Press.

Cozzolino, P.J. 2011. Trust, cooperation, and equality: A psychological analysis of the formation of social capital. British Journal of Social Psychology, 50(2): 302-320.

Crespo, J., Requier-Desjardins, D., Vicente, J. 2014. Why can collective action fail in local Agri-food Systems? A Social Network Analysis of Cheese Producers in Aculco, Mexico. Food Policy, 46(6):165-177.

Dahal, G., Adhikari, K. 2008. Bridging, Linking and Bonding Social Capital in Collective Action: the case of Kalahan Forest Reserve in the Philippines. CAPRI Working Paper. No. 79.

Davis, F. 1989. Perceived usefulness, perceived ease-of-use, and user acceptance of information technology. MIS Quarterly, 13(3):319-340.

Davis, F., Bagozzi, R., Warshaw, P. 1989. User acceptance of computer technology: A comparison of two theoretical models. Management Science, 35(8):982-1003.

De Boer, W., Baquete, D. 1998. Natural resource use, crop damage, and attitudes of rural people in the vicinity of the Maputo Elephant Reserve, Mozambique. Environmental Conservation, 25(3): $208-218$.

Dufwenberg, M, Patel, A. 2017. Reciprocity networks and the participation problem. Games and Economic Behavior, 101(9):260-272.

Fei, X. 2012. From the Soil: The Foundation of Chinese Society. Foreign Study and Research Press.

Ferragina, E. 2010. Social capital and equality: Tocqueville's legacy: rethinking social capital in relation with income inequalities. The Tocqueville Society, 31(1):73-98.

Fiallo, E., Jacobson, S. 1995. Local Communities and Protected Areas: Attitudes of rural residents towards conservation and Machalilla National Park, Ecuador. Environmental Conservation, 22(3): 241-249.

Field, J. 2003. Social capital. London: Routledge.

Freitag, M., Bühlmann M., 2009. Crafting trust: The role of political institutions in comparative perspective. Comparative Political Studies, 42 (12): 1537-1566.

Fulkerson, G., Thompson, G. 2008. The evolution of a contested concept: A meta-analysis of social capital definitions and trends, 1988-2006. Sociological Inquiry, 78(4):536-57.

Gesthuizen, M., Sheepers, P., van der Veld, W., Volker, B. 2013. Structural aspects of social capital: 
Tests for cross-national equivalence in Europe. Quality \& Quantity, 47 (2): 909-922.

Gomez-Limon, J., Vera-Toscano, E., Garrido-Fernandez, F. 2014. Farmers' contribution to agricultural social capital: evidence from Southern Spain. Rural Sociology, 79(3): 380-410.

Grootaert, C. 1998. Social capital: the missing link? The World Bank, Social Capital Initiative Working Paper, Rep.No. 3 (unpubl.).

Grootaert, C. 2001. Does Social Capital help the Poor: A Synthesis findings from the Local Level institutions Studies in Bolivia. Burkina Faso and Indonesia----Local Level Institutions Working paper. No. 10, Washington DC: World Bank.

Habyarimana, J., Humphreys, M., Posner, D., Weinstein, J. 2009. Coethnicity: Diversity and the dilemmas of collective action. New York, NY: Russell Sage Foundation.

Heckathorn, D. 1993. Collective action and group heterogeneity: voluntary provision versus selective incentives. American Sociological Review, 58(3): 329-350.

Heinen, J. 1993. Park-people relations in Koshi Tappu Wildlife Reserve, Nepal: A socioeconomic analysis. Environmental Conservation, 20(1): 25-34.

Hooper, D., Coughlan, J., Mullen, M. 2008. Structural equation modelling: Guidelines for determining model fit. Electronic Journal of Business Research Methods, 6 (1):53-60.

Huisman, M., Oldehinkel, A. 2009. Income inequality, social capital and self-inflicted injury and violence-related mortality. Journal of Epidemiology and Community Health, 63(1): 31-37.

Infield, M. 1988. Attitudes of a rural community towards conservation and a local conservation area in Natal, South Africa. Biological Conservation, 45(1): 21-46.

Iskandar, A., Jusipbek, K., Herath, M., Kahramon, J. 2010. Water user groups in Central Asia: an emerging form of collective action in irrigation water management. Water Resources Management, 24(5): 1029-1043.

Ite, U. 1996. Community perceptions of the cross river national park, Nigeria. Environmental Conservation, 23(4): 351-357.

Jicha, K., Thompson, G., Fulkerson, G. May, J. 2011. Individual participation in collective action in the context of a Caribbean Island State: Testing the effects of multiple components of social capitals. Rural Sociology, 76(2): 229-256.

Johnson, J., Bardhan, P. 2002. Inequality and conservation on the local commons: A theoretical exercise. Economic Journal, 112:577-602.

Johnson, R., Libecap, G. 1982. Contracting problems and regulation: the case of the fishery. American Economic Review, 72 (5): 1005-1023.

Jones, E. 2004. Wealth-based trust and the development of collective action. World Development, 32(4): 691-711.

Jordan, J., Anil, B., Munasib, A. Community development and local social capital. Journal of Agricultural and Applied Economics, 2010(42): 143-159.

Kemp-Benedict, E. 2013. Inequality and trust: Test a mediating relationship for environmental sustainability. Sustainability, 5(2): 779-788. 
Koutsou, S., Partalidou, M., Ragkos, A. 2014. Young farmers' social capital in Greece: trust levels and collective actions. Journal of Rural Studies, 34(4):204-211.

La Ferrara, E. 2002. Inequality and group participation: Theory and evidence from rural Tanzania. Journal of Public Economics, 85(2):235-273.

Lancee, B., Van de Werfhorst, H.G. 2012. Income inequality and participation: A comparison of 24 European countries. Social Science Research, 41(5): 1166-1178.

Lanjouw, P., Murgai, R., Stern, N. 2013. Nonfarm diversification, poverty, economic mobility, and income inequality: a case study in village India. Agricultural Economics, 44(4-5): 461-473.

Letkia, N., Mierina, I. 2015. Getting support in polarized societies: Income, social networks, and socioeconomic context. Social Science Research, 49 (1): 217-233.

Liebe, U., Preisendörfer, P., Meyerhoff, J. 2010. To pay or not to pay: Competing theories to explain individuals' willingness to pay for public environmental goods. Environment and Behaviour, 43(1): 106-130.

Mehta, J., Heinen, J. 2001. Does community-based conservation shape favourable attitudes among locals? An empirical study from Nepal. Environ Manage, 28(2): 165-177.

Miao, S., Heijman, W., Zhu, X., Lu, Q. 2015. Social capital influences farmer participation in collective irrigation management in Shaanxi Province, China. China Agricultural Economic Review, 7(3): 448-466.

McHorney, C., Ware, J., Lu, J., Sherbourne, C. 1994. The MOS 36-item short form health survey (SF36): III. Tests of data quality, scaling assumptions and reliability across diverse patient groups. Medical Care, 32 (4): 40-66.

Michelini, J. 2013. Small farmers and social capital in developing projects: Lessons from failures in Argentina's rural periphery. Journal of Rural Studies, 30(4):99-109.

Molinas, J. 1998. The Impact of inequality, gender, external assistance and social Capital on local-level cooperation. World Development, 26(3): 413-431.

Munasib, A., Jordan, J. 2011. The effect of social capital on the choice of use sustainable agricultural practices. Journal of Agricultural and Applied Economics, 43(2): 213-227.

Newmark, W., Leonard, N., Sariko, H., Gamassa, D. 1993. Conservation attitudes of local people living adjacent to five protected areas in Tanzania. Biological Conservation, 63(2): 177-183.

Nie, R., Gao, Y., Chu, D. 2015. China's rural residents income distribution gap of time and space evolution-----based on Gini coefficient decomposition. Finance and Trade, 4: 20-28.

Nooteboom, B. 2007. Social capital, institutions and trust. Review of Social Economy, 65(1): 29-53.

Nunnaly, J. 1978. Psychometric Theory. McGraw-Hill, New York.

Olson, M. 1965. The Logic of Collective Action: Public Goods and the Theory of Groups. Cambridge, MA: Harvard University Press.

Ostrom, E. 1998. A behavioural approach to the rational choice theory of collective action: Presidential address, American Political Science Association, 1997. American Political Science Review, 92(1): 1-22. 
Ostrom, E., Ahn, T. 2007. The meaning of social capital and its link to collective action. In: Svendsen, T.G., Svendsen, L.G. (Eds.), Handbook on Social Capital. Elgar, E. 2008; Indiana University, Bloomington: School of Public \& Environmental Affairs Research Paper No. 2008-11-04.

Paraskevopoulos, C. 2010. Back to Basics in the Theory of Social Capital: Corruption, Inequity and Social Capital in the EU. In: Koniordos, S. (Ed.), Social Capital. Papazisi Publications, Athens, pp. 163-208.

Pichler, F., Wallace, C. 2008. Social capital and social class in Europe: The role of social networks in social stratification. European Sociological Review, 25(3): 319-332.

Pinheiro-Alves, R., Zambujal-Oliveira, J. 2012. The ease of doing business index as a tool for investment location decisions. Economics Letters, 117(1):66-70.

Putnam, R., Leonardi R., Nanetti, R. 1993. Making Democracy Work: Civic Traditions in Modern Italy. Princeton, NJ: Princeton University Press.

Putnam, R.1995. Bowling alone: American's declining social capital. Journal of Democracy, 6(1): 6578.

Putnam, R. 2000. Bowling Alone: The Collapse and Revival of American Community. Simmon \& Schuster Paperbacks, New York, NY.

Sabatini, F. 2009. Social capital as social networks: A new framework for measurement and an empirical analysis of its determinants and consequences. Journal of Socio-Economics, 38(3): 429-442.

Sarin, M. 1996. From Conflict to Collaboration: Institutional Issues in Community Management. In Poffenberger M \& McGean B. (Eds.), Village voices, forest choices: Joint forest management in India. New Delhi: Oxford University Press.

Schulman, M., Anderson, C. 1999. The dark side of the force: A case study of restructuring and social capital. Rural Sociology, 64(3):351-372.

Shibia, M. 2010. Determinants of attitudes and perceptions on resource use and management of Marsabit National Reserve, Kenya. Journal of Human Ecology, 30(1): 55-62.

Stallman, H., James, H. 2015. Determinants affecting farmers' willingness to cooperate to control pests. Ecological Economics, 117(9): 182-192.

Tang, J., Folmer, H., Xue, J. 2013. Estimation of awareness and perception of water scarcity among farmers in the Guanzhong Plain, China, by means of a Structural Equation model. Journal of Environmental Management, 126(9): 55-62.

Tessema, M. E., Lilieholm, R. J., Ashenafi, Z. T., Leader-Williams, N. 2010. Community attitudes toward wildlife and protected areas in Ethiopia. Society and Natural Resources, 23(6): 489-506.

Tiewtoy, S., Clemente, R., Perret, S., Singh Babel, M., Weesakul, S. 2011. Irrigation sustainability assessment of selected projects in Tha Chin Basin, Thailand. Irrigation and Drainage, 60(3): 296-307.

Uslaner, E., Brown, M. 2005. Inequality, trust, and civic engagement. American Politics Research, 33 (6): 868-894.

Varughese, G., Ostrom, E. 2001. The contested role of heterogeneity in collective action: some evidence 
from community forestry in Nepal. World Development, 29(5): 747-765.

Wilkinson, R., Pickett, K. 2009. The spirit level: Why more equal societies almost always do better. Allen Lane, London.

Woolcock, M. 1998. Social capital and economic development: toward a theoretical synthesis and policy framework. Theory and Society, 27(2): 151-208.

Zak, P., Knack, S. 2001. Trust and growth. Economic Journal, 111(470): 295-321.

Zhao, J., Liu, M. 2010. Relationship contribution to rural income gap and its regional differences----A decomposition based on regression analysis. Journal of Economics, (1): 363-387. 


\title{
CHAPTER 5
}

\section{Trust or Control? The Role of Group Size in Governing Small-scale Irrigation Facilities ${ }^{6}$}

\begin{abstract}
One of the key issues in collective action is whether stakeholders are able to realize commons governance through a trust-based mode or control-based mode of management. This paper examines whether trust and control modes of management affect collective action for small-scale irrigation facilities and how group size influences participation degree and cooperative performance in commons governance through trust and control mechanisms. The data were collected from 504 farmers who participated in the collective action for small-scale irrigation facilities in Shanxi, Gansu and Ningxia Province of Northwest China. The analysis was performed by structural equation modelling with Amos 23.0. The findings show that levels of control and trust in commons governance for smallscale irrigation facilities depend on group size. Both trust-based and control-based modes of management are significant in a small group, whereas only a control-based mode of management exerts effects in a big group. A combination of high trust and low control mechanisms in small groups of users is optimum for collective action in Northwest China. The theoretical contribution of this paper clarifies the mechanisms of how the contrasting force of group size exerted on trust and control directly and indirectly influences participation degree and cooperative performance in commons governance.
\end{abstract}

Key words: trust; control; group size; commons governance; collective action; smallscale irrigation facilities

${ }^{6}$ This chapter is based on:

Miao, S., Heijman, W, Zhu, X., Xu, Z., and Lu, Q., 2019. Trust or control? The role of group size in governing small-scale irrigation facilities Under review, Rural Sociology. 


\subsection{Introduction}

The agricultural sector plays a key role in sustainable development and livelihood support in the Loess Plateau region of Northwest China (Willey and Holm-Muller, 2013). However, soil degradation and erosion lead to farmland loss by one million mu per year and soil loss by 4.5 billion tons per year in China, which mainly have affected the Loess Plateau. Small holder farming in the Loess Plateau is characterized by frequent unevenly distributed droughts, thick loess covering and intensive tillage of farmlands, making irrigation one of the most effective ways for increasing agricultural production as well as enhancing farmers' livelihood. Therefore, collective action in irrigation management has been promoted for the successful operation of common-pool resource management (Meinzen-Dick et al., 2002). However, achieving sustainable operation of collective action has been a challenge over the recent decades due to governance challenges, which include deficient rules and regulations in use, a lack of conflict resolution mechanisms as well as a lack of trust among stakeholders. Normally, the restriction on endowments and incentives is the main obstacle for collective action. However, it is observed that even if the prerequisites for collective action are satisfied and collective action is initiated in the Loess Plateau, how to sustain it is still an unresolved issue. Therefore, commons governance of natural resource management among a resource-dependent population is of vital importance for the Loess Plateau.

The difficulty of successful commons governance lies in its need to integrate individuals' interests and demands, to manage common-pool resources and to understand the mechanisms that sustain continuous participation of individuals as well as realize cooperative performance. The sustainability of collective action also has been recognised as the area with potential threats such as the opportunistic behaviour of the participants. Just as Ostrom (2000) pointed out, a self-governing community utilises control rules, such as monitoring, graduated sanctions and conflict resolution mechanisms, to sustain collective action. Trust as the key component of social capital, is also considered to be a crucial element of commons governance (Lubell, 2007; Coleman 1990; Fukuyama, 1995; Putnam, 2001). Therefore, trust and control mechanisms are considered to be alternative routes for arriving at commons objective to which individuals oriented their behaviours.

In order to regulate and maintain collective action, control-based governance relies heavily on formal regulations, such as clearly defined rights and obligations, and legal agreements for resolving conflicts (Vandaele et al., 2007). Alternatively, trust-based governance depends mainly on informal norms rather than rigidly measured sanctions and rules to secure collective action (Poppo and Zenger, 2002). However, few studies address how both 
constructs relate to commons governance and its related issues in terms of similarities and differences between trust-based and control-based modes of commons governance (Costa and Bijlsma-Frankema, 2007). Consequently, the following question arises: What is the relationship between trust and control regarding the commons governance of collective action for small scale irrigation facilities? We argue that while considering the moderating role of group size in deciding the participation degree as well as the cooperative performance in commons governance, "the two concepts should be considered in parallel so that they may supplement or substitute each other in a special way-not merely in the restricted sense of being complementary or substitution to each other" (Grey and Teng, 1998).

Group size, which Olson (1965) has hypothesised as a crucial factor affecting collective action, has a role in deciding commons governance, but consensus has not been reached regarding its effect on the subject. Some scholars contend that "unless the number of individuals in a group is quite small[...], rational, self-interested individuals will not act to achieve their common or group interests" (Olson, 1965, P2; Baland and Platteau 1999, P773; Tang, 1992), while others argue that group size is positively associated with successful collective action (Marwell and Oliver 1993, P38). With regard to food safety, Naziri et al. (2014) found that there exists a U-shaped relationship between group size and farmers' collective action when considering the economies of scale and free-riding. Recent studies reveal that the effect of group size on collective action is usually mediated by other variables such as free-riding, institutions, technology, heterogeneity and degree of excludability (Wu et al., 2013; Ostrom, 1997; Poteete and Ostrom, 2004; Gautam, 2007). Little systematic research has addressed the role of group size in exerting trade-offs between trust-based and controlbased modes of management, especially concerning their substitutive or complementary relationship moderated by group size in deciding commons governance for small-scale irrigation facilities. Therefore, understanding how trust and control mechanisms influence the participation degree and the cooperative performance in commons governance, as well as the moderating role of group size plays, is not only interesting from a theoretical perspective but also a policy perspective. Our aim is thus to develop a comprehensive framework for integrating trust, control and commons governance to ascertain whether trust or control facilitates the participation degree and cooperative performance in commons governance and the role group size played in influencing the dynamics of trust and control. The rest of the paper is structured as follows: Section 2 illustrates the theoretical background and hypothesis, Section 3 describes the study area and data, Section 4 presents the empirical model and results, Section 5 comprises discussions, and Section 6 concludes and draws policy implications. 


\subsection{Theoretical background and hypothesis}

\subsubsection{Commons governance: a conceptualisation}

Commons governance (collaborative governance) could be defined as a "governing arrangement where one or more public agencies directly engage non-state stakeholders in a collective decision-making process that is formal, consensus-oriented, and deliberative and that aims to make or implement public policy or manage public programs or assets" (Ansell and Gash, 2008). In this sense, it is of utmost importance from the transaction cost perspective to compare other governance forms of market and hierarchy. Since collective action is aimed at achieving a consensus of the participants, what the multitude of research repeatedly addressed is the importance of institutional design in shaping incentive structures of commons governance. Meanwhile, how to harness the positive attributes of the social component, largely represented by trust, to help sustain collective action is highlighted by theorists (Fukuyama, 1995; Ostrom and Ahn, 2009). Although a common consensus is that trust or control can play a role in sustaining collective action, how to deliberately make trade-offs between trust and control mechanisms by institutional design to generate positive results in collective action? It is a distinct avenue since it is a big challenge to alter incentive structures and promote stakeholders' participation in commons governance.

Due to the diversity of local contexts and their associated physical and biological resources, the tools for successful collective action in common pool resource management depend on the tentative dynamics of trust and control, as well as how either or both of them work independently or jointly to achieve consensus-oriented commons governance. Trustbased or control-based governance, reflects the use of selective incentive to "reward those who cooperate in the action or punish those who do not" (Oliver, 1980). However, how rewards and punishments generate different dynamics to sustain collective action relies on the costs induced by the number of people who cooperate. Therefore, an initiative is needed to explore the role that trust and control play in achieving commons governance by embedding group size (number of people who cooperate) into given macro-political institutional, cultural and economic circumstances. In order to obtain insight into the mechanisms responsible, it will be necessary to examine how trust and control mechanisms as modes of management in local contexts to form certain governance structure for small-scale irrigation facilities.

\subsubsection{Dimensionalizing commons governance as process and outcome}

Commons governance consists of two dimensions: (1) the process of collective action, in 
terms of the participation degree, it reflects the level of participants' contribution of cash, labour, meeting and training participation in collective action, and (2) the outcome of collective action, in terms of the efficiency, sustainability and equity of the overall cooperative performance. Compared to the traditional way of using binary membership decision (participation or not participation) as the indicator to reflect farmers' participation, employing indicators of farmers' contribution intensity will be more conducive for understanding the degree of farmers' participation (Fischer and Qaim, 2014). Therefore, a combination of process and outcome dimensions is more salient in interpreting trust and control mechanisms in commons governance.

Participation degree can be viewed as a process of commons governance since it includes a series of decision-making processes with regard to in-kind, cash, training and meeting contributions and engagement. In this process, the contribution level and engagement intensity reflect the values, norms and managerial practices that participants invest in collective action. More specifically, the existence of a trust-based mode and control-based mode of management influences the participation degree. The point is how to embed these modes of governance to alter the incentive structure so that commons governance could be realized by an increasing degree of participation (Rydin and Pennington, 2000). Thus, the proposition can be speculated as the higher the degree of participation, the better the prospects for cooperative performance.

Cooperative performance refers to the institutional arrangement evaluated by commons governance using criteria from efficiency, sustainability and equity perspectives (Ostrom et al., 2002). The improvement of the environment is recruited to reflect the sustainability criterion because commons governance not only increases the continuous extraction of natural resource but also modifies the environment conditions. Equity criteria are used to evaluate the costbenefit ratios participants contributed and derived from the collective action for small-scale irrigation facilities. Efficiency criteria focus on both economic and social benefits, i.e. the participants' welfare, that an institutional arrangement can improve. Since it includes a series of indicators, such as water availability, soil and water quality, irrigated outputs and the prices, management and maintenance of irrigation facilities, which is difficult to evaluate objectively, a satisfaction level is employed to reflect the efficiency of the commons governance.

\subsubsection{Trust and control in determining commons governance}

Common pool resources could be protected from opportunistic behaviours if a series of modes of management could be successfully manipulated. Trust and control mechanisms are recognized as the principal antecedents for facilitating participation in collective action in commons governance (Bijlsma-Frankema and Costa, 2005; Edelenbos and Eshuis, 2012). The 
mechanism lies in that trust and control can reduce possible shirking or free-riding behaviours from inside and outside respectively. Since trust and control are two alternative mechanisms in engendering collective action, the tentative and fickle nature of its combination suggests that either one by itself is insufficient to understand the mechanisms of achieving collective action ( Emsley and Kidon, 2007).

Trust is generally recognized as a main determinant for the success of commons governance. According to Rousseau (1998), trust is a "psychological state comprising the intention to accept vulnerability based on positive expectations of the intentions or the behaviour of another." Because of the multidimensional nature of trust, it can be divided into goodwill trust, competence trust (Barber, 1983; Ring and Van, 1992), fragile trust, resilient trust (Ring, 1996), deterrence-based trust, knowledge-based trust and identification-based trust (Sheppard and Tuchknsky, 1996). Since trust essentially encompasses individual and relational elements, we divide trust based on the "trustor's" and "trustee's" characteristics and features, including indicators of decision making, issue lending and trustworthiness toward others.

Control refers to "a regulatory process by which the elements of a system are made more predictable through the establishment of standards in the pursuit of some objective or state (Leifer and Mills, 1996)". In this way, control plays the role of checking and monitoring in order to ensure that collective action is oriented towards consensus objectives. Control can be classified as formal control or informal control. It can be further divided into behaviour control, output control and social control (Ouchi and Maguire, 1975; Ouchi, 1979), or it can be sort into external measure-based control or internal value-based control (Eisenhardt, 1985). Based on Ostrom's (1986) Institutional Analysis and Development (IAD) Framework, control addresses the importance of monitoring, graduated sanctions and conflict resolution mechanisms. In our study, we focus on the "establishment and utilization of formal rules, procedures, and policies to monitor and reward desirable performance" in our study (Costa and Bijsma-frankema, 2007).

The relationship between trust and control in deciding the commons governance is highly controversial not only because the relationship between trust and control contingent upon the contexts and the type of control, which can be either complementary or substitutive (Das and Teng, 2001), but also because the commons governance is a dynamic process that collective action cannot be simultaneously reached without the interaction among these constructs. A consensus has been reached, deciding that each construct of trust or control is conducive to achieving oriented objectives for collective action in commons governance (Luhmann, 1979; Nooteboom, 2002). However, how the mechanisms of trust and control exert jointly in achieving commons governance needs to be carefully examined. Some argue that trust and 
control are opposing alternatives for achieving a common goal in collective action because high trust offsets the great expense on control and vice versa (Dekker, 2004), while some others maintain that trust and control are mutually reinforced and complementarily promote the expected collective success (Sitkin and Roth, 1993; Bijlsma-Frankema and Costa, 2005). Although numerous studies have evaluated the relationship between trust and control, since a certain level of trust is a prerequisite for any cooperation and trust could be the lubricant for the control measures, we will test whether trust itself will enhance the control or not and vice versa. More specifically, the moderating role of group size is considered in our case.

\subsubsection{The role of group size in commons governance}

Group size has been widely recognised to influence the prospects for collective action (Poteete and Ostrom, 2004). However, it plays a controversial role in commons governance. Olson (1965) contended that the size of a group is negatively associated with collective action, whereas Esteban and Ray (2001) argued that group size is positively associated with collective action considering the lobbying costs. The debate on the negative, positive, curvilinear or nonsignificant effect of group size has not attained consensus until now. The complex relationship between group size and collective action can be generalised from two aspects. On one hand, when group size increases, control measures are strengthened to reduce free riding, while the trust among members declines. On the other hand, small groups have more chances for frequent interactions and have higher possibilities for building mutual trust, while having high costs to initiate control measures due to lack of resource (Agrawal and Goyal, 2001). In this regard, 'only focusing on group size itself without considering factors that influence or are influenced by group size will lead to biased conclusions'(Yang et al., 2013).

When studying collective action, many other variables will also vary as group size changes (Chamberlin, 1974). Just as Ostrom (2000) pointed out, "the key question affecting the likelihood of self-organised solutions is whether the views of the multiple groups concerning the structure of the resource, authority, interpretations of rules, trust differs or are similar". How to strike a tentative balance to realise collective action for small-scale irrigation facilities is the focal point for this case. Given a particular resource condition, trust is easily enforced in small groups to promote collective action, while control is easily enforced in large groups to reduce possibilities of free-riding or shirking behaviours. Therefore, we build our theoretical framework based on commons governance theory to explore how the contrasting force of group size exerted on trust and control directly and indirectly influences farmers participation and cooperative performance. Figure 5.1 shows the theoretical framework how dynamics of trust and control influence commons governance by incorporating group size. 


\subsubsection{Hypothesis}

The decision to participate in collective action for small-scale irrigation facilities, in essence, is a process of cost-benefit analysis considering trust and control as positive and negative incentive respectively. The general assumptions of hypothesis are: (1) every individual has the freedom choices of participating or not participating in collective action (The analysis is based on individual level); (2) the payoff from every decision is the function of $\mathrm{k}$ (the number of individuals who cooperate); (3) positive incentive (trust) and negative incentive (control) are equally valued by potential co-operators, $\mathrm{Mk}=\mathrm{M}(\mathrm{n}-\mathrm{k}), \mathrm{R}=\mathrm{N}=\mathrm{M}, \mathrm{M}$ means cooperation realized conditionally, it holds only in the case of $k=1 / 2 n$.

Based on the work of Schelling (1973) and Oliver (1980), G(m) and C(m) means the gains and costs of $\mathrm{m}$ individuals who participate in collective action. $\mathrm{R}$ means the value of positive incentive (in our case, trust) for individuals who participate in collective action, and $\mathrm{N}$ means the value of negative incentive (in our case, control) for individuals who do not participate in collective action. $\mathrm{k}$ means the number of people who cooperate, and $\mathrm{p}_{\mathrm{k}}$ means the probability that $\mathrm{k}$ equals some particular value of $\mathrm{k}$, and $\mathrm{n}$ means group size. Then the value of positive incentives (trust) could be expressed as:

$$
R=E(c)-\sum_{k=0}^{n-1} G(k+1) p_{k}+\sum_{k=0}^{n-1} c(k+1) p_{k}
$$

the value of negative incentive (control) is expressed as:

$$
N=\sum_{k=0}^{n-1} G(n-k) p_{k}-E(d)
$$

$$
R>N \text {, that is } R-N>0 \text {, then }
$$

$$
R-N=\sum_{k=0}^{n-1} c(k+1) p_{k}-\sum_{k=o}^{n-1}(k+1) p_{k}-\sum_{k=0}^{n-1} G(n-k) p_{k}+\lfloor E(c)+E(d)\rfloor
$$

Then,

If $\sum_{k=0}^{n-1} G(n-k) p_{k}+\lfloor E(c)+E(d)\rfloor>\sum_{k=0}^{n-1} c(k+1) p_{k}-\sum_{k=o}^{n-1}(k+1) p_{k}, R-N<$ 0 , therefore, $k<\frac{1}{2} n$ holds.

If $\sum_{k=0}^{n-1} G(n-k) p_{k}+\lfloor E(c)+E(d)\rfloor<\sum_{k=0}^{n-1} c(k+1) p_{k}-\sum_{k=o}^{n-1}(k+1) p_{k}, R-N>$ 0 , Therefore, $k>\frac{1}{2} n$ holds.

Therefore, we propose the hypothesis as follows:

Hypothesis 1: The selection of trust and/or control to promote participation in commons governance is based on the relative costs enforced in different group size.

Hypothesis 2: When $\mathrm{k}<1 / 2 \mathrm{n}$, the gain of positive incentive is higher than the cost of negative incentive, so trust (positive incentive) is more effective in small group size, and 
when $k>1 / 2 n$, the gain of positive incentive is lower than the cost of negative incentive, so control (negative incentive) is more effective in big group size.

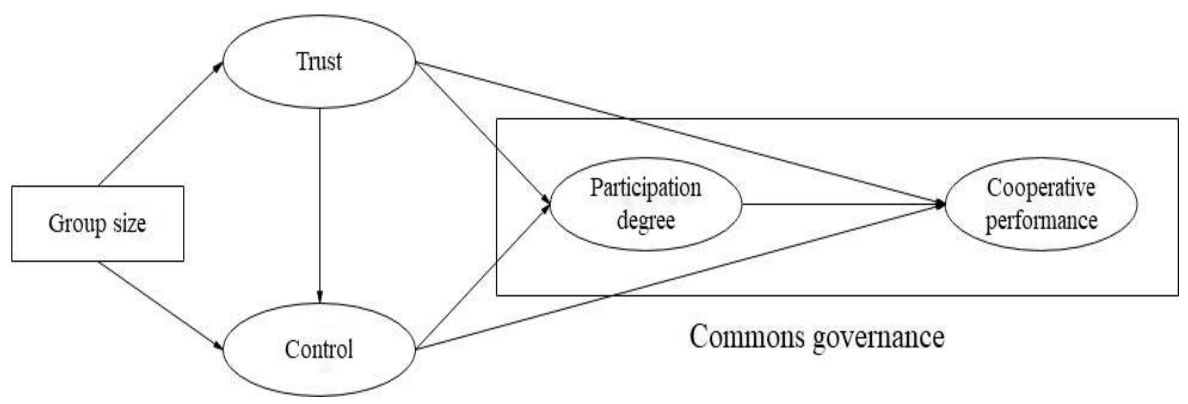

Figure 5.1 Theoretical model for commons governance for small-scale irrigation facilities

\subsection{Methodology}

\subsubsection{Data and research context}

We carried out the survey in areas with collective action for small-scale irrigation facilities, including Yulin districts of Shaanxi Province, Qingyang Districts of Gansu Province and Guyuan Districts of Ningxia Province in northwest China between October and December in 2016. A multistage stratified sampling method was employed to select Suide County, Mizhi County and Yuyang Zones in Shaanxi Province, Xifeng District and Huan County in Gansu Province as well as Pengyang County, Xiji County and Yuanzhou District in Ningxia Province as the investigation units. 10-15 villages were then randomly selected, and 10-15 farmers were randomly selected in each village, which resulted in 900 member households being interviewed. Due to incomplete information, 47 out of the 900 were removed from the sample. We also excluded 349 households since they did not participate in collective action for smallscale irrigation facilities. Accordingly, there were 504 participating farmers, from which 192 households are located in Shaanxi Province, 134 households in Gansu Province and 178 households in Ningxia Province. The total sample data include information on demographics, economic conditions, social capital indicators, and commons governance conditions as well as other issues affecting the process and outcomes of commons governance.

The survey area is the hilly-gully areas of the Loess Plateau, which has the world's highest soil erosion rates and is ecologically highly fragile. Centuries of unsustainable farming 
practices combined with huge population pressures have led to severe environmental degradation. The survey area is characterised by the typical continental monsoon climate. The precipitation is not evenly distributed over seasons and over years. July and September account for $60-80 \%$ of the annual precipitation, while only $5 \%$ is accounted for in winter. Crops planted in the surveyed areas include corns, potatoes, paddy rice, alfalfa, vegetables and fruits (grapes, medlar, jujube, etc.). Surface and underground irrigation are commonly used within the surveyed area. Normally, two rounds of irrigation last from May to June in spring and from July to late August in autumn.

Collective action for small-scale irrigation facilities is organized in three ways, namely water user organisations, contracts between rural households and individuals as well as village council cooperatives. These organisations can be very different in size from 10 households to 500 households. The irrigation water delivery order is based on the sequence of irrigation fee paid. Irrigation expenses include water and electricity charges and maintenance fees. The irrigation fee for underground irrigation is around 30-50 yuan RMB per hour. The surface irrigation fee is 130-150 yuan RMB per hectare. However, conflicts may occur because of delivery order, water availability, delayed payments and unclear expenditures.

Monitoring is carried out from time to time not only to prevent free-riding but also to check for canal leaking or pump malfunctions. Free-riding is not the main threat of collective action because of irrigation technology (underground irrigation pipelines are directed to the slots of farmland), mutual-monitoring (for surface irrigation) and cost-benefit analysis. For the farmers who do violate the rules and regulations, the penalty will be an oral warning for the first time, followed by a fine or being forbidden to participate in the next round irrigation. The most serious punishment would be being excluded from collective action. In general, the collective action for small-scale irrigation facilities is organized in a loose form of control.

\subsubsection{Variables}

Group size is generally acknowledged to influence the different modes of management (trust-based and control-based) and thus the prospects for collective action in a negative or positive way (Poteete and Ostrom, 2004). Just as Ostrom (2005) pointed out, not considering the other factors that interacted with group size will lead to biased estimation. In a small group size, mutual trust can be easily built up by frequent interactions and offers a higher possibility of homogeneous interests (Agrawal and Gibson, 1999, 2001). Whereas when group size increases, the cost of communication, monitoring and punishment for free-riding rises drastically, and frequent interactions are thus reduced, which is detrimental to collective action. On the other hand, large groups with more available resources to mobilize collective action are 
inclined to initiate control measures, such as monitoring, sanctions and conflict resolution mechanisms to reduce opportunistic behaviour (Yang et al., 2013).

Trust is one of the most important factors to influence the process and outcome of commons governance (Ostrom, 2000; Tsai and Ghoshal, 1998), and a higher level of trust leads to a higher propensity for collective action (Miao et al. 2015). Since trust functions to increase interactions among members and to reduce transaction costs in cooperatives, it is expected that trust can affect not only the participation degree but also the cooperative performance in the commons governance. Based on Mayer et al. (1995) who considered the relationship between trustors and trustees, we measured participants' trust using the answers to the questions: "Are the people around you trustworthy?" and "What is the frequency you lend things to others?" to reflect the trustor's good-will and positive expectations to others. The answer to "When people have important affairs to decide on, how often they ask you for suggestions?" reflects the trustworthiness of trustees. However, the role trust plays in sustaining collective action depends on how trust as a variable keeps the tentative equilibrium with control that is embedded in the structure of governance.

Besides trust, control plays the role of regulating and monitoring collective action to ensure effective commons governance. Normally, formal control can be divided into control of behaviours and outcomes. According to Ostrom (1986), we measure behaviour control by indicating the way of monitoring free-riding behaviour ("How many people are responsible for supervision") and the ways of punishing free-riders ("How many ways are there to punish freeridings", and "The severity degree of regulation forced"). More precisely, monitoring is perceived as a crucial factor of formal control since it gives the chance to detect the violation of rules and regulations (Bijlsma-Frankema and Costa, 2005). Some scholars found that control is conducive to cooperation since a credible threat can be executed by the enforcement of rules and regulations (Yan and Gray, 1994; Bijlsma-Frankema and Costa, 2005; Kumar and Seth, 1998). Others maintain that control may also exert negative effects on the cooperation since participants' opportunistic behaviour is positively associated with control measures (Provan and Skinner, 1989).

We consider two key dimensions of commons governance according to its process and outcome, namely the participation degree and cooperative performance. The participation degree can be a reflection of the smooth implementation of collective action, and cooperative performance demonstrates the results of collective action (Rich, 1980 a, b; Henig, 1982; Smith, 1981). Based on the field survey, the form of participation in the collective action for smallscale irrigation facilities includes money contribution, labour contribution, training and meeting participation. The more farmers contributed and participated in the collective action, 
the higher possibility of cooperative performance could be improved. Therefore, we expect that the participation degree is positively related to cooperative performance.

Cooperative performance reflects management outcomes, including indicators such as the quality (efficiency) of services, the viability of institutions as well as positive externalities from collective action. Therefore, to indicate the cooperative performance we select the indicators "the perception of costs and benefits" for the efficiency of services, "satisfaction level with commons governance" for the viability of the institution and "local ecological environment improvement" for the externality of the commons governance. In order to guarantee the sustainability of commons governance, trust-based and control-based modes of management are executed to promote the participation of farmers. In this process, a virtuous circle will be formed in which better cooperative performance can be attained with more participation in collective action.

\subsection{Structural equation model}

Structural Equation Modelling (SEM) is a multivariate statistical technique that is a hybrid of a measurement model and a structural model. Thus, the relationship between latent variables and observed variables can be explored by employing path analysis and multiple regression analysis. For our study, a Structural Equation Model has specific merits in that it creates a control variable to estimate how the opposing effects of group size exert on trust and control and simultaneously estimates the measurement model to obtain the regression equations. It can also estimate the paths of trust and control affecting the commons governance directly and indirectly. Therefore, the Structural Equation Model is employed to analyse the role of group size in commons governance by controlling factors of trust and control. The Structural Equation Model (see Miao et al., 2018) is represented as follows:

$$
\begin{gathered}
y=\Lambda_{y} \eta+\varepsilon \\
x=\Lambda_{x} \xi+\delta \\
\eta=B \eta+\Gamma \xi+\zeta
\end{gathered}
$$

Where $y$ is a $p \times 1$ vector of the endogenous observed variables, including the perception of local ecological environment improvement, the perception of benefits and costs as well as the satisfaction level with commons governance. $x$ is a $q \times 1$ vector of exogenous predictors or observed variables, i.e. group size. $\eta$ is a $m \times 1$ random vector of latent endogenous variables that are represented by participation degree and cooperative performance, and $\xi$ is a 
$n \times 1$ vector of latent exogenous variables, including trust and control. $\Lambda_{y}$ is a $p \times m$ matrix of the coefficients (or loadings) of the relationship between $y$ and $\eta . \Lambda_{x}$ is a $q \times n$ matrix of the coefficients (or loadings) of the regressions of $x$ on $\xi$. $\mathcal{E}$ and $\delta$ are $p \times 1$ and $q \times 1$ vectors of the measurement errors of $y$ and $x$ respectively. $B$ is a $m \times m$ matrix of coefficients of the $\eta$ variables in the structural model. $\Gamma$ is a $m \times n$ matrix of coefficients of $\xi$ in the structural model, it represents the effects of trust and control on commons governance. $\zeta$ is a $m \times m$ vector of random disturbances.

We estimate SEM in four steps. First, confirmatory factor analysis was recruited to estimate the measurement quality of constructs such that factor loadings were significant and greater than 0.6. The results of this step demonstrate the convergent validity of the selected indicators. The second step was to evaluate the measurement and structural model to reflect the relationship between latent and observable variables. AMOS 23.0 analysis was performed to analyse the relationship between trust and control in commons governance. Third, we used the bootstrapping method to test the mediating effects of farmers' participation degree. Finally, goodness-of-fit indices for the model were assessed to complete the structural model evaluation.

\subsection{Empirical analysis}

\subsubsection{Descriptive statistics}

In order to clarify the moderating effects of group size on trust and control and to test whether the mediating effect of trust and control on commons governance is direct or mediated by farmers' participation degree, the statistics reliability and validity test were employed. All models tested included five variables: group size, trust, control, farmers' participation degree and cooperative performance. Since trust and control are not directly observable, we used observed indicators to represent these two exogenous latent variables. The descriptive statistics of the observed indicators and all exogenous, endogenous and control variables are shown in Table 5.1. 
Table 5.1 Descriptive statistics of observed indicators, exogenous, endogenous and control variables

\begin{tabular}{|c|c|c|c|c|c|}
\hline Variables & Observable indicators & S.D. & Mean & Min. & Max. \\
\hline \multicolumn{6}{|c|}{ Exogenous variables } \\
\hline \multicolumn{6}{|l|}{ Trust } \\
\hline 1 & $\begin{array}{l}\text { When people have important affairs to decide, how often } \\
\text { do they ask you for suggestion? ( } 1 \text { =never; } \\
2=\text { occasionally; } 3=\text { sometimes; } 4=\text { frequently; } 5=\text { always })\end{array}$ & .9563 & 3.8393 & 1 & 5 \\
\hline 2 & $\begin{array}{l}\text { How often do you lend things to others? (The same as } \\
\text { above) }\end{array}$ & .8480 & 4.0238 & 1 & 5 \\
\hline 3 & $\begin{array}{l}\text { Are the people around you trustworthy? (The same as } \\
\text { above) }\end{array}$ & 1.2014 & 3.5000 & 1 & 5 \\
\hline \multicolumn{6}{|l|}{ Control } \\
\hline 4 & $\begin{array}{l}\text { How many ways are there to punish free-ridings?(based } \\
\text { on the number of real punishment measures taken, such } \\
\text { as impose a fine, labour punishment, irrigation control or } \\
\text { exit sanction) }\end{array}$ & .8135 & 1.7143 & 1 & 4 \\
\hline 5 & $\begin{array}{l}\text { How many people are responsible for supervision? }(1=1- \\
3 \text { people } 2=4-6 \text { people; } 3=7-9 \text { people; } 4=10-12 \text { people; } \\
5=13 \text { or more })\end{array}$ & .7811 & 1.7639 & 1 & 4 \\
\hline 6 & $\begin{array}{l}\text { When conflicts arise, what is the severity of the } \\
\text { regulation enforced? }(1=\text { very low; } 2=\text { below average; } 3= \\
\text { average; } 4=\text { above average; } 5=\text { very high })\end{array}$ & .8022 & 1.8095 & 1 & 4 \\
\hline \multicolumn{6}{|c|}{ Endogenous variables } \\
\hline \multicolumn{6}{|c|}{ Participation degree } \\
\hline 7 & $\begin{array}{l}\text { Money contribution to cooperatives }(1-200 \mathrm{RMB}=1,201- \\
400=2,401-700=3,701-1000=4,1001=5)\end{array}$ & 1.0495 & 2.8393 & 1 & 5 \\
\hline 8 & $\begin{array}{l}\text { Labour contribution }(1=0-1 \text { time a year, } 2=2-3 \text { times, } \\
3=4-5 \text { times, } 4=6-7 \text { times, } 5=\text { above } 8 \text { times })\end{array}$ & 1.1548 & 3.2004 & 1 & 5 \\
\hline 9 & Frequency of meeting participation (same as above). & 1.1060 & 3.6151 & 1 & 5 \\
\hline 10 & Frequency of training participation (same as above) & 1.1579 & 3.3948 & 1 & 5 \\
\hline \multicolumn{6}{|c|}{ Cooperative performance } \\
\hline 11 & $\begin{array}{l}\text { Perception of benefits and costs }(1=\text { very dissatisfied; } \\
2=\text { dissatisfied; } 3=\text { neither dissatisfied nor satisfied; } \\
\text { 4=satisfied; } 5=\text { very satisfied })\end{array}$ & 1.1964 & 3.5060 & 1 & 5 \\
\hline 12 & $\begin{array}{l}\text { Satisfaction level with commons governance (same as } \\
\text { above) }\end{array}$ & 1.2257 & 3.9325 & 1 & 5 \\
\hline 13 & $\begin{array}{l}\text { Perception of local ecological environment improvement } \\
\text { (same as above) }\end{array}$ & 1.3248 & 3.9524 & 1 & 5 \\
\hline \multicolumn{6}{|c|}{ Control variables } \\
\hline Group size & $\begin{array}{l}\text { Number of Households in cooperative organization }(1-30 \\
\text { households }=1,31-50 \text { households }=2,51-100 \\
\text { households }=3,101-200 \text { households }=4 \text {, above } 201 \\
\text { households }=5)\end{array}$ & 1.5238 & 3.0040 & 1 & 5 \\
\hline
\end{tabular}


Table 5.1 presents the statistics of the observed variables. Based on the definition in Section 2, trust is measured by the following indicators: (1) When people have important affairs to decide, how often do they ask you for suggestions? (2) How often do you lend things to others and (3) Are the people around you trustworthy? All trust indicators are coded on a 5point scale, specifically from never to always.

Indicators that corresponds to the control measures including: (4) How many ways are there to punish free-riding? (5) How many people are responsible for supervision? (6) When conflicts arise, what is the severity of the regulation enforced? Indicator (4) Is a numerical variable based on the real punishment measures such as impose a fine, labour punishment, irrigation control or exit sanction. These spectrum scales can capture the theoretical notion that more punishment imposed, more strict of the control measures. Indicator (5) that takes the value 1 if the respondent replies "one to three", 2 if the reply is "four to six", 3 if the reply is "seven to nine", 4 if the reply is "ten and twelve" and 5 if the reply is "thirteen or more", questions that tap respondents belief are with more people involved in supervision, the control will be more tightly. Indicators (6) are defined as categorical measures on a 5-point scale from very low to very high.

Participation degree is measured by the following indicators: (7) money contribution to cooperatives; (8) labour contribution to cooperatives; (9) frequency of meeting participation and (10) frequency of training participation. Indicator (7) takes value 1 if the respondent replies to "1-200 RMB", 2 if the reply is "201-400", 3 if the reply is "401-700" 4 if the reply is "7011000 " and 5 if the reply is "above 1001 RMB". Indicator (8) takes the value 1 if the respondent contributes to " $0-1$ time a year", 2 if the reply is " $2-3$ times", 3 if the reply is " $4-5$ times", 4 if the reply is "6-7 times" and 5 if the reply is more than 8 times. (9) and (10) take the same categorization method.

Commons governance is measured by the following indicators: (11) perception of benefits and costs; (12) satisfaction level with commons governance and (13) perception of local ecological environment improvement. Indicators are measured on a 5-point scale from strongly disagree to strongly agree.

The group size is measured by a 5-point scale takes value 1 if the reply is 1-30 households, 2 if the reply is 31-50 households, 3 if the reply is 51-100 households, 4 if the reply is 101-200 households and 5 if the reply is over 201 households and more.

\subsubsection{Empirical results of estimated SEM}

To test the model fit, we used a reliability test (internal consistency test) and a validity test (convergent validity and discriminant validity). Cronbach's alpha reliability test was performed 
to evaluate the measurement model fit (Table 5.2), which indicates a fairly good result of the whole model (0.669). Normally, a cut-off value above 0.7 is ideal for internal consistency. For the four constructs that are illustrated in the previous section, the value lies between 0.6990.850 (trust $=0.699$, control $=0.829$, farmers' participation degree $=0.850$, cooperative performance $=0.825$ ), indicating acceptable reliabilities for the construct measurements. Moreover, the approximate statistics value of $\chi^{2}$ in the Bartlett test being 2572.407, the results of the KMO test being 0.748 and the significant coefficient of $\mathrm{Sig}=0.000<0.01$ indicate high reliability of the model fit. Finally, convergent validity and discriminant validity were evaluated based on the average variance extracted (AVE) and composite reliability (CR). As shown in Table 5.2, almost all values of AVE above 0.5 and of CR above 0.7 are confirmed for the good validity of the latent constructs, except for trust, for which the AVE is contingent on the limit of this threshold.

Table 5.2 Estimation results of the measurement model

\begin{tabular}{|c|c|c|c|c|c|}
\hline Construct & Indicators & Coefficient & Cronbach's alpha & AVE & Critical Ratio \\
\hline \multirow{3}{*}{ Trust } & Trust 1 & 0.638 & \multirow{3}{*}{0.699} & \multirow{3}{*}{0.458} & \multirow{3}{*}{0.716} \\
\hline & Trust 2 & 0.730 & & & \\
\hline & Trust 3 & 0.658 & & & \\
\hline \multirow{3}{*}{ Control } & Control 1 & 0.727 & \multirow{3}{*}{0.829} & \multirow{3}{*}{0.624} & \multirow{3}{*}{0.832} \\
\hline & Control 2 & 0.858 & & & \\
\hline & Control 3 & 0.779 & & & \\
\hline \multirow{4}{*}{$\begin{array}{l}\text { Participation } \\
\text { degree }\end{array}$} & Participation 1 & 0.638 & \multirow{4}{*}{0.850} & \multirow{4}{*}{0.596} & \multirow{4}{*}{0.853} \\
\hline & Participation 2 & 0.839 & & & \\
\hline & Participation 3 & 0.728 & & & \\
\hline & Participation 4 & 0.862 & & & \\
\hline \multirow{3}{*}{$\begin{array}{l}\text { Cooperative } \\
\text { performance }\end{array}$} & Effect 1 & 0.704 & \multirow{3}{*}{0.825} & \multirow{3}{*}{0.632} & \multirow{3}{*}{0.835} \\
\hline & Effect 2 & 0.934 & & & \\
\hline & Effect 3 & 0.727 & & & \\
\hline
\end{tabular}

Common method bias (CMB) happens when variations in responses are caused by the instrument rather than the actual predispositions of the respondents that the instrument attempts to uncover (Podsakoff et al., 2012). Therefore, an anonymous questionnaire was designed to change the questionnaire sequence to perform process control and avoid the common method 
bias effect. Moreover, Harman's single factor model was employed to test whether common method bias existed. All items (measuring latent variables) were loaded into one common factor (four distinct factors with an eigenvalue greater than 1.0), and the total variance for the first single factor accounts for $25.75 \%$ of variance which is less than $50 \%$. Therefore, a consensus can be reached that common method bias does not affect the results.

The goodness-of-fit indices and the chi-squared test were executed to measure the overall model fit. The model fit is validated by using $\chi^{2}$ (237.897, CMIN/DF=3.399), the root-meansquare error of approximation (0.069, RMSEA), the goodness of fit index (0.934, GFI), the adjusted goodness-of-fit index (0.900, AGFI) and the comparative fit index (0.935, CFI). Due to the sensitivity of $\chi^{2}$ to the sample size, CMIN/DF is deemed acceptable. Based on the recommended cut-off criteria for RMSEA (0.1), GFI and CFI (greater than 0.8) (Hooper et al. 2008), the model and data indicate a reasonably fair fit.

A mediation test was conducted to evaluate step-by-step the partially or completely mediated effects. Table 5.3 and Figure 5.2 demonstrate the direct, indirect and total effects of trust and control on participation degree and cooperative performance as well as the moderating role of group size. Direct effects are the pathway estimates of a construct that link trust and control to participation degree, group size to trust and control as well as participation degree to cooperative performance. "Indirect effects are calculated by multiplying the pathway estimates of the significant intervening process" (Turner, 1983), for example multiplying the pathway estimate of control on participation degree by the pathway estimate of participation degree on cooperative performance. Total effects are the summation of direct and indirect effects. 
Table 5.3 Total, direct and indirect effects of SEM

\begin{tabular}{|c|c|c|c|c|c|}
\hline & Group size & Trust & Control & $\begin{array}{l}\text { Participation } \\
\text { degree }\end{array}$ & $\begin{array}{l}\text { Cooperative } \\
\text { performance }\end{array}$ \\
\hline \multicolumn{6}{|l|}{ Total effects } \\
\hline Trust & $\begin{array}{l}-.069 * * \\
(0.024)\end{array}$ & & & & \\
\hline Control & $\begin{array}{l}.051 * * \\
(0.021)\end{array}$ & $\begin{array}{l}.014 \\
(0.069)\end{array}$ & & & \\
\hline $\begin{array}{l}\text { Participation } \\
\text { degree }\end{array}$ & $\begin{array}{l}-.050 * * * \\
(0.016)\end{array}$ & $\begin{array}{l}.371 * * * \\
(0.088)\end{array}$ & $\begin{array}{l}-.471 * * * \\
(0.080)\end{array}$ & & \\
\hline $\begin{array}{l}\text { Cooperative } \\
\text { performance }\end{array}$ & $\begin{array}{l}-.021 * * * \\
(0.012) \\
\end{array}$ & $\begin{array}{l}.242^{* * * *} \\
(0.099) \\
\end{array}$ & $\begin{array}{l}-.084 \\
(0.085)\end{array}$ & $\begin{array}{l}.150^{* * *} \\
(0.062)\end{array}$ & \\
\hline \multicolumn{6}{|l|}{ Direct effects } \\
\hline Trust & $\begin{array}{l}-.069 * * \\
(0.024)\end{array}$ & & & & \\
\hline Control & $\begin{array}{l}.052^{* * *} \\
(0.022)\end{array}$ & & & & \\
\hline $\begin{array}{l}\text { Participation } \\
\text { degree }\end{array}$ & & $\begin{array}{l}.378 * * * \\
(0.086)\end{array}$ & $\begin{array}{l}-.471 * * * \\
(0.080)\end{array}$ & & \\
\hline $\begin{array}{l}\text { Cooperative } \\
\text { performance }\end{array}$ & & $\begin{array}{l}.187 \\
(0.103)\end{array}$ & $\begin{array}{l}-.014 \\
(0.087)\end{array}$ & $\begin{array}{l}.150 * * \\
(0.062)\end{array}$ & \\
\hline \multicolumn{6}{|c|}{ Indirect effects } \\
\hline \multicolumn{6}{|l|}{ Trust } \\
\hline Control & $\begin{array}{l}-0.01 \\
(.005)\end{array}$ & & & & \\
\hline $\begin{array}{l}\text { Participation } \\
\text { degree }\end{array}$ & $\begin{array}{l}-0.050^{* * * *} \\
(.016)\end{array}$ & $\begin{array}{l}-0.007 \\
(.033)\end{array}$ & & & \\
\hline $\begin{array}{l}\text { Cooperative } \\
\text { performance }\end{array}$ & $\begin{array}{l}-0.021 * * * \\
(.012)\end{array}$ & $\begin{array}{l}0.055^{* * *} * \\
(.027)\end{array}$ & $\begin{array}{l}-0.070 * * \\
(.033)\end{array}$ & & \\
\hline
\end{tabular}

${ }^{*} p<.05, * * p<.01$ and ${ }^{* * *} p<.001$ using a two-tailed $t$-test. Standard errors are reported in parentheses.

Group size negatively and directly affects trust $(-0.069, \mathrm{P}<0.05)$, whereas it positively and significantly influences control $(0.051, \mathrm{P}<0.05)$. It reveals that trust is decreased with group size increased, since intrinsic material value and social approval originated from these incentives declined with the number of people who shared them. Control is increased with group size becomes larger, since control measures are cost-effective in big group size where potential defection is high. Therefore, the total effect of group size is predisposed by the dynamics of two contrasting force, trust and control. Group size also exerts indirect effects on participation degree $(-0.050, \mathrm{P}<0.01)$ as well as cooperative performance $(-0.021, \mathrm{P}<0.01)$. The direct and indirect effects of group size influence participation degree and cooperative 
performance through trust and control mechanisms support, highlighting the importance of group size in deciding the selection of trust and/or control mechanisms in commons governance.

Trust has not only direct positive effects $(0.378, \mathrm{P}<0.01)$ on participation degree but also indirect positive impacts on cooperative performance via participation degree $(0.055, \mathrm{P}<0.01)$. In general, the total effect of trust on the commons governance (both participation degree $(0.371, \mathrm{P}<0.01)$ and cooperative performance $(0.242, \mathrm{P}<0.01))$ is positive and significant. It demonstrates that trust can promote co-operators to have higher participation degree and cooperative performance, since collective action for small-scale irrigation facilities needs high fixed costs to initiate and low marginal costs to utilise as positive incentive for sustainability. The trust-based mechanisms that promote voluntary cooperation are also widely recognised (Bijlsma-frankema and Costa, 2005). The mediation analysis demonstrates that participation degree partially mediates the relationship between trust and cooperative performance.

Control has direct effects on the participation degree $(-0.471, \mathrm{P}<0.01)$ and indirect effects on cooperative performance $(-0.07, \mathrm{P}<0.05)$. In general, it exerts mediation effects on cooperative performance. Our empirical results verify the previous studies the notion that when control is increased, farmers may exercise pronounced restraint in their participation degree (Baldvinsdottir et al., 2011; Baldvinsdottir and Johansson, 2005; Tomkins, 2001). That is because control belongs to a kind of negative incentive, it is only exerted on those who do not cooperate. In this regard, the cost of using a negative selective incentive is normally a decreasing function of benefits for the participants who cooperate (Oliver, 1980), the need for negative incentives to be executed is not high in totally cooperative circumstances. However, our findings are contrary to Ostrom (1990), who contended that without strict and effective institutions and regulations (similar to control), common pool resources would be overexploited. This discrepancy can be explained by the fact that in contrast to the hierarchical relationships used to dominate in the age of collective economy, cooperatives that mobilise the enforcement of rules and regulations are transferred to a more horizontal type (Sheppard and Tuschinsky, 1996). Moreover, the decision to free-ride is a cost-benefit analysis, and social pressure plays an institutional role for farmers to self-discipline.

Participation degree is positively and directly associated with cooperative performance $(0.15, \mathrm{P}<0.05)$. It implies that participation degree is closely related to cooperative performance in commons governance. This relation can be explained by social identity theory, which states that participation in collective action can strengthen one's sense to be identified and accepted by the group members and make more contributions to efforts and participation. Thus, the cooperative performance could be enhanced when participation degree increased with proper 
trust and control mechanisms. Therefore, the conceptualisation of commons governance into process and outcome dimensions adds significantly explanatory power to the understanding of commons governance.

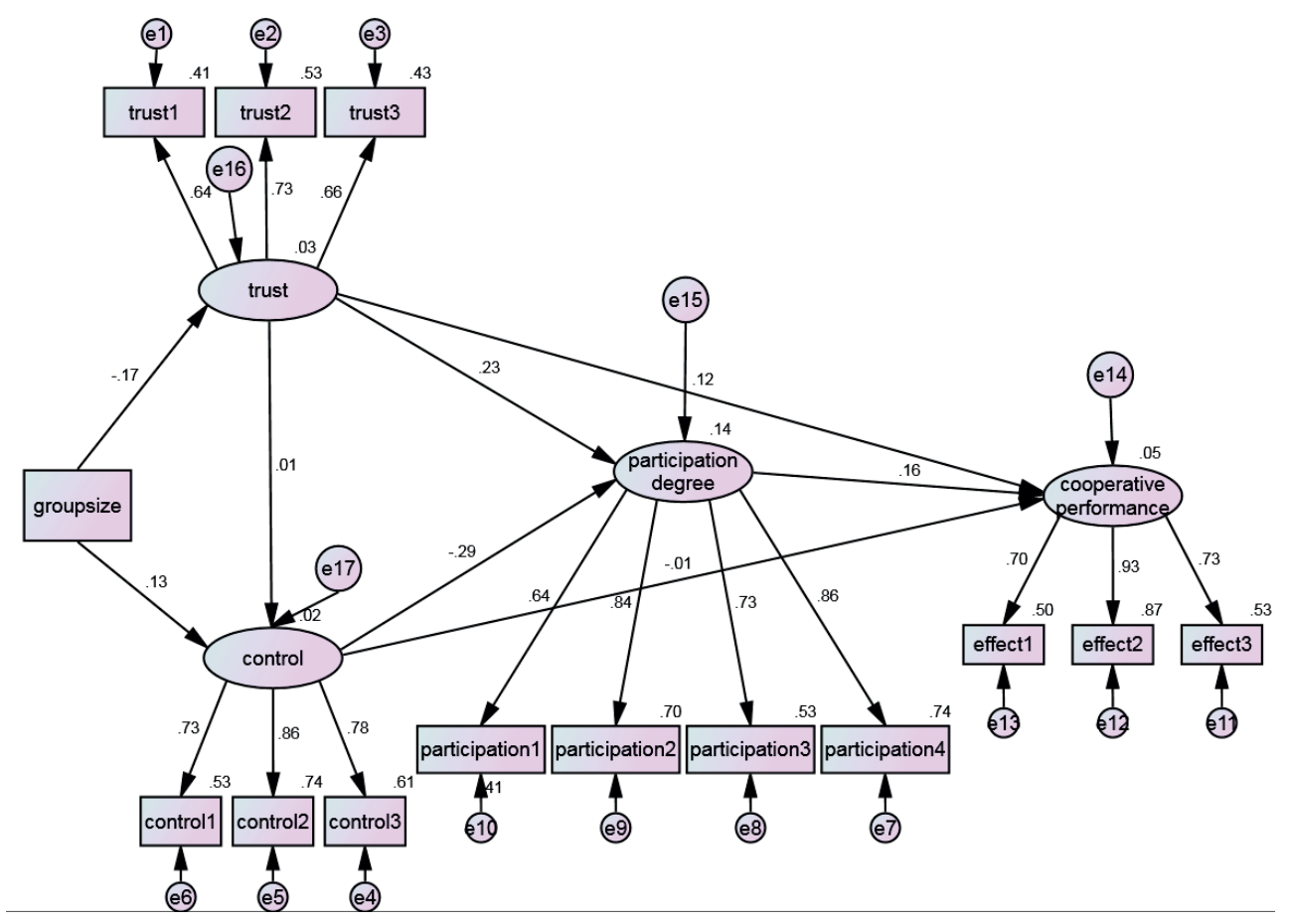

Figure 5.2 The empirical results of SEM model

\subsubsection{The moderating effects of group size}

This study tested the moderating effect of group size on the relationship between trust and control as well as commons governance. We employ the multi-group analysis of the Structural Equation Model to explore structural variances across the different group sizes. The sample was divided into small groups and large groups based on the number of cooperatives. Cooperatives that have 80 or more members are classified as a big group, and the others are small groups. Then, we built a default model and test model to examine whether there exists significant difference between big groups and small groups. The result demonstrates that $\mathrm{P}=0.03$, so the null hypothesis is rejected. Therefore, moderating effects can be verified. 
Table 5.4 Moderating effects of group size in Multi-group analysis

\begin{tabular}{|c|c|c|c|c|}
\hline \multirow{2}{*}{$\begin{array}{c}\text { The relationship between group size and trust or control, trust } \\
\text { or control and participation degree, and group size and } \\
\text { participation degree }\end{array}$} & \multicolumn{2}{|c|}{ Small group } & \multicolumn{2}{|c|}{ Big group } \\
\hline & Coefficient & C.R. & Coefficient & C.R. \\
\hline Group size------------------trust & $-0.241^{* * *}$ & -3.871 & 0.010 & 0.202 \\
\hline Group size----------------control & $0.083^{*}$ & 1.782 & $0.117^{*}$ & 1.936 \\
\hline Trust-------participation degree & $0.248^{* * * *}$ & 2.614 & 0.187 & 1.055 \\
\hline Control----participation degree & $-0.369^{* * *}$ & -3.207 & $-0.479^{* * * *}$ & -3.991 \\
\hline Group size-participation degree & $-0.422^{* * *}$ & -5.507 & -0.064 & -0.704 \\
\hline
\end{tabular}

Note: The C.R. (Critical Ratio) value is the value of t. *,** and *** represent the significance under the levels of $10 \%$, $5 \%$ and $1 \%$ respectively.

The findings demonstrate that the direction and magnitude of the association between trust and participation degree as well as control and participation degree are significantly different across small and big groups (see Table 5.4). For small group sizes, trust and control exert contrasting effects simultaneously on participation degree. Namely, trust is positively related to participation degree $(0.248, \mathrm{P}<0.01)$, while control is negatively associated with participation degree $(-0.369, \mathrm{P}<0.01)$. For big group sizes, only control is negatively related to participation degree $(-0.479, \mathrm{P}<0.01)$. Trust exerts no effects within big groups. This is also verified by Warsen et al. (2019) who contended that "if trust is lacking, other mechanisms have to be inserted to manage uncertainty in the project". The path coefficients that describe the relationship between trust and participation degree as well as control and participation degree were significantly different between big groups and small groups. Therefore, hypothesis 1 is supported.

We tried to explore the whole mechanism of the relationships among group size, trust, control and participation degree. In small groups, trust and control are contrasting forces exerted via group size to influence participation degree. In big groups, only control exerts a contrasting force between group size and participation degree. This result demonstrates that as group size increases, control replaces trust to be the main mode of management. The transformation from the trust-based mode of management in small groups to control-based mode of management lies in the difference in cost related to the number of participants in the collective action, i.e. group size. A positive incentive (trust) is cheaper when a small group cooperates $(\mathrm{k}<1 / 2 \mathrm{n}, \mathrm{k}$ is the number of people who actually cooperate, $\mathrm{n}$ is the group size), and a negative incentive (control) is cheaper when a large group cooperates $(k>1 / 2 n)($ Oliver, 1980). Therefore, Hypothesis 2 is supported. 


\subsection{Discussion}

Our starting point was the debate "trust or control? which is the best mechanism for crafting commons governance in collective action for small-scale irrigation facilities", in order to answer this question, we therefore proposed an integrative framework of trust, control and participation degree as well as cooperative performance in commons governance. On the whole, the framework demonstrates that trust and control are parallel constructs to govern collective action for small-scale irrigation facilities. However, they influence participation degree as well as cooperative performance in a different way. The mediating role of participation degree is identified in cooperative performance of overall commons governance. Despite flourishing trust and control research in organizational economics, trust and control mechanisms remain a puzzle in the domain of collective action, especially the role of group size in exerting effects on trust and control is unexplored, and this raises question whether the relationship between trust \& control and commons governance is moderated by group size. We also examined the moderating effect of group size on both participation degree and cooperative performance by controlling for the potential contrasting force of trust and control.

The first key finding is that our research reveals pathway how trust and control mechanisms directly or indirectly affect participation degree and cooperative performance in commons governance for small-scale irrigation facilities. That is, trust exerts both direct and indirect positive effects on cooperative performance via participation degree, whereas control only exerts negative and indirect effects on cooperative performance. This finding resonates with Mizrachi et al. (2007), who contend that trust and control are "alternative mechanisms for absorbing uncertainty and reducing risk". Our study contributes to irrigation management literature by clarifying both of trust and control modes of management are necessary for achieving successful commons governance. Moreover, other combinations (high control and low trust, high trust and high control, low trust and low control) may also possible to be explored to deepen the knowledge of causal pathways and mechanisms to form a good match in commons governance based on different local contexts.

The second notable result is that different from previous studies that mainly concentrate on the relationship between trust and control itself, our study contributes to the literature by addressing the moderating role of group size in exerting opposing effects between trust and control. Our finding indicates that whether trust and control mechanisms are substitute or complement depends on the group size. That is, small group requires commons governance to be based both on trust and control, commons governance in big group size to be based exclusively on control. Therefore, trust and control were found to be alternative routines that 
are discretionarily selected based on the scale (group size) of the cooperatives. Since an "optimal combination of trust and control mechanism depends on their respective cost" (Das and Teng, 1998), Trust, a positive incentive, is particularly efficient for motivating collective action in small groups, while control, a negative incentive, is more capable when in big groups potential defectors are numerous enough to threaten the sustainability of collective action. In general, the selective incentive based on group size is important for sustaining commons governance.

The third noteworthy finding is that a combination of high trust and low control mechanism is optimum by small group users for commons governance. It demonstrates a decentralisation trend of irrigation management from high-control and low-trust modes to a high-trust and low-control management style. Because these modes of management could greatly reduce transaction cost as well as information asymmetry. Therefore, how to design local institutions based on appropriate technology strategies is critical to sustaining commons governance for small-scale irrigation facilities (Goebel, 1999). Moreover, our study verifies Olson's (1965) research that participation and cooperative performance decrease with the group size increases. Specifically, our empirical results modify his conclusions that selective incentive should be discretionarily chosen based on different group size. Therefore, irrigation cooperatives tend to utilize both modes of management (i.e., trust and control act as complements) rather than one or another (i.e., trust and control act as substitutes) to sustain commons governance, concerning for the complexity of human and natural systems (Lamothe and Lamothe, 2011; Wu et al., 2013). Finally, commons governance, divided into the dimensions of participation degree and cooperative performance, is more salient in terms of exploring the mechanisms of how trust and control mechanisms that have a direct and total effect. In this sense, user participation and shared management responsibilities are the trend in common pool resource management.

\subsection{Conclusions and policy implications}

Our study explored the effects of group size on trust and control mechanisms in commons governance for small-scale irrigation facilities in the Loess Plateau of Northwest China. We first constructed a theoretical framework to conceptualise the three-set relationship between trust, control and commons governance. Then we tested the mediating effects of participation degree on cooperative performance in commons governance. Finally, we conducted a multigroup analysis to test the moderating effects group size exerts on the trust and control 
mechanisms as well as on the participation degree. Empirical results indicate that trust and control exert opposing effects directly and indirectly mediated by participation degree towards achieving commons governance. In essence, "any form of management is about managing people, with the explicit or implicit aim to alter the incentive structure of those people (Richter, 2011)". Therefore, successful commons governance depends on how trust and control mechanisms interact in certain group size to alter people's incentives for achieving desired behaviours.

This study sheds lights on the role of group size by controlling for the contrasting force of trust and control mechanisms in sustaining commons governance for small-scale irrigation facilities. Three policy implications can be put forward: Firstly, all groups of different sizes can promote participants to contribute by discretionarily selecting a combination of trust and control mechanisms for forming governance structures as selective incentives. We suggest that group size effects could be altered by investing in social capital among villagers, enhancing monitoring and graduated sanctions or improving conflict resolution mechanisms. Secondly, the commons governance for small-scale irrigation facilities could benefit from efforts to encourage participation, namely contributing more labour and money or taking more training and meetings. Pursuing these benefits would have implications on common pool resource management policies in the rural areas of China, in that more emphasis should be put on strengthening public participation to enhance the effects of commons governance.

Finally, our study is based on cross-sectional data, although it allows us to observe the field area in-depth, we cannot control for time-invariant unobserved characteristics of irrigation systems, for example, the change of management mechanisms. For future studies recruiting panel data are therefore recommended to explore and compare short-term effects and long-term effects of policy implications. In addition, Sustainable commons governance encourages strategies to improve commons governance by calibrating trust and/or control mechanisms based on the group size and devising rules that fit the local contexts. Our findings would help further elucidate the mechanisms by which farmers are encouraged to participate in collective action. These findings have potential implications beyond the scope of collective action for small-scale irrigation facilities as trust and control are basic modes of management in any organization. A similar dynamic should also exist in voluntary organizations, charity groups and social movements. 


\section{References}

Agrawal, A., Gibson, C.C. 1999. Enchantment and disenchantment: the role of community in natural resource conservation. World Development, 27(4): 629-649.

Agrawal, A., Goyal, S. 2001. Group size and collective action: Third-party monitoring in common-pool resources. Comparative Political Studies, 34(1): 63-93.

Agrawal, A., Gibson, C.C. 2001. Communities and the Environment: Ethnicity, Gender, and the State in Community-based Conservation, Rutgers University Press.

Ansell, C., Gash, A. 2008. Collaborative governance in theory and practice. Journal of Public Administration Research and Theory, 18 (4): 543-571.

Baldvinsdottir, G., Hagberg, A., Johansson, I., Jonäll, K., Marton, J. 2011. Accounting research and trust: A literature review. Qualitative Research in Accounting \& Management, 8(4): 382-424.

Baldvinsdottir, G., Johansson, I. 2005. Crush the crisis with actions, accounts and accounting. In S. Jönsson, \& J. Mouritsen (Eds.). Accounting in Scandinavia-The northern lights, 3(18):243-262.

Barber, B. 1983. The Logic and Limits of Trust. New Brunswick. NJ: Rutgers University Press.

Baron, R.M., Kenny, D.A. 1986. The moderator-mediator variable distinction in social psychological research: conceptual, strategic and statistical considerations. Journal of Personality and Social Psychology, 51(6):1173-1182.

Bijlsma-Frankema, K., Costa, A.C. 2005. Understanding the trust-control nexus. International Sociology, 20(3):259-282.

Chamberlin, J. 1974. Provision of collective goods as a function of group size. American Political Science Review, 68(2):707-716.

Coleman, J. 1990. Foundations of Social Theory. Cambridge. MA: Harvard University Press.

Costa, C., Bijlsma-Frankema, K. 2007. Trust and control interrelatedness: new perspectives on the trustcontrol nexus in organizational relations. Group and Organization Management, 32(4):392-406.

Crona, B., Gelcich, S., Bodin, Ö. 2017. The importance of interplay between leadership and social capital in shaping outcomes of rights-based fisheries governance. World Development, 91(2): $70-83$.

Das, T.K., Teng, B.S. 1998. Between trust and control: developing confidence in partner cooperation in alliances. Academy of Management Review, 23(3): 491-512.

Das, T.K., Teng, B.S. 2001. Trust, control, and risk in strategic alliances: an integrated framework. Organization Studies, 22(2): 251-283.

Dekker, H.C. 2004. Control of inter-organizational relationships: evidence on appropriation concerns and coordination requirements. Accounting, Organizations and Society, 29(1): 27-49.

Edelenbos, J., Eshuis, J. 2012. The interplay between trust and control in governance processes: A conceptual and empirical investigation. Administration \& Society, 44(6):647-74.

Eisenhardt, K. 1985. Control: Organizational and economic approaches. Management Science, 31(2):134-49.

Fischer, E., Qaim, M. 2014. Smallholder farmers and collective action: what determines the intensity 
of participation? Journal of Agricultural Economics, 65(3):683-702.

Flanagin, A.J., Stohl, C., Bimber, B. 2006. Modelling the structure of collective action. Communication Monographs, 73 (1): 29-54.

Fukuyama, F. 1995. Trust. New York: Free Press.

Gautam, A.P. 2007. Group size, heterogeneity and collective action outcomes: evidence from community forestry in Nepal. International Journal of Sustainable Development \& World Ecology, 14(6): 574-583.

Henig, J.R. 1982. Neighbourhood response to gentrification: conditions of mobilization. Urban Affairs Quarterly, 17(12):343-58.

Kumar, S., Seth, A. 1998. The design of coordination and control mechanisms for managing joint venture-parent relationships. Strategic Management Journal, 21(19):579-599.

Leifer, R., Mills, P.K. 1996. An information processing approach for deciding upon control strategies and reducing control loss in emerging organizations. Journal of Management, 22(1): 113-137.

Lubell, M. 2007. Familiarity breeds trust: collective action in a policy domain. The Journal of Politics, 69(1):237-250.

Luhmann, N. 1979. Trust and Power. New York: John Wiley.

Mayer, R.C., Davis, J. H., Schoorman, F.D. 1995. An integrative model of organizational trust. Academy of Management Review, 20(3): 709-734.

Meinzen-Dick, R., Raju, K.V., Gulati, A. 2002. What affects organization and collective action for managing resources? Evidence from canal irrigation systems in India. World Development, 30(4): 649-666.

Miao, S., Heijman, W., Zhu, X.Q., Lu, Q. 2015. Social capital influences farmer participation in collective irrigation management in Shaanxi Province, China. China Agricultural Economic Review, 7 (3): 448-466.

Miao, S., Heijman, W, Zhu, X., Qiao, D., Lu, Q. 2018. Income groups, social capital, and collective action on small-scale irrigation facilities: a multigroup analysis based on a structural equation model. Rural Sociology, 83 (4): 882-911.

Naziri, D., Aubert, M., Codron, J.M., Loc, N.T.T., Moustier, P. 2014. Estimating the impact of smallscale farmer collective action on food safety: the case of vegetables in Vietnam. Journal of Development Studies, 50(5): 715-730.

Nooteboom, B. 2002. Trust: Forms, Foundations, Functions, Failures and Figures. Cheltenham, UK: Edward Elgar.

Oliver, P. 1980. Rewards and punishments as selective incentives for collective action: theoretical investigations. American Journal of Sociology, 85(6):1356-1375.

Ostrom, E. 1986. An agenda for the study of institutions. Public Choice, 48 (1): 3-25.

Ostrom, E. 1990. Governing the Commons: The Evolution of Institutions for Collective Action. Cambridge University Press, New York, USA.

Ostrom, E. 2000. Collective action and the evolution of social norms. Journal of Economic Perspectives, 
14(1):137-158.

Ostrom, E. 2000. Reformulating the commons. Swiss Political Science Review, 6(1):29-52.

Ostrom, E. 2005. Understanding Institutional Diversity. Princeton University Press. Princeton, NJ.

Ostrom, E., Dietz, T.E., Dolšak, N.E, Stern, P.C., Stonich, S.E. 2002. The Drama of the Commons. National Academy Press.

Ostrom, E., Ahn, T. 2009. The meaning of social capital and its link to collective action. Handbook of social capital: The Troika of Sociology. Political Science and Economics, 17-35.

Ouchi, W.G. 1979. A Conceptual Framework for the Design of Organizational Control Mechanisms. In Readings in Accounting for Management Control, pp. 63-82. Springer, Boston, MA.

Ouchi, W.G., Maguire, M.A. 1975. Organizational control: two functions. Administrative Science Quarterly, 12 (1): 559-569.

Podsakoff, P.M., MacKenzie, S.B., Podsakoff, N.P. 2012. Sources of method bias in social science research and recommendations on how to control it. Annual Review of Psychology, 63(1):539569.

Poteete, A.R., Ostrom, E. 2004. Heterogeneity, group size and collective action: the role of institutions in forest management. Development and Change, 35(3):435-461.

Provan, K., Skinner, S. 1989. Inter-organizational dependence and control as predictors of opportunism in dealer-supplier relations. Academy of Management Journal, 32(12): 202-212.

Putnam, R. 2001. Bowling Alone: The Collapse and Revival of American Community. New York: Simon and Schuster.

Rich, C.R. 1980a. A Political-economy approach to the study of neighbourhood Organizations. American Journal of Political Science, 24(4): 559-592.

Rich, C.R. 1980b. The dynamics of leadership in neighbourhood organizations. Social Science Quarterly, 60(4):570-587.

Richter, A. 2011. The coevolution of renewable resources and institutions----Implications for policy design. Wageningen University Dissertation.

Ring, P.S., Van de Ven, A.H. 1992. Structuring cooperative relationship between organizations. Strategic Management Journal, 13(7):483-498.

Ring, S. 1996. Fragile and resilient trust and their roles in economics exchange. Business \& Society, 35(1):148-175

Rousseau, D.M., Sitkin, S.B., Burt, R.S., Camerer, C. 1998. Not so different after all: across-discipline view of trust. Academy of Management Review, 23(3):393-404.

Ruttan, L. M. 2008. Economic heterogeneity and the commons: Effects on collective action and collective goods provisioning. World Development, 36(5): 969-985.

Rydin, Y., Pennington, M. 2000. Public participation and local environmental planning: the collective action problem and the potential of social capital. Local Environment, 5(2):153-169.

Sheppard, B., Tuchinsky, M. 1996. Micro-OB and the Network Organization in Trust in Organization: Frontiers of Theory and Research. Roderick M. Kramer and Tom R. Tyler(eds.), 31(12): 140- 
165.

Sitkin, B.S., Roth, N.L. 1993. Explaining the limited effectiveness of legalistic "remedies" for trust/distrust. Organization Science, 4(3):367-392.

Smith, H.D. 1981. Altruism, volunteers, and volunteerism. Journal of Voluntary Action Research, 10(1): 21-36.

Tomkins, C. 2001. Interdependencies, trust and information in relationships, alliances and networks. Accounting, Organizations and Society, 26(2): 161-191.

Tsai, W., Ghoshal, S. 1998. Social capital and value creation: The role of intrafirm networks. Academy of Management Journal, 41(4):469-476.

Turner, R.J. 1983. Direct, Indirect, and Moderating Effects of Social Support on Psychological Distress and Associated Conditions. In Psychosocial stress (pp. 105-155).

Yang, W., Liu, W., Viña, A., Tuanmu, M.N., He, G., Dietz, T., Liu, J. 2013. Nonlinear effects of group size on collective action and resource outcomes. Proceedings of the National Academy of Sciences, 110 (27): 10916-10921.

Yan, A., Gray, B. 1994. Bargaining power, management control, and performance in United StatesChina joint ventures: A Comparative Case Study. Academy of Management Journal, 37(6):1478-1517.

Yu, H.H., Edmunds, M., Lora-Wainwright, A., Thomas, D. 2016. Governance of the irrigation commons under integrated water resources management----A comparative study in contemporary rural China. Environmental Science \& Policy, 55(1): 65-74. 


\section{CHAPTER 6}

\section{Synthesis}

\subsection{Introduction}

Water is crucial for agricultural production and rural livelihood, especially in the Northwest China where irrigation farming is smallholders' main income source. Due to market failure and government malfunction, collective action for small-scale irrigation facilities is a viable choice for local users. It requires commons governance by different stakeholders, especially local users who directly use these resources and concern its sustainability (Araral, 2009). However, with the fast urbanisation and economic development, economic heterogeneity leads to difficulties in integrating farmers' demands and preferences in achieving consensus in collective action. The social transformation from an acquaintance society to an atomised society also poses a great challenge for nurturing and cultivating social capital, which is an important prerequisite of collective action.

A wealth of literature have demonstrated that local communities can overcome social dilemmas and successfully initiate and sustain common pool resource management (Chaudhry, 2018; Yu et al., 2016; Joshi and Jooja, 2000; Lam, 1999; Tang, 1992; Ostrom, 1990). Many factors have been identified to influence collective action, such as local contexts, group size, heterogeneity, resource size, and proximity to market (McCord et al., 2018; Reyes-Garcia et al., 2011; Adger, 2010; Poteete and Ostrom, 2004). However, one of the key factors, the role of social capital in influencing collective action has not reached any consensus. Because the definition of social capital is not unified, which components should be incorporated into social capital multi-dimensionality is not ascertained. More importantly, although the positive effects of social capital on collective action has been widely accepted by the academia, the negative effect it exerts received scanty attention (Ghazouani et al., 2012; Adhikari and Goldey, 2010; Ostrom, 1990; Uphoff, 2000). Therefore, the mixed effects of social capital components on collective action should be further studied, especially under the condition of increasing heterogeneities.

The objective of this study is to understand how to initiate and manage collective action as well as the elements that impact collective action. We collected data through surveys carried out in the Loess Plateau Areas of Shaanxi Province, Ningxia Province, Gansu Province and Shanxi Province. In order to initiate collective action, social network heterogeneity and relative income position are explored as key elements in addressing social dilemmas of farmers' 
attitude-behaviour paradox (Chapter 2). Then, social capital is dimensionalised into social trust, social network, social participation and social reciprocity, in order to study the relationships between social capital components and farmers' willingness to cooperate (Chapter 3). Concerning the role of economic heterogeneity in motivating farmers' participation and sustaining collective action, we examined whether the relationship between social capital and collective action is moderated by farmers' incomes (Chapter 4). Finally, because of the importance of organisational heterogeneity in sustaining collective action, we explored how trust and control mechanisms influence the commons governance for small-scale irrigation facilities for different group sizes (Chapter 5).

\subsection{Key findings}

\subsubsection{Farmers' attitude-behaviour paradox and collective action}

In Chapter 2, we studied the factors influencing social dilemmas of farmers' attitudebehaviour paradox for initiating collective action. The findings demonstrated that social network heterogeneity ('weak ties' versus 'strong ties') and the relative income position significant influence the farmers' attitude-behaviour paradox. Furthermore, in order to reveal the mechanisms behind, after dividing attitude-behaviour paradox into two subgroups of "having attitude but no behaviour" and "having behaviour but no attitude". We found that 'weak ties' and interaction effects (between 'weak ties' and relative income position) reduce farmers' paradox for "having behaviour but no attitude", while relative income position reduces the farmers' paradox for "having attitude but no behaviour".

Our finding shows the importance of socio-economic heterogeneity in addressing social dilemmas of farmers' attitude-behaviour paradox. Specifically, the role of 'weak ties' played in reducing farmers' paradox in "having behaviour but no attitude". Because of its function to link different social groups in social structures, 'weak ties' are responsible for embedding people into social network and transmitting information through these networks (Wellman, 1992). In this regard, it is crucial to understand 'weak tie' as a bridge to transmit novel information or values to people who are poorly connected and thus attitude-behaviour could be resonant. This also can be explained by critical mass theory that the initiation of collective action is in a serial sequence rather than parallel choices, potential participants' decision is based on how many others have participated, once the participants overpass the threshold, farmers followed from the choice of others can spread the chain reactions easily (Macy, 1991).

Relative income positions reflect the role of economic heterogeneity in social dilemmas of farmers "attitude-behaviour paradox". Although a large number of articles studied the effects 
of economic heterogeneity in collective action, whether it is positive, negative, neutral or Ushaped, the debate has not reached any consensus (Bardhan \& Dayton-Johnson, 2002; Varughese and Ostrom, 2001). In all these studies, the relationship between socio-economic heterogeneity and farmers' attitude-behaviour paradox is rarely addressed. Our findings mainly concentrated on social and economic heterogeneities, however, the other possible variables, such as resource dependence, as well as cultural or preference heterogeneities are not considered in our case (Ruttan, 2008). Therefore, further research should incorporate all these variables into the framework.

\subsubsection{Components of social capital and collective action}

In Chapter 3, we explored how components of social capital (e.g., social network, social trust, social reciprocity and social participation) influence farmers' participative behaviour in collective action for small-scale irrigation facilities. Although the multi-dimensionality of social capital is widely recognised (Koka and Prescott, 2002), which components should be incorporated into social capital has not reached any consensus. For example, Nahapiet and Ghoshal (1998) divided social capital into structural, relational, and cognitive dimensions, while Putnam (1995) took social trust and social network as the core of social capital. There is an urgent need to incorporate all potential components of social capital, and to validate empirically its multidimensional nature and effects. Moreover, a grain of research found the positive effects of social capital in promoting collective action. Its downsides are rarely addressed by academia. In order to bridge this knowledge gap, we outsourced the main definition of social capital from different scholars, and refined core components in its definition, we tried to indicate different components of social capital based on the designed questionnaire by employing factor analysis to correlate a number of indices into different principal components. Then, we used the logit model to examine the relationship between social capital components and farmers' participative behaviour. We found that social trust and social participation exert positive effects on farmers' participative behaviour, whereas social reciprocity exerts negative effects on farmers' participative behaviour. In this process, wellorganized services and maintenance of irrigation systems play an important role in promoting farmers' participative behaviour.

Chapter 3 contributes to the literature about social capital's multi-dimensional nature and its mixed effects in influencing farmers' participative behaviour in collective action. Combining social network, social trust, social reciprocity and social participation into social capital framework provides a well-rounded perspective in understanding farmers' participative behaviour in collective action. We revealed that components of social capital exert different 
mechanisms in deciding farmers' participative behaviour. For example, bounded generalised reciprocity is conducive to a small range connection whereas detrimental to a wider scale of cooperation among villagers in a community. In general, cultivating multi-dimensional social capital and suppressing its downsides is of vital importance for initiating collective action from a policy perspective. Moreover, on no circumstances can we underestimate the role institutional arrangements play in maintaining common pool resource.

For future research, we should consider the transition of social capital (from primitive social capital to renewed social capital) with regard to Chinese social structural stratification and increasing economic heterogeneity. In addition, because of China's historical and cultural characteristics, the design of social capital should be based upon typical Chinese social circumstances rather than western scholars' ideas. Therefore, how to design an index system that reflects the transition of social capital as well as its social structure in China is an important research direction. Finally, future studies should go beyond individual level and measure social capital in the community or even larger scale to reflect its association with regional level collective action or national level economic development.

\subsubsection{Income groups, social capital and collective action}

In Chapter 4, we examined whether the relationships between social capital components and farmers' willingness to cooperate is moderated by their incomes. We developed a theoretical framework to explore the relationship between social capital and collective action as well as heterogeneity and collective action. We found that low and middle-income farmers attach importance to social network, social reciprocity and social participation, while highincome farmers address interpersonal trust and social participation. Social capital and income differences exert complex effects on farmers' willingness to cooperate. Therefore, farmers in different income groups can enhance collective action by using certain components of social capital to maximise their benefits.

The importance of economic heterogeneity on collective action has been discussed intensively. However, what role of differences in income play in the relationship between social capital components and collective action is rarely addressed. Our research revealed that differences in income have leveraging effects that encourage farmers to allocate their social capital components in an efficient way. In general, when different income groups are taken into the analysis, the influence of social capital components on farmers' willingness to cooperate depends on differences in income. From a policy perspective, solely addressing increase or decrease of economic heterogeneity is not enough for the initiation of collective action, since economic heterogeneity is not the prerequisite to deciding farmers' willingness to cooperate 
(Varughese and Ostrom, 2001). To the contrary, how to understand the role differences in income play in formulating social structures and attaining collective action is the key for common pool resource management. Thus, future studies should go beyond the economic heterogeneity and incorporate the other social-cultural heterogeneities into the research framework. Moreover, how to examine the endogeneity of institutions and consider its interaction with social capital components should also be considered for future research.

\subsubsection{Group size, trust or control and collective action}

Trust-based mode of management and control-based mode of management are crucial in common pool resource management. In Chapter 5, we examined how does group size influence the commons governance for small-scale irrigation facilities based on the trust and control mechanisms. The findings demonstrated that trust exerts partial mediating effects through participation degree in deciding cooperative performance, while control only exerts indirect effects on cooperative performance. The relationship between trust and control are moderated by group size in a special complementary character. Dividing commons governance into process dimension and outcome dimension has higher explanatory power to understand collective action for small-scale irrigation facilities. Finally, we divided cooperative groups into big ones and small ones based on our sample to explore the variance effects of group size, the results showed that both trust-based and control-based modes of management are efficient in a small group, whereas only a control-based mode of management exerts its effects in a big group.

The role of group size in collective action has attracted countless debates and has not reached any consensus (Olson, 1965; Cheikbossian and Fayat, 2018). Our study revealed that group size itself has undetermined effects on collective action, that is, it depends on trust and control mechanisms to decide whether the commons governance will be successful or not. With group size increases, information asymmetry and transaction costs are greatly increased. Control (negative incentive) is more effective in big groups compared to trust (positive incentive), which is more effective in small groups. Considering China's devolution trend (devolution of authority and resources from nation-states to regions and localities) of management, a combination of high-trust and low-control modes of management in small groups of users is desired in order to be sustainable in collective action.

Our study contributes to irrigation management literature by clarifying that how the contrasting force of group size exerted on trust \& control mechanisms directly and indirectly influences commons governance. Since the contexts of collective action task are hardly programmable (irrigation normally is carried out during the night in order to reduce evaporation, 
and the quantity and frequency to irrigation depend on precipitation) and outcomes could not be objectively measured. Thus formal control is very difficult in regards to high information asymmetry and transaction costs. For policy implications, it is important to design combined modes of management that fit local contexts to accommodate the devolution trend for the future common pool resource management. Moreover, because we employ cross-section data to study the relationship between trust and control mechanisms in commons governance from a static perspective, for future studies, we need to explore the other scenarios such as low-trust and low-control, high-trust and high-control as well as low-trust and high-control as the options for managing common pool resources.

\subsection{The insights from this study}

Four additional conclusions can be drawn when we take all the studies as a whole. They are generalised as follows:

\subsubsection{Social dilemmas and collective action}

Social dilemma is characterized by a condition participants follow short-term individual interests and result in the degradation of the common pool resources, while this "tragedy of commons" could be overcome based on institutional arrangements, user groups, resource characteristics, group identification and social norms, etc. (Ostrom, 2000; Klandermans, 2002; Totin et al., 2014). Under the conditions of increasing economic and social-cultural heterogeneity, it needs to explore in depth how these interacting differences influence the initiation and sustainability of collective action. Our study aims to understand how social network heterogeneity ('strong ties' versus 'weak ties') and relative income position influence the social dilemmas of farmers' attitude-behaviour paradox. Our findings demonstrated that 'weak ties' play a crucial role in reducing farmers' paradox for having behaviour but no attitude, and relative income position has a significant impact on resolving farmers' paradox for having attitude but no behaviour. However, the challenge for the policy implications is how to build up 'weak ties' and help the poor to extend network far beyond normal reach (e.g., formal institutions, such as development agency) in accessing information, resources and development opportunities.

Our results indicated that not only socio-economic heterogeneity is important in addressing social dilemmas of farmers' attitude-behaviour paradox, but also rules and institutions matter. In our case, socio-economic heterogeneity (relative income positions and 'weak ties' versus 'strong ties') combined with institutions, to some extent, are conducive for 
overcoming social dilemmas of farmers' attitude-behaviour paradox under moderate water scarcity conditions. For development interventions, the role of institutions should be calibrated in order to identify the modes of management that are crucial for sustaining collective action. Although lots of literature attaches importance to control, in our case, a combination of hightrust and low-control modes of management is optimal for the commons governance for smallscale irrigation facilities. Therefore, understanding how trust and control mechanisms influence commons governance is an important issue. The design of development policies requires taking into account interaction effects as a whole to evaluate intervention measures.

\subsubsection{The multi-dimensionality of social capital and collective action}

The multi-dimensionality of social capital has been recognised by various classification criteria. For example, some scholars divide it into bonding and bridging social capital (Woolcock and Narayan, 2000), while others address cognitive and relational social capital (Inkpen and Tsang, 2005). To this end, social capital is the "resource potential of social relationships" which distributes trust, reciprocity and solidarity within a community (Putnam, 2000: 22). Its source is the social structure within which people interact through market relations, hierarchical relations and social relations. In essence, the multi-dimensionality of social capital relates to its quality and configuration. The quality refers to people who can access and mobilise the resources, the higher the quality of social capital people own, the more chances they can acquire support from the social structures. On the other hand, the configuration of social capital includes structural and normative perspectives. Thus, individuals through interactions with people or institutions gain access to resources, interests and other benefits.

Our study demonstrated that some components of social capital have perverse effects for collective action. For example, social reciprocity is negatively related to farmers' participative behaviour for collective action for small-scale irrigation facilities (Chapter 2, Chapter 3). Rubio (1997) recognized the downside of social capital, he contended that the communities with isolated or parochial networks are conducive for organizations' own interests, while largely hindered future social development. We have identified the upside and downside of social capital, our study further revealed that participants could realize collective action based on their endowments, to target certain components of social capital, and to embed in social structure for their common or personal interests (Chapter 4). In general, it reflects that whatever the multi-dimensions or its upside and downside of social capital, the key is how participant makes use of these instruments to embed them into the certain social structure for obtaining interests. 


\subsubsection{The importance of heterogeneity and collective action}

The association between heterogeneity and collective action have gained much attention in recent years (Doss and Meinzen-Dick, 2015; Ruttan, 2008; Adhikari and Lovett, 2006). However, despite great advancement in theoretical and empirical studies, the effects of heterogeneity on irrigation collective action are still highly contentious (Takayama et al., 2018; Ito, 2012; Nakano and Ostuka, 2011; Meinzen-Dick et al., 2002; Bardhan, 2000; DaytonJohnson, 2000; Tang, 1992). The difficulty in addressing the role of heterogeneity originates from two aspects. On one hand, heterogeneity has many aspects: economic heterogeneity, socio-cultural heterogeneity, ethnic heterogeneity, preference heterogeneity and group heterogeneity. Putting them into lumpiness will lead to different even contradictory conclusions. On the other hand, the relationship between heterogeneity and collective action is quite contextual-dependent, every community's conditions on resource endowments, environment conditions, institutions are different.

We address this issue from two perspectives. Firstly, we tried to combine social capital heterogeneity (social network) and economic heterogeneity into one framework to address the social dilemmas of farmers' attitude-behaviour paradox for initiating collective action (Chapter 2). Then, we divided social capital into four components, and examined their relationships with farmers' participative behaviour. It demonstrated that social trust and social participation are positively related to farmers' participative behaviour while social reciprocity is negatively associated with farmers' participative behaviour (Chapter 3). Finally, we explored the role of farmers' incomes (economic heterogeneity) in the relationship between social capital and farmers' willingness to cooperate. We found that farmers in various income groups address different components of social capital to align themselves with irrigation collective action (Chapter 4). Our study demonstrated that heterogeneity itself is not a key factor in the management of common pool resource, rather, how the way heterogeneity embedded in the institutions and social structures matters.

\subsubsection{The devolution trend of commons governance}

Commons governance is one of the key issues to sustain collective action for small-scale irrigation facilities. In recent years in China, natural resource management was decentralized from central government agencies to local user groups. Therefore, a discussion about the relationships between trust \& control modes of management and commons governance gained much attention. Some scholars argued that the relationship between trust and control is dualistic, while others plead complementary or substitutes (Varoutsa and Scapens, 2018; Kalkman and 
de Waard, 2017; Zwikaed and Smyrk, 2015). Based on our findings, the devolution of natural resource management means a change from the traditional way of high-control and low-trust modes of management to a high-trust and low-control management style.

The new combination of high-trust and low-control mode of management is rooted in two aspects. On one hand, irrigation task programmability and output measurability determine the availability of control measures in different local contexts. Because measuring irrigation performance is difficult, trust, to some extent, substitutes for control to mitigate opportunistic behaviours (Dekker, 2004; Tomkin, 2001; van der Meer-Kooistra and Vosselman, 2000; Vosselman and van der Meer-Kooistra, 2006). On the other hand, it also relates to the group size, for which to evaluate the relative transaction costs for implementing positive (trust) or negative (control) incentives in different member scales. Our study verifies Olson (1965)'s research that participation degree and cooperative performance decrease with the group size increases. Moreover, our empirical results modify his conclusions that selective incentive should be discretionarily chosen based on different group size.

The complexity between trust and control mechanisms to influence commons governance does not lie in its relationship, but in the complementary character moderated by group size. Therefore, trust-based mode and control-based mode of management should be calibrated based on group size to sustain collective action for small-scale irrigation facilities. This is corroborated by Khodyakov (2007) who contended, "it was hard to understand when collaboration is facilitated by trust or control, which suggests that these governance strategies cannot be fully understood without considering the roles both of them play at the same time". In our case, trust and control can be seen as parallel components moderated by group size to reduce uncertainty and achieve oriented behaviours, since "a trust-based pattern is not necessarily a substitute for formal control, but that trust (building) may interact with formal control as it is incorporated in a governance structure" (Vosselman and van der Meer-Kooistra, 2009 p.6).

\subsection{Main contribution and policy implications}

In general, social capital is a crucial variable in common pool resource management as well as the sustainable use of resources, while how the role of economic heterogeneity exerts in this process is rarely addressed. Therefore, we explored the role of social network heterogeneity and relative income positions in explaining farmers' attitude-behaviour paradox, and we developed a framework for measuring the relationship between components of social capital and farmers' participative behaviour. Then we examined whether components of social 
capital and farmers' willingness to cooperate is moderated by farmers' incomes. Finally, we studied how group size influences the commons governance based on the trust and control mechanisms. It has essential implications for irrigation development policies, for which previous studies mainly focused on technological and financial perspectives. Therefore, addressing social capital and economic heterogeneity not only allows us to understand how individuals interact to cooperate with each other, but also for elaborating the mechanisms of economic heterogeneity in common pool resource management.

The implications for future policy design can be summarized as follows. Firstly, synergy analysis should be employed to understand the multi-dimensionality of social capital as well as its positive or negative effects on collective action. Therefore, policy interventions are proposed to cultivate multiple components of social capital and promote its positive aspects. Because of the downsides of social capital, the accumulation and application of it should be used with caution (Teilmann, 2012). Moreover, based on our observation and practice, social capital conceived at the individual level can be beneficial for cooperatives and communities development (Lewis, 2010). Implication for future policy is that we should promote social capital lead by the bottom-up process, and it is conducive for farmers' livelihood improvement and rural development.

Secondly, in order to initiate irrigation collective action, social networks is of critical importance for farmers against vulnerabilities and risks, however, how to transform their 'strong ties' connected with friends, relatives or families into 'weak ties' connected with more formal institutions, such as nongovernmental organizations, extension services is the key for addressing this issue. Moreover, economic heterogeneity is conducive for reducing farmers' attitude-behaviour paradox. However, a prerequisite for policymakers is how to design a compatible incentive mechanism (subsidies, incentives, priority policy) for the appropriate income gap for stimulating the rural elites to initiate collective action.

Thirdly, social transformation driven by urbanization and devolution called for a change of governance modes in collective action, especially under conditions that participants are more concerned about economic interests, the costs and benefits of their action. In order to adapt to the new trends, a combination of high-trust and low-control mode of management is identified in the successful commons governance. These findings have important implications for shifting from bureaucratic governance to a more democratic one. In this sense, user participation and shared management responsibilities are the trends in common pool resource management. From this perspective, we stress the importance of participatory management of collective action, by which to facilitate trust-building and social cohesion under the background of increasing heterogeneities. 
Fourthly, although the importance of social capital has been widely recognized, it also needs the combination of local contexts, resource systems, user groups as well as institutions, etc., to exert effects jointly to reduce transaction costs and motivate farmers' participation. Just as Berkes (2010) pointed out, "institutions-building goes hand in hand with social capital". However, it is worth noting that participants devising their own institutions without disruption by external agencies can be seen as minimum rights to cooperatives, it is also a basic principle for successful commons governance (Ostrom, 1990). Based on all these issues, we can predict that through capacity building to integrate social capital and institutions, the collective action for small-scale irrigation facilities will thrive in Northwest China. For the practical implications for sustaining collective action in a transition economy with long traditions of top-down management, it should develop democratic institutions systematically through capacity building, self-institutional development and multi-dimensional social capital nurturing.

\subsection{Limitations and suggestions for future research}

This thesis started with the question of how to initiate collective action by overcoming social dilemmas of farmers' attitude-behaviour paradox. Then, we proposed a multidimensional social capital framework, to study the relationship between social capital components and farmers' participative behaviour. This thesis continued by examining the role of farmers' incomes in the relationship between social capital components and farmers' willingness to cooperate. Finally, the influence of the group size on commons governance through trust and control mechanisms was explored.

One limitation of our research relates to its contexts in a semi-arid climate that means the moderate degree of water scarcity. Based on Araral (2009) and Agrawal (2001), the relationship between water scarcity and irrigation collective action is an inverted U-shaped curve. So what will happen if water is scarcer or more abundant? Is it possible to calibrate the water scarcity at a more precise level? What management arrangements should be designed for different level of water scarcity? Future studies are necessary to compare management patterns in different water scarcity levels.

Moreover, previous studies were mainly from the static perspective to examine the relationship between social capital components and collective action, future research could investigate the relationship between social capital transition (from primitive social capital to renewed social capital) and collective action from a dynamic perspective. Scholars have divided components of social capital into more detailed different dimensions. For example, trust is decomposed into contractual trust, competence trust and goodwill trust (Connelly et al., 
2018; Shi et al., 2015). For future studies, we suggest exploring the relationship between social capital and collective action from a more dynamic and detailed perspective.

Finally, our study is based on cross-sectional data, although it allows us to observe the field area in-depth, we cannot control for time-invariant unobserved characteristics of irrigation systems, for example, the change of geographical conditions and management mechanisms. Future studies on the panel data of irrigation collective action are therefore recommended to explore and compare short-term effects and long-term effects of policy interventions. 


\section{Reference}

Adger, W.N. 2010. Social Capital, Collective Action, and Adaptation to Climate Change. Springer, Der Klimawandel.

Adhikari, K.P., Goldey, P. 2010. Social capital and its "downside": the impact on sustainability of induced community-based organizations in Nepal. World Development, 38(2): 184-194.

Araral, E. 2009. What explains collective action in the commons? Theory and evidence from Philippines. World Development, 37(3): 687-697.

Bardhan, P., Dayton-Johnson, J. 2002. Unequal Irrigators: Heterogeneity and Commons Management in Large-scale Multivariate Research. In E. Ostrom, t. Dietz, N, Dolsak, P.C.Stern, S. Stonich, E.U. Weber(Eds.), The drama of the commons(pp.87-112). Washington, DC: National Academy Press.

Bardhan, P. 2000. Irrigation and cooperation: an empirical analysis of 48 irrigation communities in South India. Economic Development and cultural change, 48(4): 847-865.

Berkes, F. 2010. Devolution of environment and resources governance: trends and future. Environmental Conservation, 37(4):489-500.

Chaudhry, A.M. 2018. Improving on-farm water use efficiency: Role of collective action in irrigation management. Water Resources and Economics, 22(4):4-18.

Cheikbossian, G., Fayat, R. 2018. Group size, collective action and complementarities in efforts. Economics Letters, 168(7):77-81.

Coleman, J. 1988. Social capital in the creation of human capital. American Journal of Sociology, 94:95120.

Connelly, B.L., Crook, T.R., Combs, J.G., Ketchen, J.R., Aguinis, H. 2018. Competence-and integritybased trust in inter-organisational relationships: Which matters more? Journal of Management, 44(3): 919-945.

Dayton-Johnson, J. 2000. Determinants of collective action on the local commons: A model with evidence from Mexico. Journal of Development Economics, 62(1): 181-208.

Dekker, H.C. 2004. Control of inter-organisational relationships: evidence on appropriation concerns and coordination requirements. Accounting, Organizations and Society, 29(1): 27-49.

Doss, C.R. Meinzen-Dick, R. 2015. Collective action within the household: Insights from natural resource management. World Development, 74(10):171-183.

Garcia, X., Muro, M., Ribas, A., Llaus, S., Jeffrey, A., Saur, P.D. 2013. Attitudes and behaviours towards water conservation on the Mediterranean coast: the role of socio-demographic and placeattachment factors. Water International, 38(3): 283-296.

Ghazouani, W., Marlet, S., Mekki, I., Harrington, L.W., Vidal, A. 2012. Farmers practices and community management of irrigation: why do they not match in Fatnassa oasis? Irrigation and Drainage, 61(1): 39-51.

Granovetter, M. 1973. The strength of weak ties. American Journal of Sociology, 78(6):1360-1380.

Inkpen, A.C., Tsang, E.W. 2005. Social capital, networks, and knowledge transfer. Academy of 
Management Review, 30(1):146-165.

Ito, J., 2012. Collective action for local commons management in rural Yunnan, China: Empirical evidence and hypotheses using evolutionary game theory. Land Economics, 88(1): 181-200.

Joshi, L.K., Hooja, R. eds. 2000. Participatory irrigation management: Paradigm for the 21st century (Vol. 1). Rawat Pubns.

Kalkman, J.P., de Waard, E.J. 2017. Inter-organisational disaster management projects: Finding the middle way between trust and control. International Journal of Project Management, 35(5):889-899.

Khodyakov, D.M. 2007. The complexity of trust-control relationship in creative organisations: insights from a qualitative analysis of a conductorless orchestra. Social Forces, 86(1):1-22.

Klandermans, B. 2002. How group identification helps to overcome the dilemma of collective action. American Behavioural Scientist, 45(5):887-900.

Koka, B.R., Prescott, J.E. 2002. Strategic alliances as social capital: A multidimensional view. Strategic Management Journal, 23(9):795-816.

Lam, W.F., 1999. Governing Irrigation Systems in Nepal: Institutions, Infrastructure, and Collective Action. ICS Press Institute for Contemporary Studies.

Lewis, J.M. 2010. Connecting and Cooperating: social capital and public policy. Sydney, UNSW Press.

Macy, M.W. 1991. Chains of cooperation: Threshold effects in collective action. American Sociological Review, 56(6):730-747.

McCord, P., Waldman, K., Baldwin, E., Dell'Angelo, J., Evans, T. 2018. Assessing multi-level drivers of adaptation to climate variability and water insecurity in smallholder irrigation systems. World Development, 108(8):296-308.

Meinzen-Dick, R., Raju, K.V., Gulati, A. 2002. What affects organization and collective action for managing resources? Evidence from canal irrigation systems in India. World Development, 30(4):649-666.

Nahapiet J., GhoshalSocial S. 1998. Capital, intellectual capital, and the organisational advantage. Academy of Management Review, 23(2): 242-266.

Nakano, Y., Otsuka, K. 2011. Determinants of household contributions to collective irrigation management: the case of the Doho Rice scheme in Uganda. Environment and Development Economics, 16(5): 527-551.

Olson, M. 1965. The Logic of Collective Action: Public Goods and the Theory of Groups. Harvard University Press, Cambridge, Mass.

Ostrom, E. 1990. Governing the Commons: The Evolution of Institutions for Collective Action. Cambridge University Press, New York, USA.

Ostrom, E. 2000. Social capital: A Fad or A Fundamental Concept? in Dasgupta, P. (Eds.): Social Capital: A Multifaceted Perspective, World Bank, Washington, DC, 172-215.

Portes, A. 2014. Downsides of social capital. Proceedings of the National Academy of Sciences, 111(52):18407-18408. 
Poteete, A.R., Ostrom, E. 2004. Heterogeneity, group size and collective action: the role of institutions in forest management. Development and Change, 35(3): 435-461.

Putnam, R.D., Leonardi, R, Nanetti, R.Y. 1994. Making Democracy Work: Civic traditions in modern Italy. Princeton University Press.

Putnam, R.D., 1995. Tuning in, tuning out: The strange disappearance of social capital in America. Political Science \& Politics, 28(4): 664-683.

Putnam, R.D., 2000. Bowling alone: America's declining social capital. In Culture and politics (pp. 223-234). Palgrave Macmillan, New York.

Reyes-Garcia, V., Aubriot, O., Ariza-Montobbio, P., Gal N-Del-Castillo, E., Serrano-Tovar, T., Martinez-Alier, J. 2011. Local perception of the multi-functionality of water tanks in two villages of Tamil Nadu, South India. Society and Natural Resources, 24(5):485-499.

Rubio, M. 1997. Perverse Social Capital: Some evidence from Colombia. Journal of Economic Issues, 31(3):805-816.

Ruttan, E. 2008. Economic heterogeneity and the commons: effects on collective action and collective goods provisioning. World Development, 36(5):969-985.

Shi, H.X., Shepherd, D.M., Schmidts, T. 2015. Social capital in entrepreneurial family businesses: the role of trust. International Journal of Entrepreneurial Behaviour \& Research, 21(6):814-841.

Stone, W. 2001. Measuring social capital: towards a theoretically informed measurement framework for researching social capital in community life. (24). Melbourne: Retrieved from http://www. aifs. gov. au/institute/pubs/RP24. pdf.

Takayama, T., Matsuda, H., Nakatani, T. 2018. The determinants of collective action in irrigation management systems: Evidence from rural communities in Japan. Agricultural Water Management, 206(7):113-123.

Tang, S.Y. 1992. Institutions and collective action: self-governance in irrigation. San Francisco, CA: Institute for Contemporary Studies Press.

Teilmann, K. 2012. Measuring social capital accumulation in rural development. Journal of Rural Studies, 28(4): 458-465.

Tomkins, C. 2001. Interdependencies, trust and information in relationships, alliances and networks. Accounting, Organizations and Society, 26 (2):161-191.

Totin, E. 2014. Drivers of cooperative choice: canal maintenance in smallholder irrigated rice production in Benin. International Journal of Agricultural Sustainability, 12(3):334-354.

Uphoff, N. 2000. Understanding Social Capital: Learning from the Analysis and Experience of Participation In: Social Capital: A Multifaceted Perspective, pp. 215-249.

Van der Meer-Kooistra, J., Vosselman, E. 2000. Management control of interfirm transactional relationships: the case of industrial renovation and maintenance, Accounting, Organizations and Society, 25 (1):51-77.

Varoutsa, E., Scapens, R.W. 2018. Trust and control in evolving inter-organisational relationships: Evidence from the aerospace industry. Accounting, Auditing \& Accountability Journal, 
31(1):112-140.

Varughese, G., Ostrom, E. 2001. The contested role of heterogeneity in collective action: some evidence from community forestry in Nepal. World Development, 29(5):747-765.

Vosselman, E., van der Meer-Kooistra, J. 2009. Accounting for control and trust building in interfirm transactional relationships. Accounting, Organizations and Society, 34(2): 267-283.

Wellman, B. 1992. What ties provide what kinds of support? Advances in Group Processes, 9:207-235.

Woolcock, M., Narayan, D. Social capital: implications for development theory, research and policy. The World Bank Research Observer, 15(2): 225-249.

Yu, H.H., Edmunds, M., Lora-Wainwright, A., Thomas, D. 2016. Governance of the irrigation commons under integrated water resources management----A comparative study in contemporary rural China. Environmental Science \& Policy, 55(1): 65-74.

Zwikael, O., Smyrk, J. 2015. Project governance: Balancing control and trust in dealing with risk. International Journal of Project Management, 33(4):852-862. 


\section{Appendix Questionnaires}

\section{Questionnaire for Household Survey on Small-scale Irrigation Facilities}

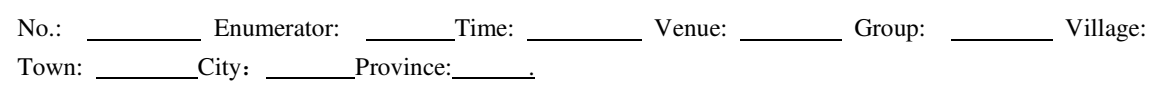

\section{General Information}

1. Gender: A. male; B. female

2. Age: A. under 17; B. $18 \sim 35$; C. $36 \sim 50$; D. $51 \sim 65$; E. 66 and above

3. Position in the village: A. villager; B. team leader; C. village cadre

4. You are engaged in agricultural production for years. The average annual agricultural production time is months. Are you currently working in farming sector?

A. yes; B. no

5. The education you accepted is years.

6. Your political identity: A. no political identity; B. communist party member; C. communist youth league; D. religious members

7. Your source of income (multiple choices): A. farming or aquaculture; B. migrant working or doing small business; C. doctor or teacher; D. village cadre

8. Are you willing to save the extra money? A. strongly unwilling; B. unwilling; C. neither unwilling nor willing; D. willing; E. strongly willing

9. Are you still engaged in other economic activities except for planting grain? A. planting vegetable; B. managing orchard; C. doing small business; D. transporting business; E. other 10. Your health condition: A. very bad; B. bad; C. neither bad nor good; D. good; E. very good

11. There are members in your family, including farmers. Number of female: Number of male 
12. Annual household income is Yuan. The farming income accounts for Yuan.

Animal husbandry income accounts for Yuan. Forestry income accounts for

Yuan. Fishery income accounts for Yuan; Non-farming business accounts for

Yuan. The government provides grain subsidies for Yuan. Water conservancy facility subsidies are Yuan.

13. Your family spends ___ yuan a year, __ yuan for agriculture, yuan for irrigation water, yuan for socializing, education spend yuan.

14. Have you gone to the metropolitan city for migrant working? A. Yes; B. No. If Yes, people doing migrant work in the family, for male: for female , migrant

working every year are months, annual income is yuan.

15. The fee hand over to the village is Yuan per year. The fee for constructing and maintenance of small-scale irrigation facilities is Yuan per year.

16. The village's distance to the highway? A. 1-2 kilometres; B. 3-5 kilometres; C. 6-8 kilometres; D. 9-12 kilometres; E above 12 kilometres

\section{Planting and Irrigation Conditions}

1. The cultivated farmland of the family is mu. The dry land is mu. Irrigation area is mu.

2. Planting structure and water features

\begin{tabular}{|c|c|c|c|c|c|c|c|}
\hline & $\begin{array}{l}\text { Cultivated } \\
\text { Area (mu) }\end{array}$ & $\begin{array}{l}\text { Irrigation } \\
\text { area }(\mathrm{mu})\end{array}$ & $\begin{array}{c}\text { Per unit } \\
\text { yield }\end{array}$ & $\begin{array}{c}\text { Procurement } \\
\text { price }\end{array}$ & $\begin{array}{c}\text { Irrigation } \\
\text { times }\end{array}$ & $\begin{array}{c}\text { Irrigation } \\
\text { fee }\end{array}$ & $\begin{array}{l}\text { Irrigation } \\
\text { equipment }\end{array}$ \\
\hline Wheat & & & & & & & \\
\hline Paddy & & & & & & & \\
\hline Corn & & & & & & & \\
\hline Vegetables & & & & & & & \\
\hline Other crops & & & & & & & \\
\hline Fruit tree & & & & & & & \\
\hline
\end{tabular}

\section{Perception of Small-scale Irrigation Facilities}

1. What is the primary function of small-scale irrigation facilities?

A. anti-drought; B. drainage; C. increase production; D. solve the problem of human and livestock water consumption; E. increase income

2. Are small-scale irrigation facilities important to agricultural production? 
A. not important at all; B. less important; C. neither unimportant nor important; D. important;

E. very important

3. Are small-scale irrigation facilities important to increase family income?

A. not important at all; B. unimportant; C. neither unimportant nor important; D. important;

E. very important

4. What type of small-scale irrigation facilities are available in the village?

A. government funded, villager labour construction; B. private investment and construction;

C. government funded, private contract management; D. villager cooperation construction; E. government, villagers jointly funded and built

5. Who proposed the construction of small-scale irrigation facilities in the village?

A. local government; B. village cadre; C. farmer's joint fundraising; D. agricultural association, etc.; E. Others

The total investment is yuan, the cost personal bear is yuan, government subsidy is yuan, bank loan is__ yuan.

6. Does the investment in small-scale irrigation facilities construction change compared to three years ago?

A. decrease; B. does not change; C. increase

7. What kind of irrigation method do you mainly use:

A. sprinkler irrigation; B drip irrigation; C micro-irrigation; D canal irrigation

8. Does your farmland have irrigation facilities within 0.5 kilometre? Such as rivers, well, reservoir, and motor-pumped well? A. Yes; B. No

9. Do you know the government's subsidy policy or investment policy for small-scale irrigation facilities?

A. not at all; B. very little; C. only a bit; D. know a few policies; E. know thoroughly about the policies.

10. What is the condition of the village's investment in small-scale irrigation facilities?

A. almost nothing; B. only few investment; C. neither too few nor too many; D. many investments; E. too many investments

If the investment is not enough, the reason is:

A. poor organization of government; B. lack funds; C. farmers lack interests; D. the way of investment has problems; E. other reasons

11. What is the maintenance condition of the small-scale irrigation facilities in the village? A. very bad; B. bad; C. neither bad nor good; D. good; E. very good 
12. Who is responsible for the maintenance of the small-scale irrigation facilities?

A. village committee cadres; B. technical administrator; C. professional association such as water user association; D. individual farmers; E. No one responsible

13. Does the irrigation technicians repair small-scale irrigation facilities timely?

A. not in time at all; B. not in time; C. neither late nor fast; D. in time; E. very fast

14. I spend___ Yuan on the maintenance of irrigation facilities, the maintenance cost should be undertaken by: A. village committee cadres; B. technical administrator; C.

professional association such as water user association; D. collective or individual farmers; E. others

15. Are you clear about the funding used on small-scale irrigation facilities construction and maintenance?

A. not clear at all; B. unclear; C. neither unclear nor clear; D. clear; E. very clear

16. How is your income level change (perception about benefits and costs) after utilizing small-scale irrigation facilities?

A. reduce significantly; B. reduce; C. no change; D. has certain improvement; E. has dramatically improvement

17. Are you satisfied with the existing irrigation facilities service?

A. very dissatisfied; B. dissatisfied; C. neither dissatisfied nor satisfied; D. satisfied; E. very satisfied

If it is not satisfied, the main reason is: A. irrigation water is not enough; B. no one repairs small-scale irrigation facilities; C. too far away to get water; D. the price is too high; E. It is too long to wait for getting water.

18. Does it exist irrigation water stealing phenomenon in the village? A. yes; B. no

19. Does it often happen water use disputes in the village?

A. never; B. occasionally; C. sometimes; D. frequently; E. always

20. Whether your family own irrigation equipment? A. Yes; Mainly is: B. No

21. Do you participate in small-scale irrigation facilities' collective action? A. yes; B. no

22. What is your role in small-scale irrigation facilities collective action? A. organizer; B. follower; C. initiator; D. others

23. Who can integrate different viewpoints in small-scale irrigation facilities collective action?

A. village cadre; B. irrigation management personnel; C. water user organization; D. local elites; E. team leader; F. others 
24. If someone puts forward to suggestions for small-scale irrigation facilities collective action, would you like to participate? A. yes; B. no

if cooperate, which way do you prefer? A. money contribution; B. labour contribution; C. both labour and money contribution; D. neither

25. The main reason you would like to cooperate: A. increase income; B. reduce cost; C. convenient for water use; D. trust the organizer; E. just follow the others

If not, the main reason you do not cooperate with others is: A. no money; B. interest conflicts; C. no proper organizer; D. I do not need; E. other reasons

26. What do you think who should responsible for the principal investment and maintenance of small-scale irrigation facilities?

A. central government; B. county and township government; C. village committee; D. village collectives; E. individual contracting; F. investment together with different subjects

27. Which way do you prefer to share the cost of construction and maintenance of small-scale irrigation facilities?

A. based on income; B. based on the number of the labour force; C. based on the irrigation acreage; D. based on the cost of the irrigation facilities; E. others

28. Would you like to spend money on construction and maintenance of small-scale irrigation facilities?

A. Yes; B. No

\section{Measurement of Social Capital}

1. The number of people you normally contact with is When you are in difficulties, number of people you can ask for help is

2. Please choose the following personal communication level according to your own experience.

\begin{tabular}{|l|l|l|l|l|l|}
\hline Frequency of contact & Never & Occasionally & Sometimes & Frequently & Always \\
\hline Friends & & & & & \\
\hline Relatives & & & & & \\
\hline Village leaders & & & & & \\
\hline Neighbors & & & & & \\
\hline Agricultural organizations & & & & & \\
\hline Family members & & & & & \\
\hline Best friends & & & & & \\
\hline
\end{tabular}


3. What is your best friend's career? (Multiple choices)

A. farming; B. migrant working or doing small business; C. doctor or teacher; D. village cadres; E. other

4. What is your best friend's income status?

A. very poor; B. poor; C. neither poor nor wealthy; D. wealthy; E. very wealthy

5. What is your primary relative's occupation? (Multiple choices)

A. farming; B. migrant working or doing small business; C. doctor or teacher; D. village cadres; E. other

6. What is your primary relative's income status?

A. very poor; B. poor; C. neither poor nor rich; D. wealthy; E. very wealthy

7. What is your family member's primary occupation? (Multiple choices)

A. farming; B. migrant working or doing small business; C. doctor or teacher; D. village cadres; E. other

8. What is your family member's income status?

A. very poor; B. poor; C. neither poor nor wealthy; D. wealthy; E. very wealthy

9. Social reciprocity conditions

\begin{tabular}{|l|l|l|l|l|l|}
\hline & Never & Occasionally & Sometimes & Frequently & Always \\
\hline $\begin{array}{l}\text { Your friends come to help in case of a } \\
\text { wedding ceremony }\end{array}$ & & & & & \\
\hline $\begin{array}{l}\text { When others have important affairs to } \\
\text { decide, they turn to you for discussion }\end{array}$ & & & & & \\
\hline $\begin{array}{l}\text { In the harvesting season, others come } \\
\text { to help }\end{array}$ & & & & & \\
\hline $\begin{array}{l}\text { The villagers respect you } \\
\text { When you build a house, your friends } \\
\text { come over and help }\end{array}$ & & & & & \\
\hline $\begin{array}{l}\text { When others have domestic conflicts, } \\
\text { they turn to you for help }\end{array}$ & & & & & \\
\hline
\end{tabular}


10. Social trust level conditions

\begin{tabular}{|l|l|l|l|l|l|}
\hline & Never & Occasionally & Sometimes & Frequently & Always \\
\hline Trust level to close friends & & & & & \\
\hline Trust level to close relatives & & & & & \\
\hline Trust level to village leaders & & & & & \\
\hline Trust level to the respectful farmer & & & & & \\
\hline Trust to agriculture organization & & & & & \\
\hline Trust level to a family member & & & & & \\
\hline Trust level to acquaintances & & & & & \\
\hline Trust level to strangers & & & & & \\
\hline Trust level to neighbours & & & & & \\
\hline
\end{tabular}

\section{Social participation conditions}

\begin{tabular}{|l|l|l|l|l|l|}
\hline & Never & Occasionally & Sometimes & Frequently & Always \\
\hline $\begin{array}{l}\text { You ask other farmers to solve the issue } \\
\text { together when the village has them }\end{array}$ & & & & & \\
\hline $\begin{array}{l}\text { You participate in group activities in the } \\
\text { village }\end{array}$ & & & & & \\
\hline $\begin{array}{l}\text { You participate in the village cadre's } \\
\text { election }\end{array}$ & & & & & \\
\hline $\begin{array}{l}\text { You propose suggestions or opinions } \\
\text { when deciding public affairs in the } \\
\text { village }\end{array}$ & & & & & \\
\hline $\begin{array}{l}\text { You participate in "one project, one } \\
\text { discussion" }\end{array}$ & & & & & \\
\hline
\end{tabular}

\section{Community Conditions}

1. What is the community's atmosphere?

A. very bad; B. bad; C. neither good nor bad; D. good; E. very good

2. What is the relationship among villagers in the village? 
A. very bad; B. bad; C. neither good nor bad; D. good; E. very good

3. Would you like to migrate to other villages?

A. strongly reluctant; B. reluctant; C. neither reluctant nor willingness; D. willingness; E. strongly willingness

4. How are your village's rules and regulations executive conditions?

A. very bad; B. bad; C. neither bad nor good; D. good; E. very good

5. How is your village's information circulation?

A. very slow; B. slow; C. neither fast nor slow; D. fast; E. very fast 


\section{Questionnaire for Household Survey on Water and Soil Conservancy}

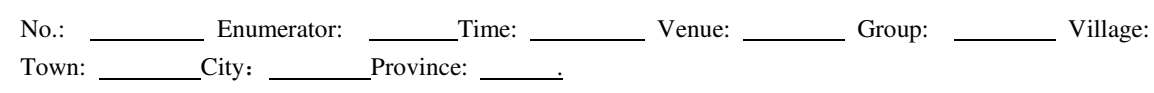

\section{General Information}

1. The age of household head: ; education years: ; sex: (1) male (2) female;

Ethnicity: (1) Han (2) minority

2. The type of work positions:(1) farming; (2) migrant work; (3) small business; (4) doctor or teacher; (5) village leader; (6) civil servant; (7) retired; (8) others

3. Does any of your family member work as village leader or civil servant? (1) Yes (2) No; Does any of your family members is communist party member? (1)Yes (2) No; Does any of your family member work in a financial institution? (1) Yes (2) No.

4. There are people in your family, male labour force: ; female labour force:

Age under 15: ; age over 65:

5. Who makes the important decisions of the family? (1) male; (2) female; (3) we make the decision together.

6. There are floors of the house, rooms; the type of the house: (1) concrete;

(2) tiles and bricks; (3) bricks and wood; (4) wood and mud; (5) straw house. The cost of house construction:

7. The family's main transportation means: (1) nothing; (2) bicycle; (3) motorbikes or electronic bikes; (4) car; the value of the vehicles:

8. Your family's main agricultural machine including: (1) ; price

(2) ; price ; (3) ; price:

9. The average food consumption of your family: Yuan/month; telephone communication: Yuan/month; socializing cost: Yuan/month; the total consumption: Yuan/year. 


\section{Collective Action}

1. Collective action perception and participation

\begin{tabular}{|c|c|c|c|c|c|}
\hline \multicolumn{2}{|c|}{ Organizational form } & $\begin{array}{c}\text { Cooperatives (water } \\
\text { user organization) }\end{array}$ & $\begin{array}{l}\text { Village } \\
\text { Council }\end{array}$ & $\begin{array}{l}\text { Firm+ } \\
\text { farmers }\end{array}$ & Contracting \\
\hline \multicolumn{2}{|c|}{ Whether or not to participate } & & & & \\
\hline \multicolumn{2}{|c|}{ The reason to participate } & & & & \\
\hline \multicolumn{2}{|l|}{ Group size (number) } & & & & \\
\hline \multicolumn{2}{|c|}{ The function in the organization } & & & & \\
\hline \multicolumn{2}{|c|}{ Perception of objective and conter } & & & & \\
\hline \multicolumn{2}{|l|}{ Perception of the rules } & & & & \\
\hline \multicolumn{2}{|c|}{ Perception of the expenses } & & & & \\
\hline \multicolumn{2}{|c|}{ Perception of the regulations } & & & & \\
\hline \multicolumn{2}{|c|}{ The importance on production } & & & & \\
\hline \multicolumn{2}{|c|}{ Money contribution (Yuan) } & & & & \\
\hline \multicolumn{2}{|c|}{ Labour contribution (times) } & & & & \\
\hline \multicolumn{2}{|c|}{ Meeting participation (times) } & & & & \\
\hline \multicolumn{2}{|c|}{ Training participation (times) } & & & & \\
\hline Note & $\begin{array}{l}3 . \\
4 . \\
5 . \\
6 . \\
7 .\end{array}$ & $\begin{array}{l}\text { ether or not to particip } \\
\text { e reason to participate: } \\
\text { nanded; (3) follow the } \\
\text { share cost; (6) scaled e } \\
\text { e function in the organi } \\
\text { nager; (4) participants; } \\
\text { ceptions: } 1-5 \text { scale fron } \\
\text { ney contribution: } 1-20 \\
0=4 \text {, above } 1001=5 \text {. } \\
\text { bour contribution: } 1=0 \text { - } \\
6-7 \text { times, } 5=\text { above } 8 \text { ti } \\
\text { tring and training parti } \\
\text { tribution. }\end{array}$ & $\begin{array}{l}\text { (1) Yes; } \\
\text { income i } \\
\text { ers; (4) e } \\
\text { nomy; (7) } \\
\text { ion: (1) ir } \\
\text { others } \\
\text { ery low t } \\
\text { uan=1, } 2 \\
\text { ime a yea } \\
\text { es. } \\
\text { ation: the }\end{array}$ & $\begin{array}{l}\text { No } \\
\text { ease; (2) } \\
\text { onment i } \\
\text { luce risks } \\
\text { tor; (2) le } \\
\text { ery high. } \\
400=2 ; 4 \\
=2-3 \text { time } \\
\text { ne as lab }\end{array}$ & $\begin{array}{l}\text { icy } \\
\text { rovement; } \\
\text { 8) others } \\
\text { ler; (3) } \\
700=3,701 \text { - } \\
3=4-5 \text { times, }\end{array}$ \\
\hline
\end{tabular}


2. The organization of the collective action

\begin{tabular}{|c|c|c|c|c|c|}
\hline & Organization form & Cooperative & $\begin{array}{l}\text { Village } \\
\text { Council } \\
\end{array}$ & $\begin{array}{l}\text { Firm+ } \\
\text { farmers }\end{array}$ & Contracting \\
\hline \multirow{2}{*}{ Award } & $\begin{array}{l}\text { Whether or not to have incentive } \\
\text { measures? }\end{array}$ & & & & \\
\hline & How many incentive measures? & & & & \\
\hline \multirow{2}{*}{ Punishment } & $\begin{array}{l}\text { Whether or not to have } \\
\text { punishment measures? }\end{array}$ & & & & \\
\hline & $\begin{array}{l}\text { How many ways are there to } \\
\text { punish free-ridings? }\end{array}$ & & & & \\
\hline \multirow{2}{*}{ Management } & $\begin{array}{l}\text { Whether or not to have } \\
\text { specialized personnel? }\end{array}$ & & & & \\
\hline & How many personnel? & & & & \\
\hline \multirow{2}{*}{ Supervision } & $\begin{array}{l}\text { Whether or not to have } \\
\text { specialized supervision? }\end{array}$ & & & & \\
\hline & $\begin{array}{l}\text { How many people are responsible } \\
\text { for it? }\end{array}$ & & & & \\
\hline \multirow{4}{*}{ Institutions } & $\begin{array}{l}\text { Whether or not to have } \\
\text { regulations? }\end{array}$ & & & & \\
\hline & $\begin{array}{l}\text { The effects of regulation } \\
\text { execution }\end{array}$ & & & & \\
\hline & The frequency of rules violation & & & & \\
\hline & The severity of rules violation & & & & \\
\hline \multirow{3}{*}{ Conflict } & $\begin{array}{l}\text { Whether or not to have conflicts } \\
\text { with others? }\end{array}$ & & & & \\
\hline & The frequency of conflicts & & & & \\
\hline & $\begin{array}{l}\text { what is the severity of the } \\
\text { regulation enforced in conflicts? }\end{array}$ & & & & \\
\hline \multirow{4}{*}{ Effects } & Perception of benefits and costs & & & & \\
\hline & $\begin{array}{l}\text { perception of local ecological } \\
\text { environment improvement }\end{array}$ & & & & \\
\hline & The relationships among villagers & & & & \\
\hline & $\begin{array}{l}\text { Satisfaction level with commons } \\
\text { governance }\end{array}$ & & & & \\
\hline
\end{tabular}




\begin{tabular}{|c|l|l|l|l|l|}
\hline \multirow{2}{*}{$\begin{array}{l}\text { Management } \\
\text { of water and } \\
\text { soil loss } \\
\text { conservancy }\end{array}$} & Whether or not organize measures & & & & \\
\cline { 2 - 6 } & The categories of measures & & & & \\
\hline & Number of participants & & & \\
\hline \multicolumn{2}{|l}{ Note } & $\begin{array}{l}\text { 1. The questions related yes or no, } 1=y e s, 0=\text { no. } \\
\text { 2. The other questions answered in } 1-5 \text { scales from rarely to almost. }\end{array}$ \\
\hline
\end{tabular}

3. If you do not participate in collective action, the reasons are: (1) no one organizes; (2) not useful; (3) high costs; (4) no labour force; (5) no time

4. Will you vote in village leader election? (1) yes; (2) no

5. Will you always work together to resolve your village's daily issues? (1) never; (2) occasionally; (3) sometimes; (4) always; (5) quite often

6. Do you often make suggestions or comments when making public issues decisions in the village? (1) never; (2) occasionally; (3) sometimes; (4) always; (5) quite often.

7. Do you often participate in the "one-project-one-discussion" in the village collective decision? (1) never; (2) occasionally; (3) sometimes; (4) always; (5) quite often

\section{The Farmers' Social Capital}

1. The number of people you often contact is , and numbers stored in your cell phone's contact list has people.

2. How much do you think people respect you in the village? $1=$ strongly disrespectful; $2=$ disrespectful; 3=neither disrespect nor respect; 4= respectful; 5=strongly respectful

3. If there are some problems in the village that need to be resolved, will you call on other farmers to work together? (1) yes; (2) no

4. Do you believe in the policy information released in the village? $1=\mathrm{I}$ don't believe it at all; 2=only a little; $3=$ generally believe; 4 =most believe; $5=$ fully believe

5 . What is the atmosphere in your village? $1=$ very bad; $2=$ bad; $3=$ =neither bad nor good; 4=good; 5=very good

6. What do you think of relationship between the villagers in this village? $1=$ not harmonious at all; $2=$ not harmonious; $3=$ Neither bad nor good; 4=Harmonious; $5=$ Very harmonious 


\begin{tabular}{|c|c|c|c|c|c|}
\hline & Never & Occasionally & Sometimes & Frequently & Always \\
\hline Do you often visit neighbours? & & & & & \\
\hline Does your family often have guests visiting? & & & & & \\
\hline $\begin{array}{l}\text { Will your family, relatives and friends often } \\
\text { visit each other? }\end{array}$ & & & & & \\
\hline $\begin{array}{l}\text { Are there any relatives and friends who are } \\
\text { willing to help in happy events? }\end{array}$ & & & & & \\
\hline $\begin{array}{l}\text { In harvesting season, are there people willing } \\
\text { to come and help? }\end{array}$ & & & & & \\
\hline $\begin{array}{l}\text { When you build a house, do you have } \\
\text { relatives and friends to come and help? }\end{array}$ & & & & & \\
\hline $\begin{array}{l}\text { When people have important affairs, how } \\
\text { often do they ask you for suggestions? }\end{array}$ & & & & & \\
\hline $\begin{array}{l}\text { When someone else's family is in conflict, } \\
\text { will you give help to mediate? }\end{array}$ & & & & & \\
\hline $\begin{array}{l}\text { Do you often participate in activities such as } \\
\text { weddings, funerals and? }\end{array}$ & & & & & \\
\hline $\begin{array}{l}\text { Do you often have fun with your neighbours } \\
\text { (such as playing cards, dancing)? }\end{array}$ & & & & & \\
\hline Do you often borrow money from others? & & & & & \\
\hline Do you often lend money to others? & & & & & \\
\hline $\begin{array}{l}\text { Do you often borrow things from people } \\
\text { around you? }\end{array}$ & & & & & \\
\hline How often do you lend things to others? & & & & & \\
\hline Are the people around you trustworthy? & & & & & \\
\hline $\begin{array}{l}\text { In your interactions with the villagers, do you } \\
\text { often worry about the loss of interests? }\end{array}$ & & & & & \\
\hline
\end{tabular}

Note: The content not relatd to the paper is omitted. 


\section{Summary}

Collective action for small-scale irrigation facilities is crucial for smallholder farmers' livelihood and welfare improvement in the Loess Plateau Areas of Northwest China. However, under the challenge of China's increasing economic heterogeneity and social transformation, understanding what influences the initiation of collective action and how to sustain it is the key for common pool resource management. This thesis starts with how to initiate collective action by addressing the social dilemma of farmers' attitude-behaviour paradox. After finding that relative income position and social network heterogeneity are the main factors for the occurrence of this social dilemma, we develop a theoretical framework to identify how social capital components contribute to the realisation of collective action. Then, we study how economic heterogeneity particularly farmers' income levels influence their willingness to cooperate in sustaining collective action. Finally, given the different organisational forms in the management of collective action, we study how organisational heterogeneity influences commons governance for small-scale irrigation facilities based on the trust and control mechanisms. In Chapter 1, we draw a blueprint of the whole thesis, propose research questions and introduce the study areas as well as methodologies employed in the following four chapters.

Chapter 2 explores why farmers, who have a positive attitude towards small-scale irrigation collective action, do not transform into real participative behaviour or who do not have the attitude, yet have real participative behaviour, that is, the attitude-behaviour paradox. We use data from household survey with farmers in Shaanxi Province of Northwest China. Given the potential endogeneity of the social network in estimating farmers' attitude-behaviour paradox, an instrumental variable probit model is used to investigate how social network heterogeneity and relative income position affect farmers' social dilemmas. The results show that social network heterogeneity, decomposed into 'weak ties' and 'strong ties', combined with relative income position, reduced farmers' attitude-behaviour paradox. Moreover, after dividing farmers' paradox into "having attitude but no behaviour" and "having behaviour but no attitude", different mechanisms are revealed to understand further the role of socioeconomic heterogeneity in addressing social dilemmas of farmers' attitude-behaviour paradox.

The effects of social capital components on farmers' participative behaviour in collective action are examined in Chapter 3. A theoretical framework is developed to reflect the relationship between social capital and collective action. Based on household survey data with farmers in Shaanxi Province of Northwest China, we derive four components of social capital by employing exploratory factor analysis, namely, social network, social reciprocity, social trust and social participation. Then, the logit model is used to estimate the influence of social 
capital components on farmers' participative behaviours in the realisation of collective action. It is found that social trust and social participation have positive effects on farmers' participative behaviour, whereas social reciprocity will reduce the possibility of initiating collective action. Other factors, such as education levels, cultivated area, cropping patterns and grain subsidies also have significant positive effects.

Chapter 4 examines whether the relationship between social capital components and farmers' willingness to cooperate is moderated by income levels. Based on the theoretical framework to link social capital, economic heterogeneity and collective action, a structural equation model is estimated to analyse the influence of social capital components on the willingness of farmers to cooperate. The analysis is complemented by a multi-group analysis to measure the variance effects across income groups. The results show that low- and middleincome farmers attach importance to the components of social network, social reciprocity and social participation, while high-income farmers emphasize interpersonal trust and social participation. Our research reveals that the success of collective action largely relies on how farmers' align certain components of social capital with social structures to get benefits based on their economic endowments.

Chapter 5 studies how group size influences commons governance for small-scale irrigation facilities through trust and control mechanisms. The analysis is also performed by a structural equation model with farmers who participated in the collective action for small-scale irrigation facilities in Shaanxi, Gansu and Ningxia Province of China. The findings demonstrate that trust-based and control-based management mechanisms have different impacts on sustaining commons governance. Specifically, trust positively, whereas control negatively affects participation degree as well as cooperative performance. Both trust-based and control-based modes of management are effective in small groups, whereas only a controlbased mode of management effective in big groups. Group size exerted contrasting force on trust and control mechanisms that directly and indirectly influence commons governance. Our study reveals that selective incentives should be discretionarily chosen based on the group size to sustain commons governance.

Finally, Chapter 6 presents the main conclusions of the four previous chapters, proposes insights from collective action for small-scale irrigation facilities, generalises the main contributions and presents policy implications as well as limitations and suggestions for future research. 


\section{Acknowledgement}

Pursuing Ph.D. in Wageningen is one of the most unforgettable things that I have experienced in my life. I feel so lucky to have the inspiration and company from all those great people. I am very grateful for their help and support through the journey of my $\mathrm{Ph} . \mathrm{D}$.

First of all, I would like to express my earnest gratitude to my promotors, prof. dr. Wim Heijman and associate prof. dr. Xueqin Zhu for their encouragement, kindness, insights and knowledge. Wim, I will never forget the first time I met you in Northwest Agriculture \& Forestry University. It was you who gave me the chance to see the outside world, to get new knowledge, and to touch the newest research frontier. Your rich experience in research and your innovative thinking always inspire me to explore the new directions and try to combine different disciplines in the research. Xueqin, you are the best role model in my life. I really admire your hardworking, intelligence, wisdom and nonstop pursuing in academics, and these qualities also encourage me to insist in my Ph.D. study. I still remember you taught me how to write in good structure and logically when I wrote my first paper in English. After the first paper was rejected by several journals, you still encouraged me to keep it up. You are a legend in my heart. All of these are the treasures for me to learn and appreciate in my whole life.

Then, I would like to express my gratitude to my two mentors. Professor Qian Lu has given me a lot of support from academics to life philosophy. My research would not be finished without his support and help. Professor Jianfei Lu encouraged me to finish my Ph.D. and tried his best to help me overcome various difficulties. Many thanks also go to the president of Yangzhou University and officials from the HR department.

Many thanks go to all members of Agricultural Economics and Rural Policy Group and Environmental Economics and Natural Resource Group as well. I will never forget all your friendliness and kindness to me. I would like to thank you all for bringing me different culture experiences and different perspectives of opinions. The outings and Christmas dinners are some of the best experiences in my memory. Karen, Dineke, Betty, Wil and Gré, thank you all so much for your kind help in the group. Anastasia, Kadirbyek, Mohammed, Eko, Tesfahun, Guangcheng, Pini, Shinta, Kasia, my dear office mates, thank you all for your encouragement and small talks which relieved my loneliness greatly during my time in Wageningen.

I would also like to express my gratitude to all my Chinese friends. Shumin, Wuyan, Jinghui, Qianqian, Minjie, Guangcheng, Li Fan, Yu Tian, Cao Hui, Jiaqi, Zhang Jin, Xiangxiang, Liu Yan, Jin Yan, Yujue, Xinyuan. Thank you all for the time you spent 
together with me. I have enjoyed the happiness of friendship with all of you.

Finally, I would like to express my greatest gratitude to my family. My parents have tried their best to support me for pursuing Ph.D., and I am so lucky to be your daughter. Zengwei and Ruirui, you always love me unconditionally, and without you I would never have managed to this moment.

Shanshan Miao

May, 2019 


\section{Funding}

The research described in this thesis was financially supported by Wageningen University and National Natural Science Foundation of China (number 71503071).

Financial support from the Agricultural Economics and Rural Policy Group of Wageningen University for printing this thesis is gratefully acknowledged. 



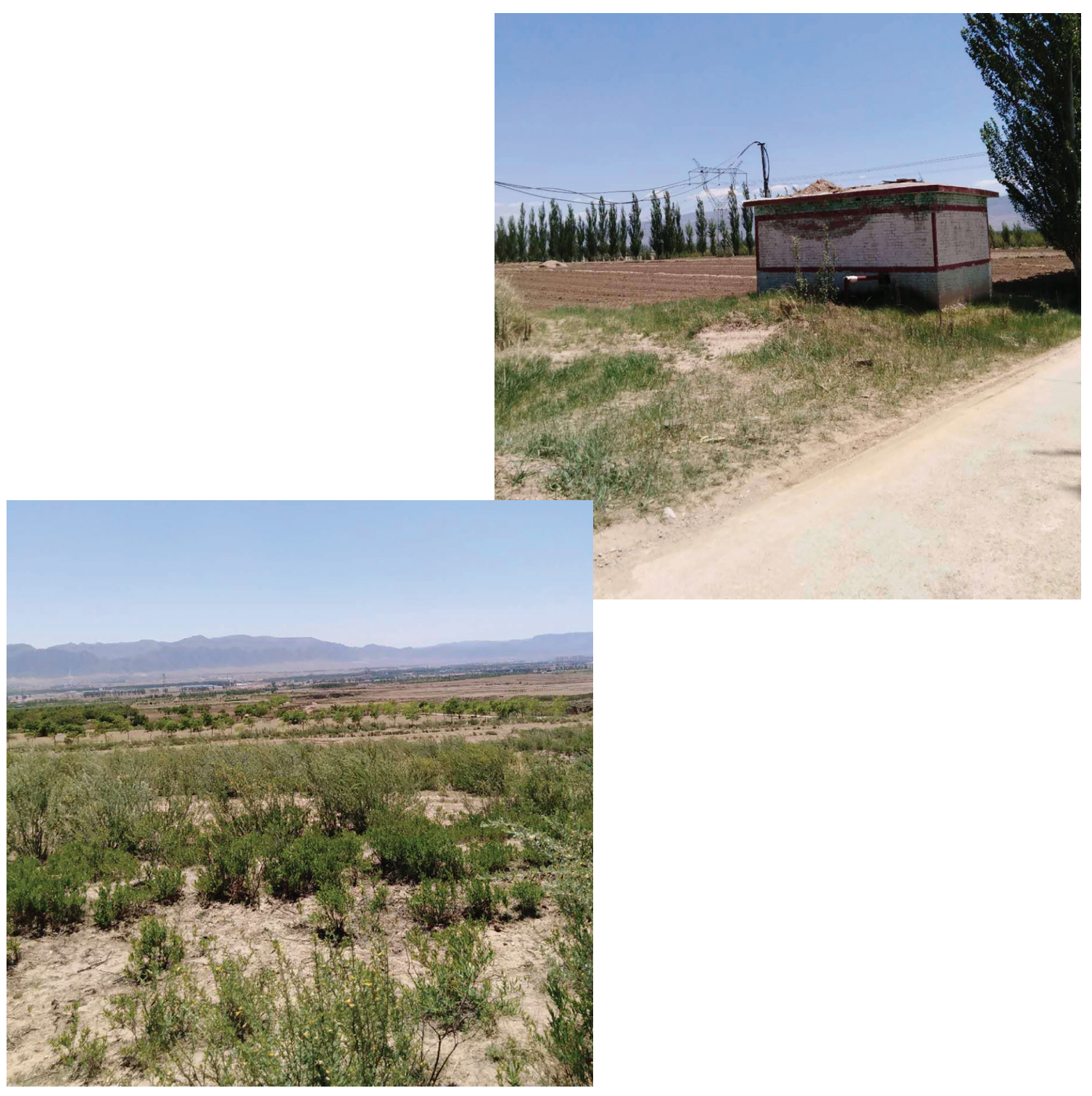

